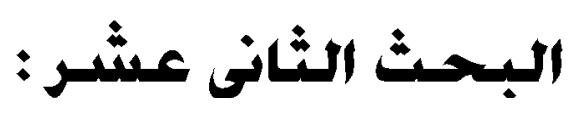

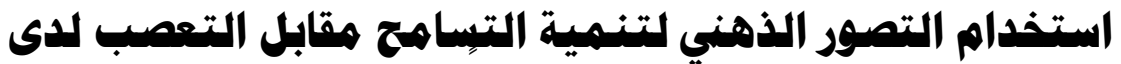 المراهقين المعاقين سمعيا "دراسة حاله"
}

\section{: إلحإ}

د. هاني محمد فكري أبوهاشم

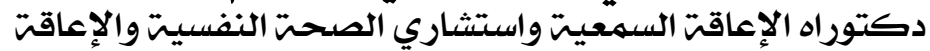

بمستشفي الأحرار التعليمي بالزقازيق الصنيق 



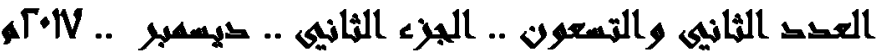

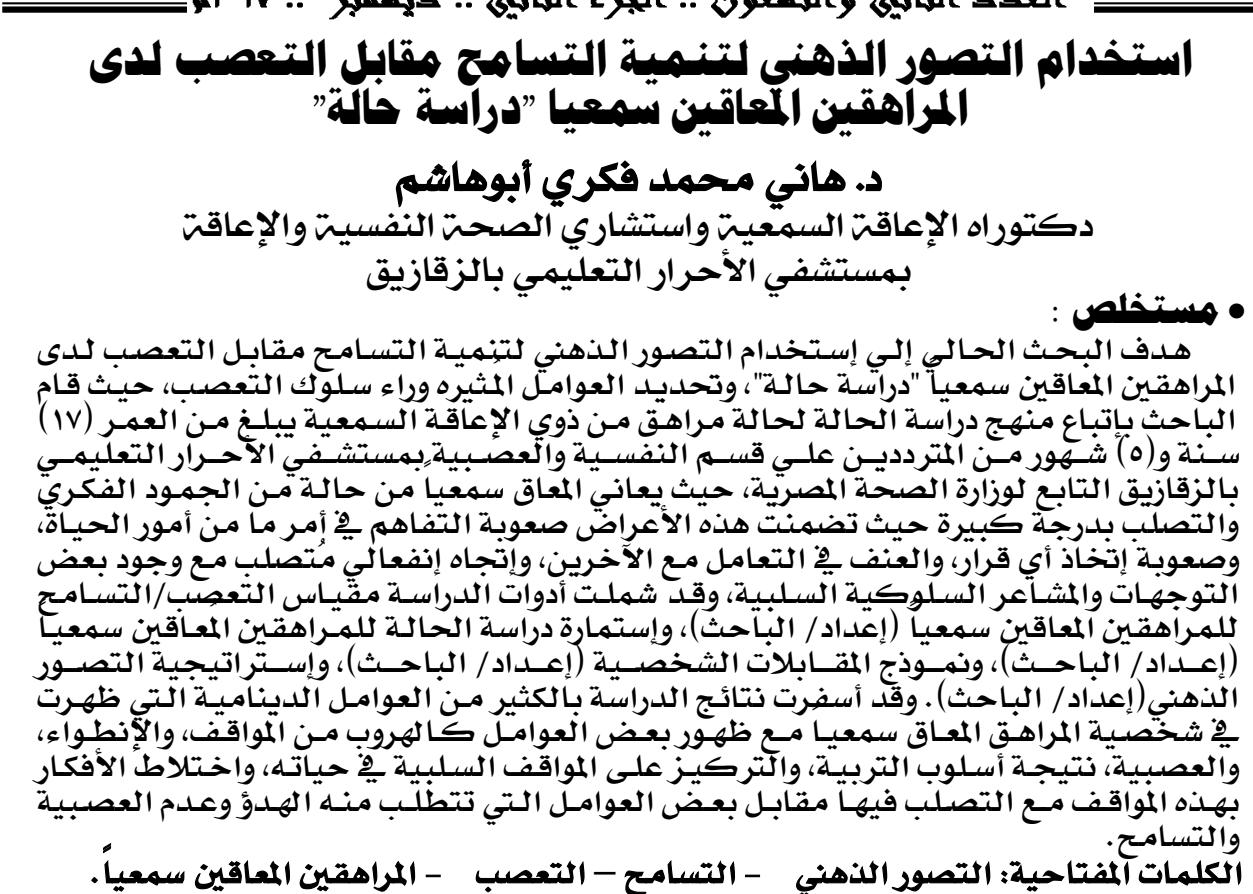

Using Mental Imagery to Develop Tolerance Versus Intolerance

Prejudice with Hearing Impaired Adolescents "Case Study"

\section{Dr. Hani Muhammad Fikri Abu Hashem}

\section{Abastract}

This study investigated to use mental perception to develop tolerance versus intolerance in adolescents with hearing impairment as a "case study", and to identify the factors that provoke the behavior of intolerance, as the researcher followed the case study approach for a teenager with a hearing disability aged (17) years and (5) Months of frequent attendance at the Psychological and Neurological Department of the Al-Ahrar Teaching Hospital in Zagazig of the Egyptian Ministry of Health, where the hearingimpaired suffers from a state of intellectual stagnation and stiffness to a large extent, as these symptoms included difficulty understanding about something in life, difficulty in making any decision, and violence in dealing The study tools included the intolerance scal/ tolerance for the hearing impaired adolescents (preparation/ researcher), the case study form for the hearing impaired adolescents (preparation / researcher), and the personal interviews form (preparation $/$ researcher), And mental visualization strategy (preparation / researcher). The results of the study resulted in many dynamic factors that appeared in the personality of the hearing-impaired adolescent with the emergence of some factors such as escape from situations, introversion, and nervousness, as a result of the parenting style, focusing on negative situations in his life, and mixing ideas in these situations with stiffness in them in exchange for some factors that require from him calmness, lack of nervousness and tolerance.

Key words: mental Imagery, Tolerance, Prejudice, Hearing Impaired adolescents. 


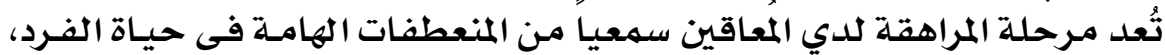

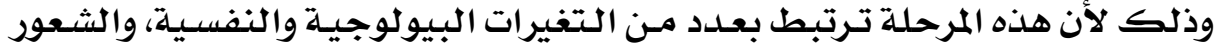

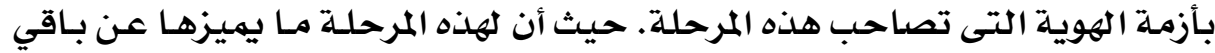

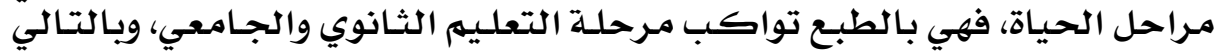

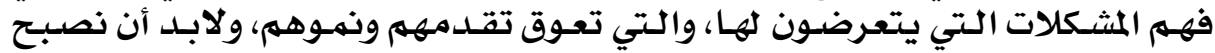

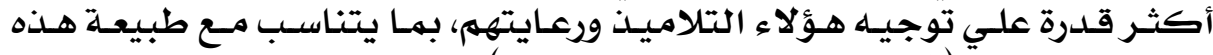

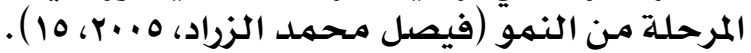

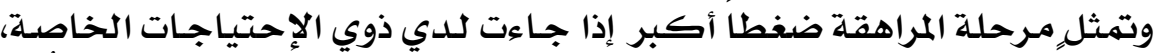

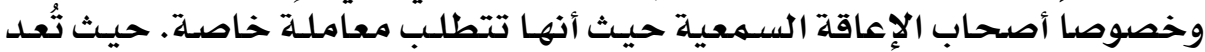

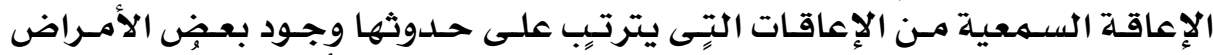

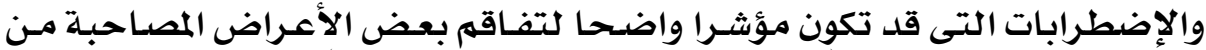
بينها العزلة والإنسحاب (Stednitz,\& Epkins, 2006, 151).

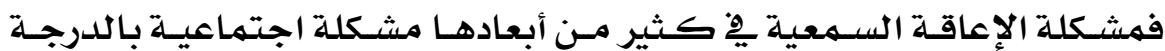

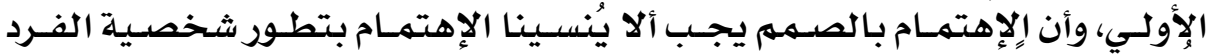

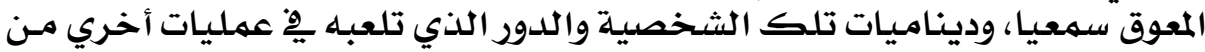

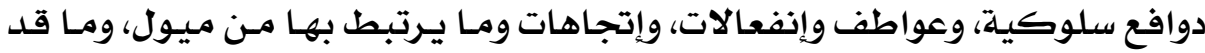

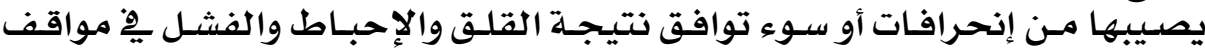

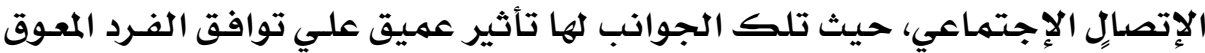

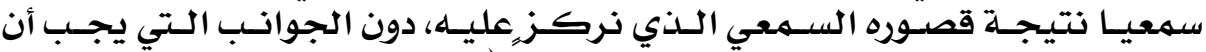

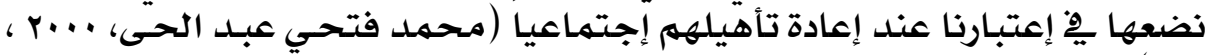
(rYo

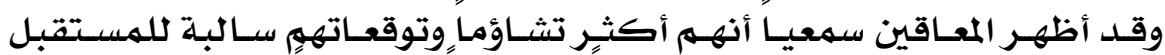

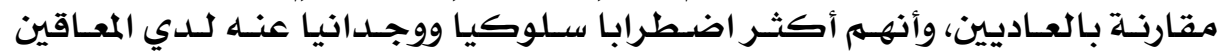

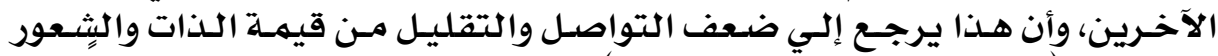

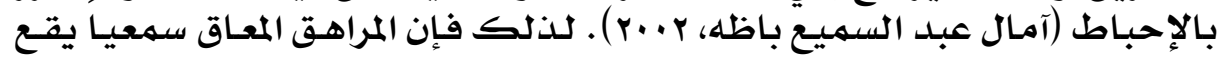

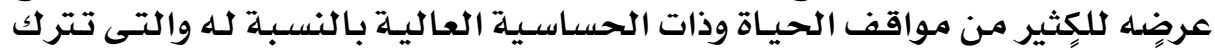

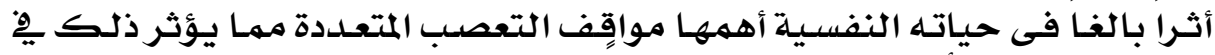

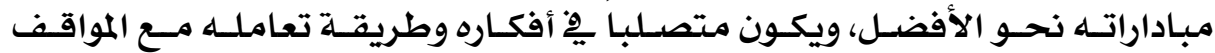

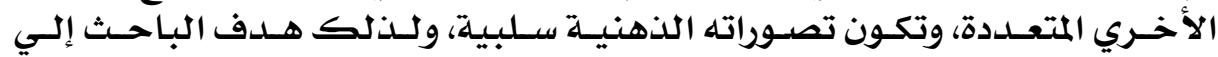

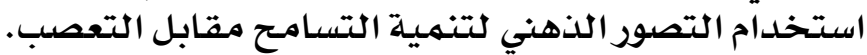

ويعتمدد التصور الذهني بشكلا أسـاسي علي تكوين الصور الذهنيـة ذات الصسبغة

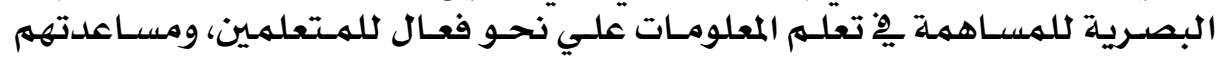

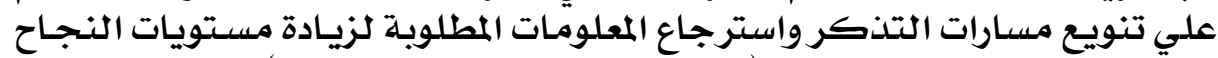

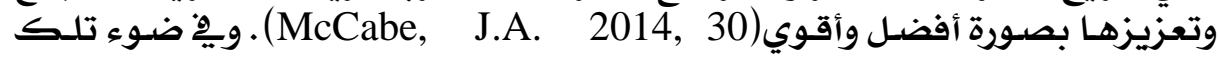

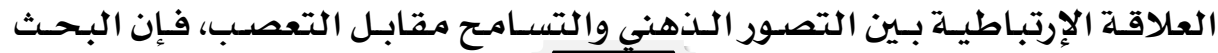




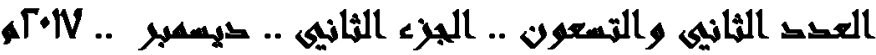

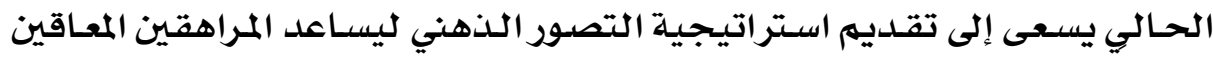

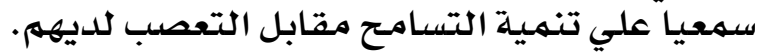

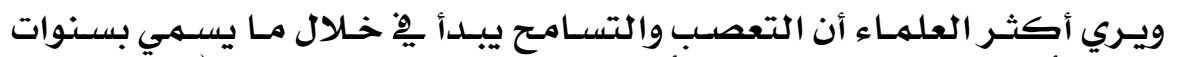

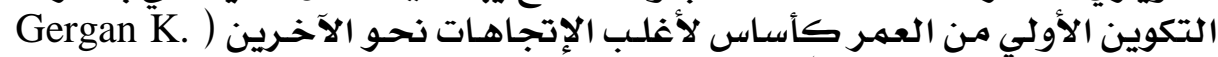
.(\& Gergan M. 1981, 131

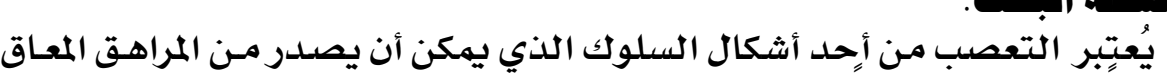

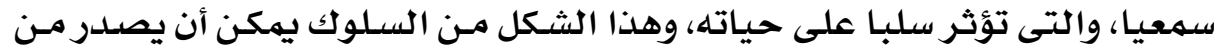

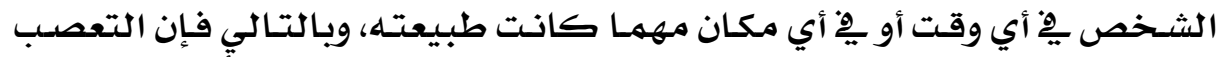

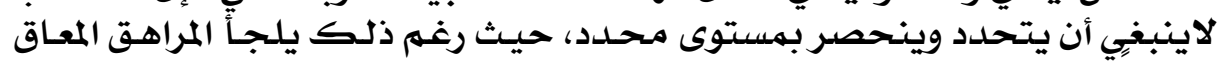

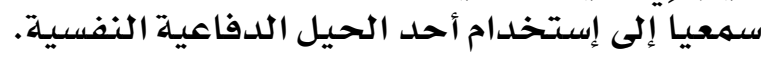

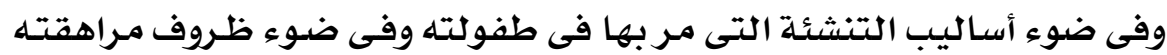

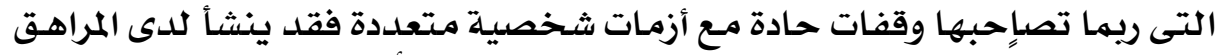

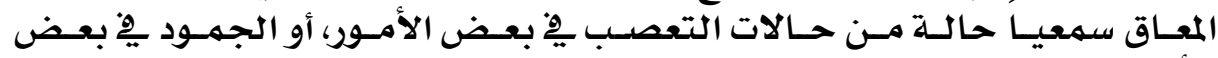

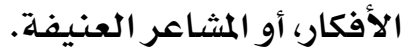

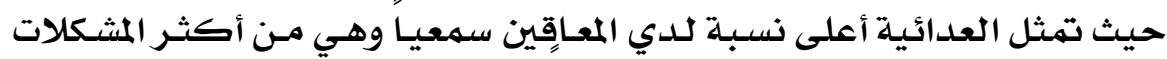

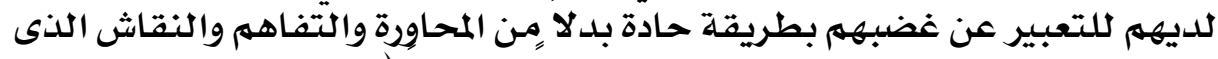

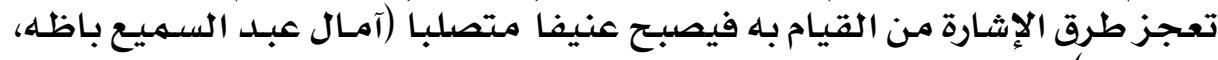

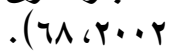

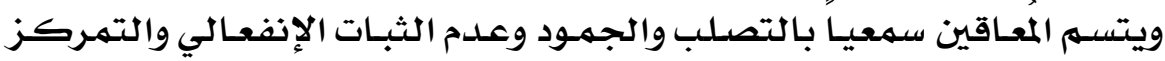

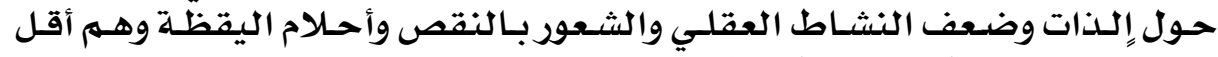

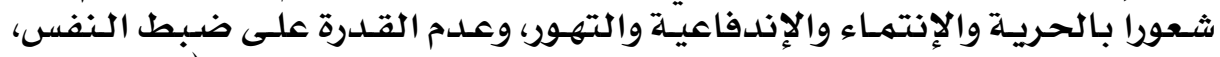

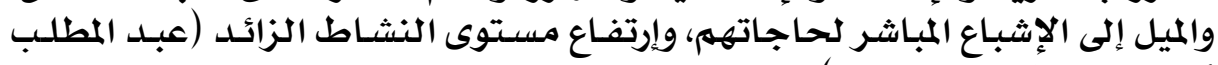

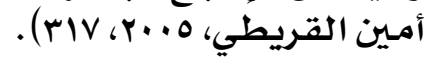

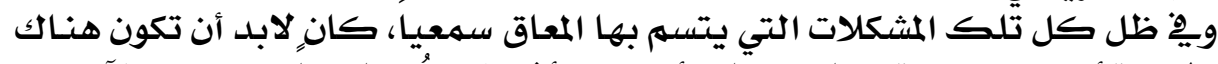

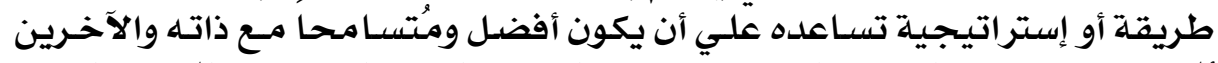

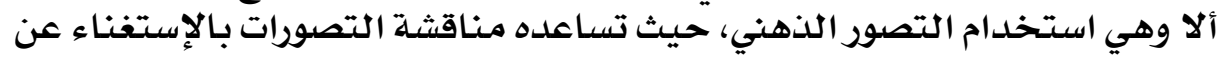

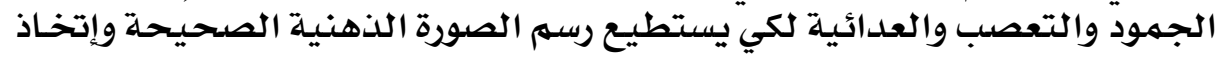

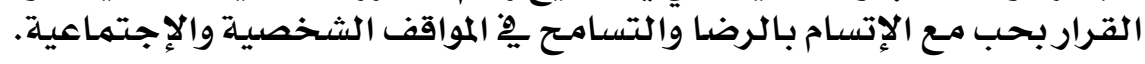

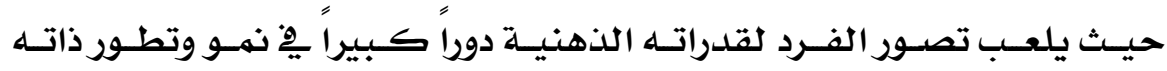

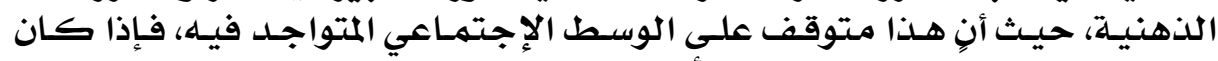

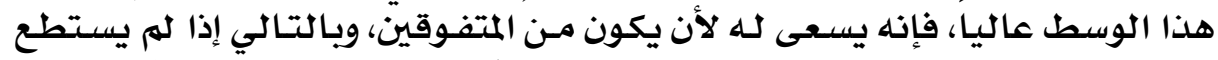

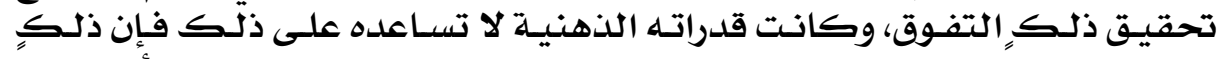

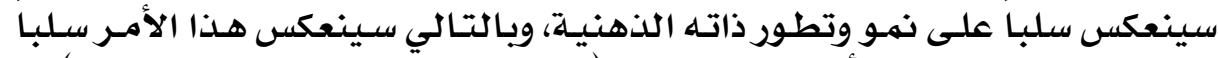

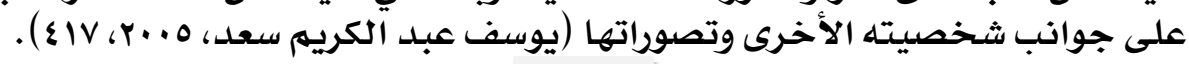




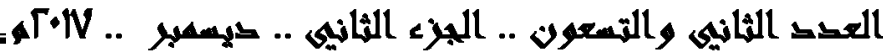

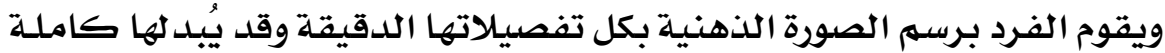

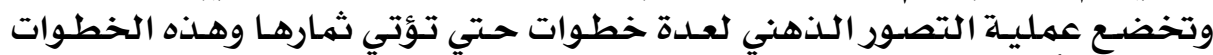

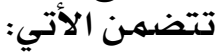

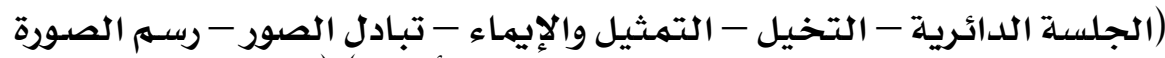

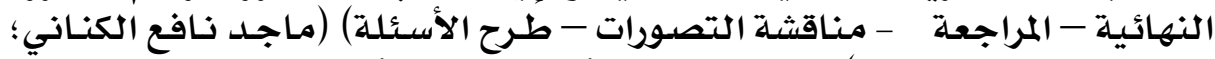

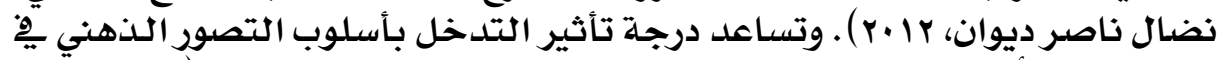

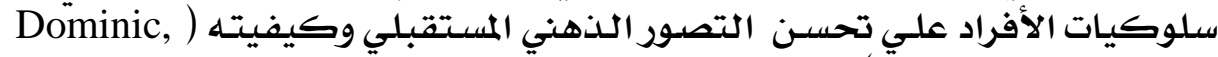

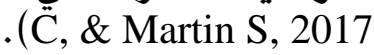

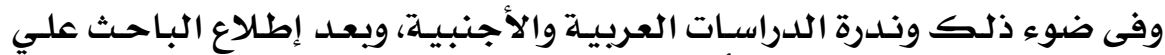

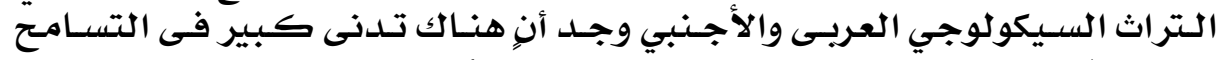

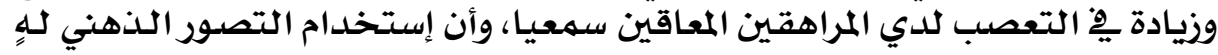

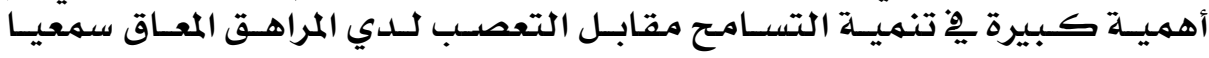

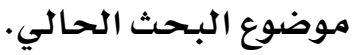

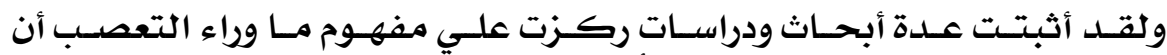

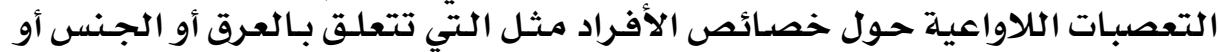

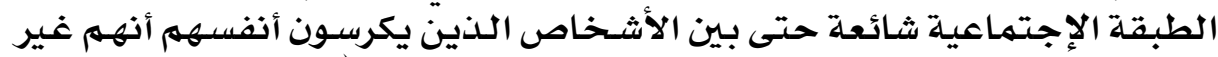

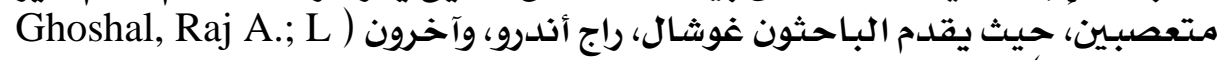
(etal., 2013

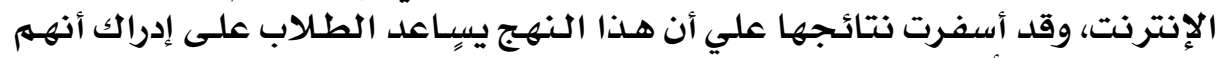

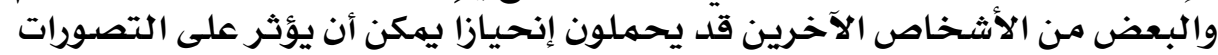

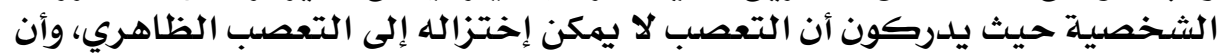

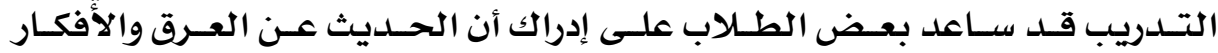

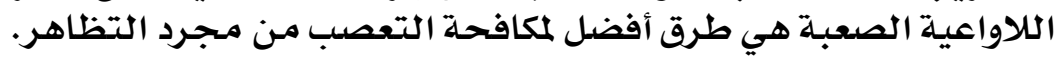

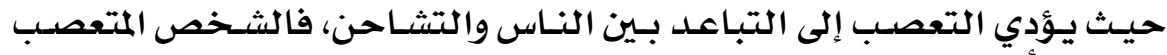

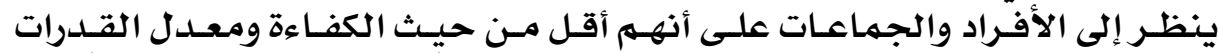

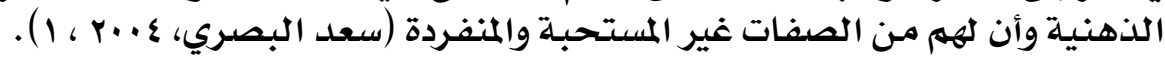

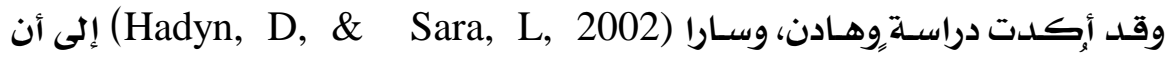

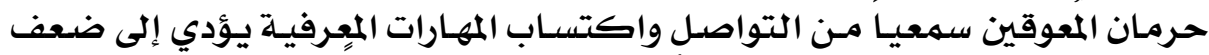

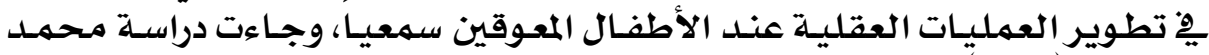

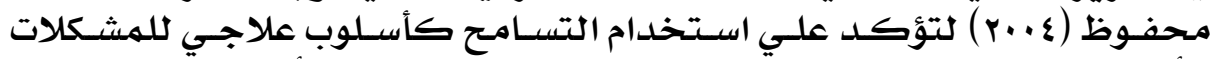

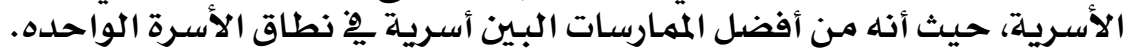

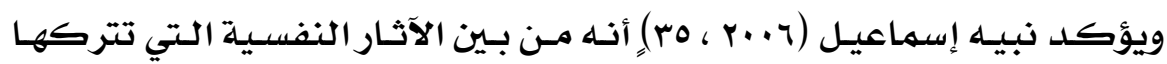

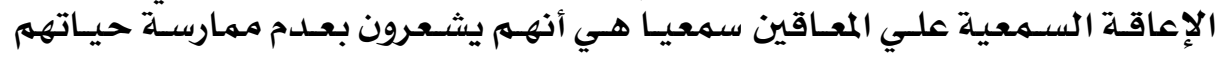

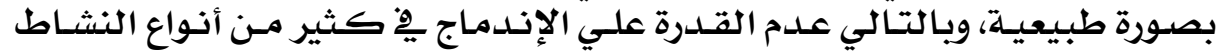

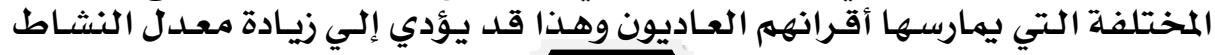




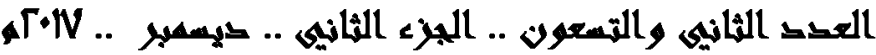

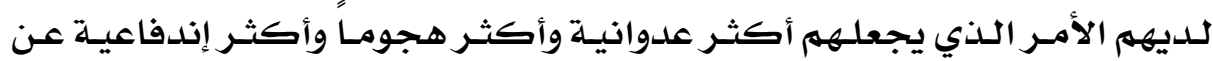
غيرهم من العاديين.

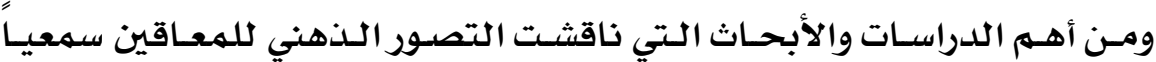

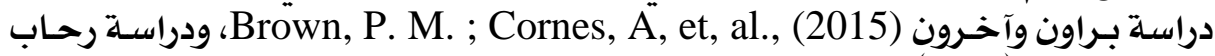

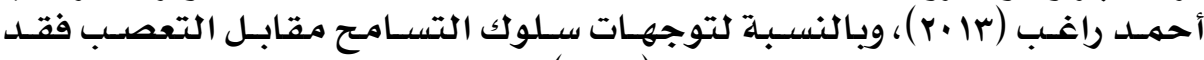

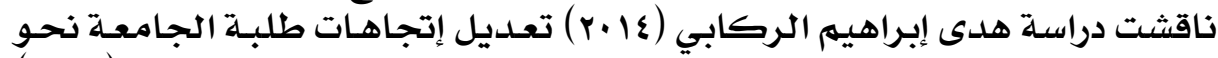

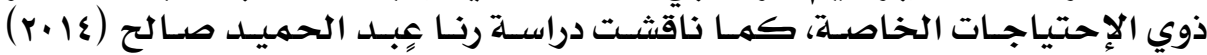
سمتي الخجل والإنطواء لدئ الخاهي المراهقين المعوقين سمعيا.

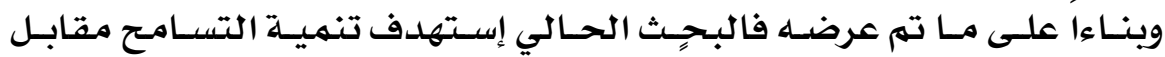

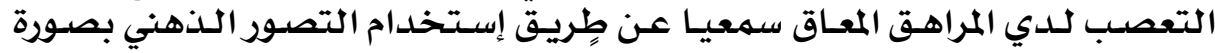

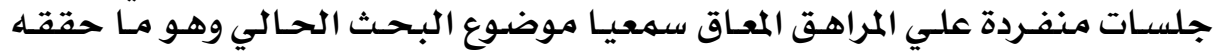

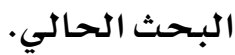

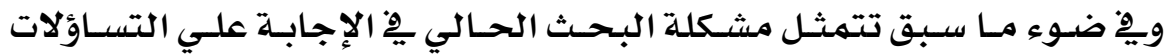
التالية:

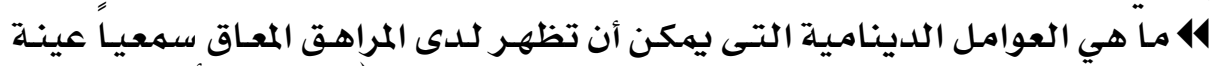

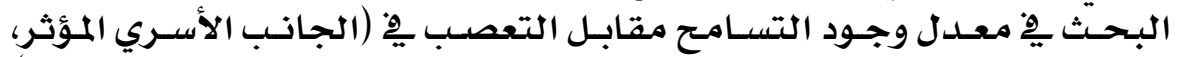

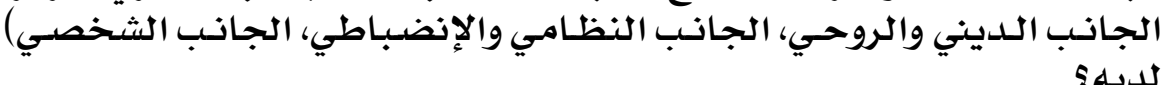

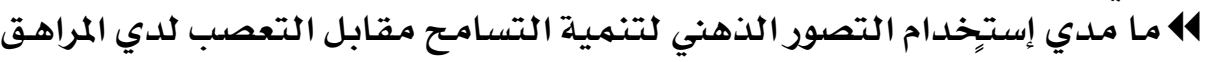
المعاق سمعيا عينة البحث.

يسعى البحث الحمالي إلى تحقيق الأهداف الدئ التالية:

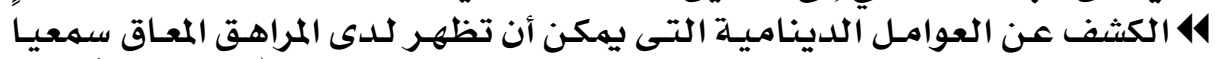

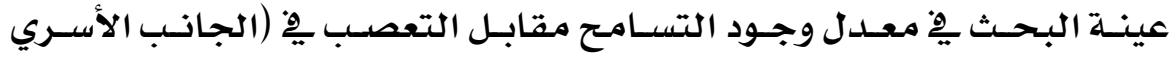

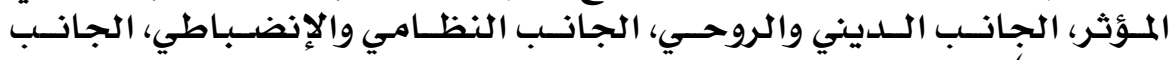

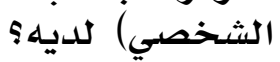

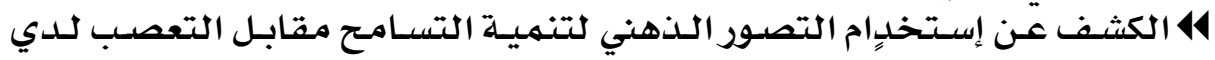

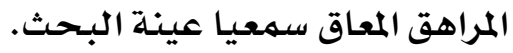

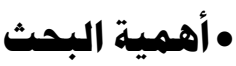
للدراسـة جانبان من الأهمية همـا:

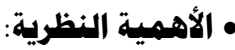

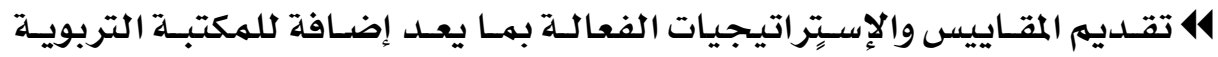

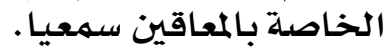

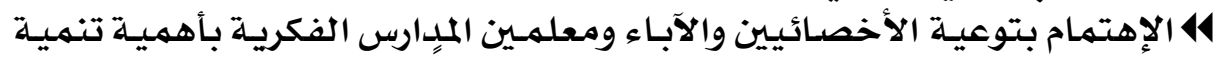

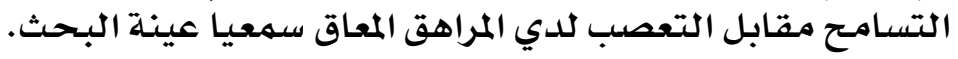




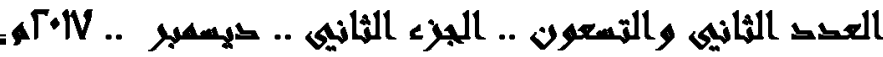

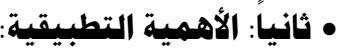

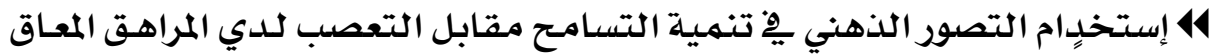
سمعيا.

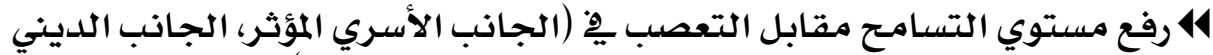

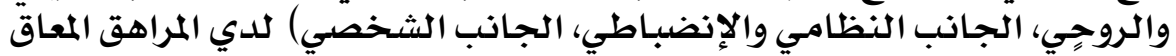

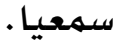

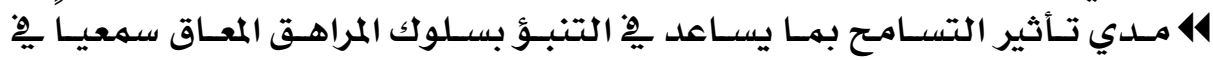
مواقفه المختلفة.

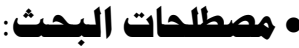
1 التصور الذهني:

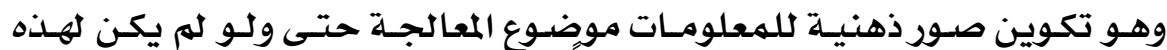

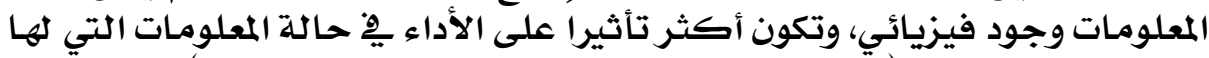

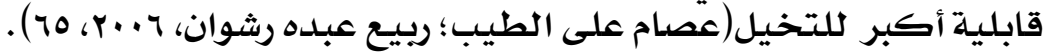
• التعريف الإجرائي التصور الذهِيني:

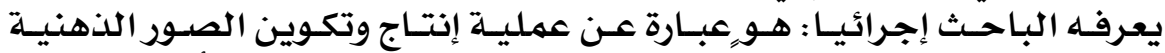

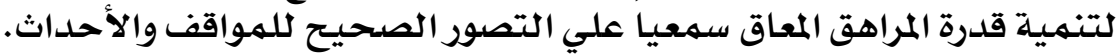

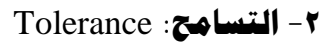

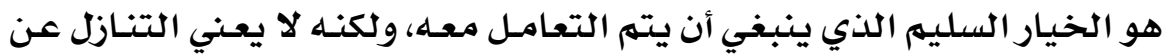

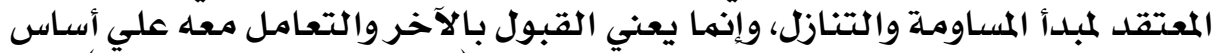

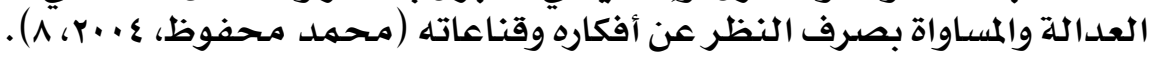

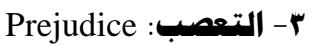

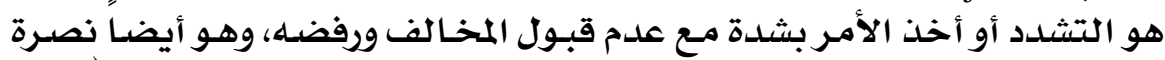

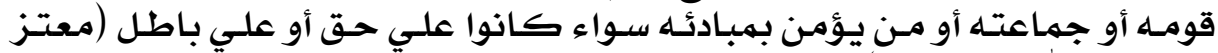

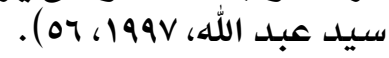

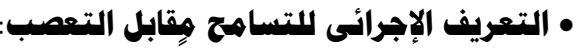

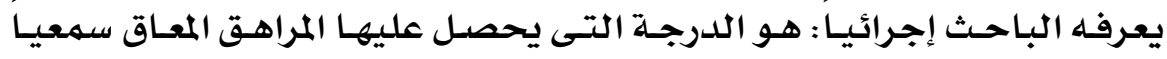

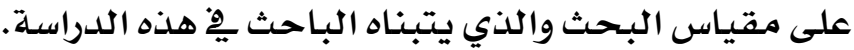

צ- الإعاقة السمعية: Hearing Impairment

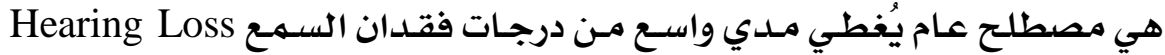

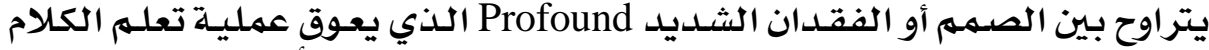

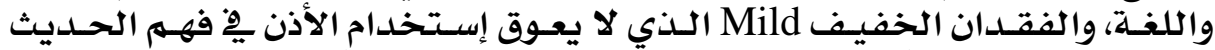

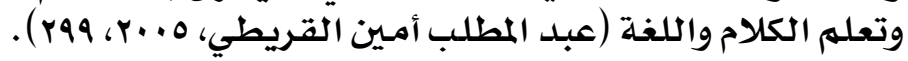

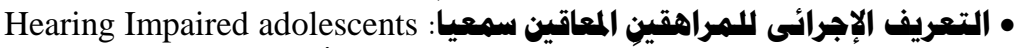

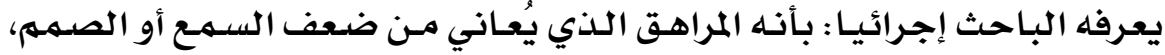

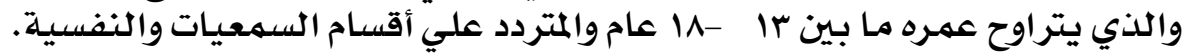




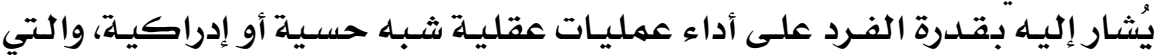

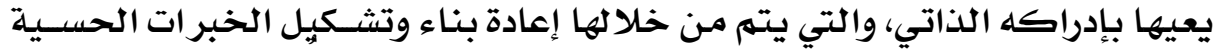

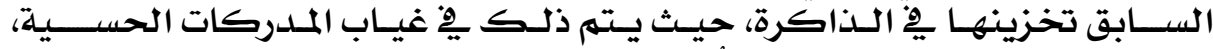

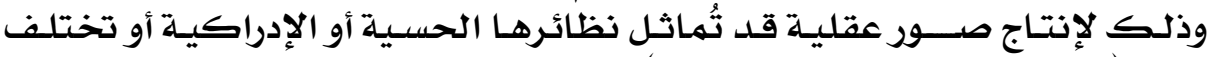

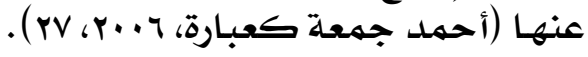

• مفهوم التصور الذهني:

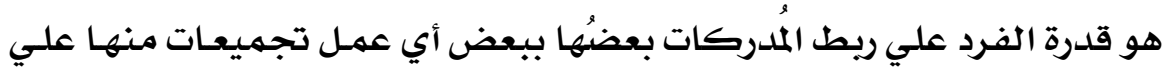

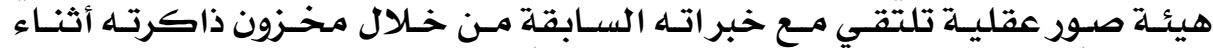

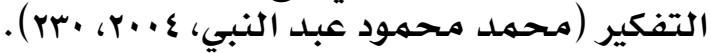

وهو أيضاً قدرة المتحعلم علي معالجـة المعلومـات غير المحسوسـة مـع غيـاب المصسلدر الخارجي للهعلومات المحسوسئة (Anderson, J. 2015, 79) .

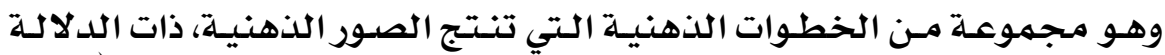

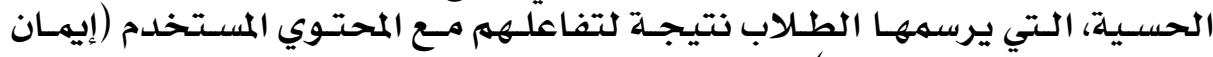

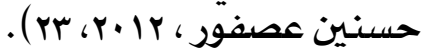

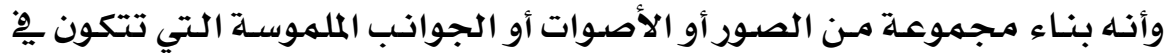

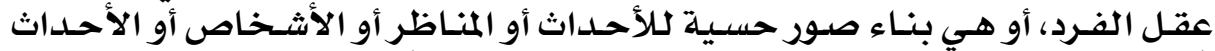
.(Crawley \& Merrit, 1996, 64 \& Jordan, E, 1995)

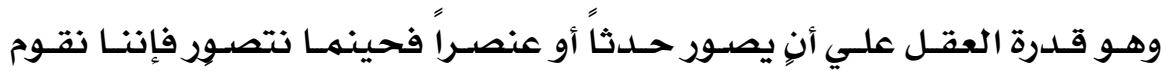

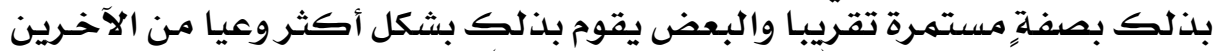

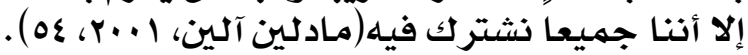
وهو عبـارة عن تهثيل معـرِيْ فردي للوقائع الخـارجيـة المجربـة مـن طـرف الفـرد" (Matlin, 2005, 96 \& Olivier, H, 1998, 345)

• أههية استراتيجية التصور الذهني:

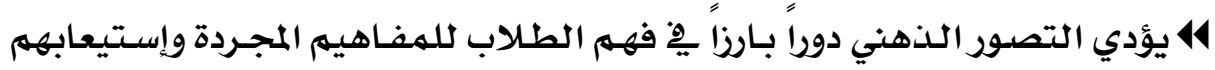

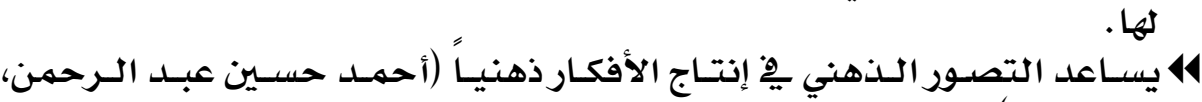
. (1. 1 , r. $1 \varepsilon$

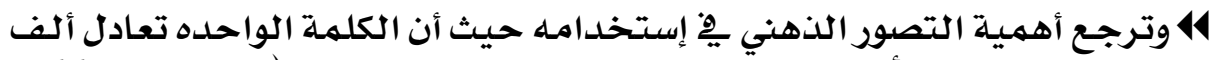

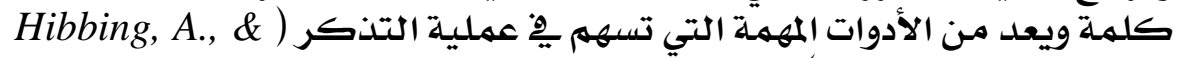
.(Rankin, J. 2003, 762 \$ يساعد علي شموليـة الإثارة الدافعية لتنظيهم الإستثارة والحفاظ علي مستويات القلق. 


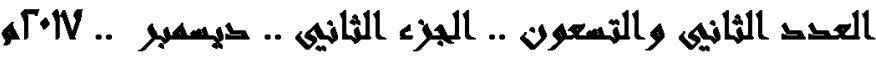
4 الدافعية العامـة لزيادة الثقة بالنفس والإحتفـاظ بالتوجـه الإيجـابي نحو الأداء .(Oliver, E. 2002, 6)

\section{• خصائص التصور الذهني: تتمثل خصائص التصوري: التصور الذهني يِّ عدة نقاط وهي ما يلي:}

ا - التصور الذهني "المتعدد الحواس":

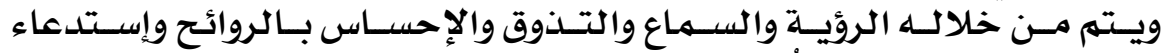

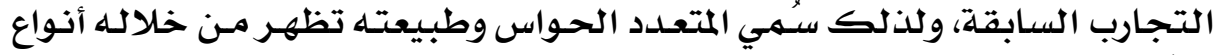
مختلفة من الصور الذهنية ولندية.

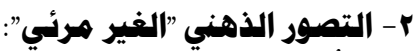

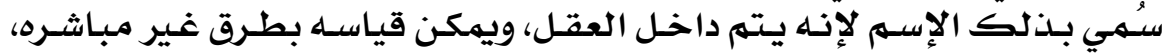

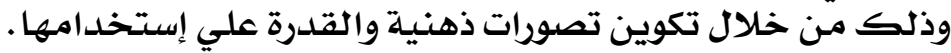

r- التصور الذهني المتعلق بالخلايا العصبية:

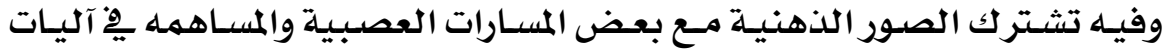

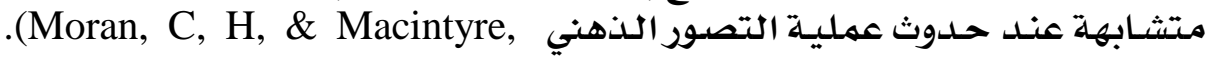
2012, 96-97)

ومن أهم خصائص التصور الذهني أيضاً:

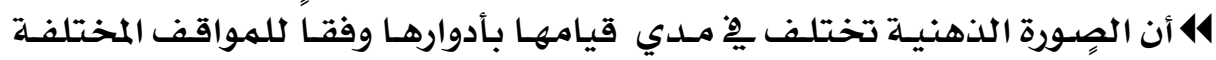

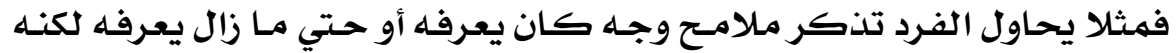

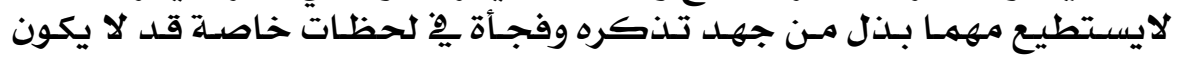

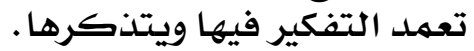

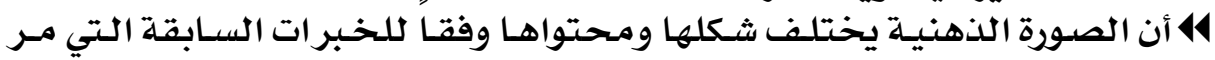

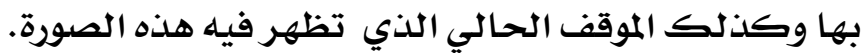

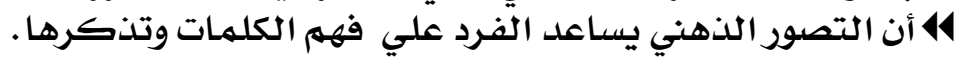

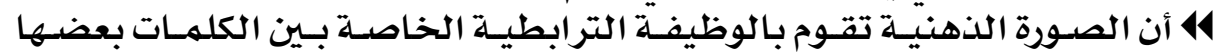

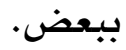

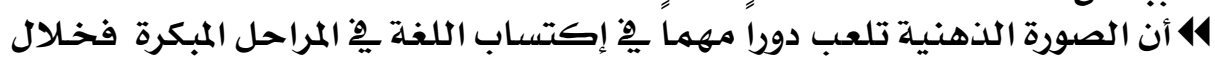

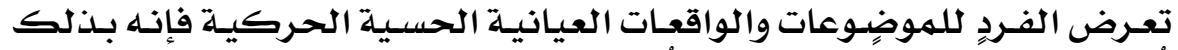

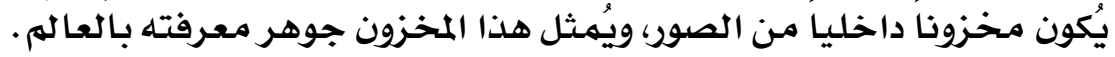

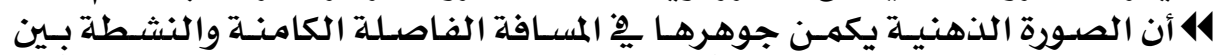

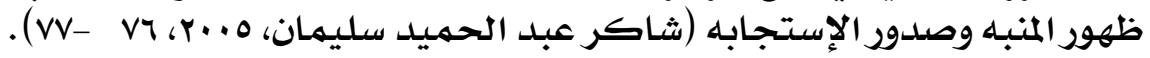
• إجراءات التصور الذهني:

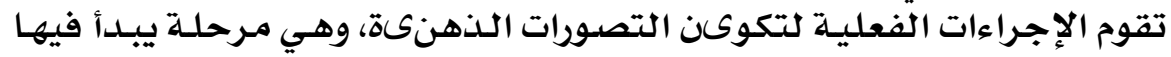

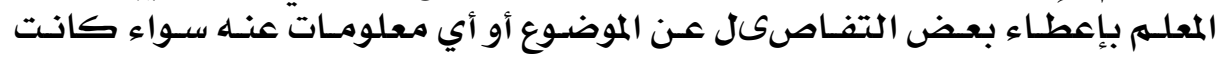

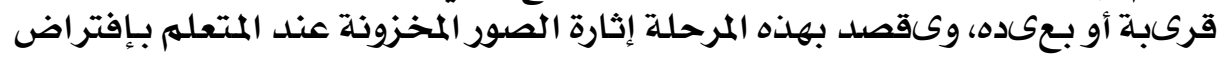

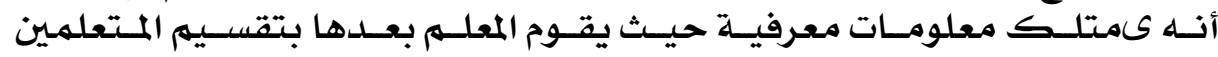

\section{7}




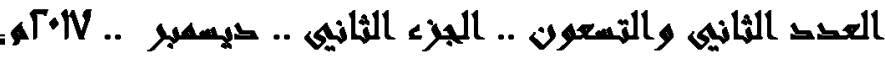

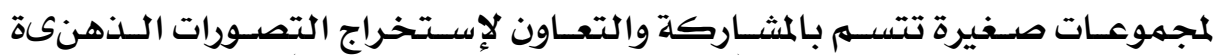

الملائمة للتغلب على الصعوبات (Day, Richard, R. 1993, 69).

ومن الإجراءات المتبعة للتدريب علي التصور الذهني هي كما يلي:

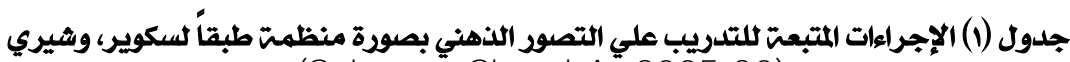
:(Schauer, Sheryl A, 2005:30)

\begin{tabular}{|c|c|c|}
\hline عمليت التدريب & الإجراءات & م \\
\hline يقوم الطالب بعمل نشاط يستطيع من خلاله تكوين صور ذهنيت عن الموضوع. & التخطيط & 1 \\
\hline تحديب الطلاب الذين لم يتمكنوا من تكوين صور ذهنيت. & ملاحظت الأداء & $r$ \\
\hline التعرف على الهدف الرئيسى من عمليت التصور الذهنى. & التأمل & $r$ \\
\hline يتم تقديم نموذج عن عمليت التصور الذهنى للطلاب، وتأمله. & مرض التخطيط & $\varepsilon$ \\
\hline 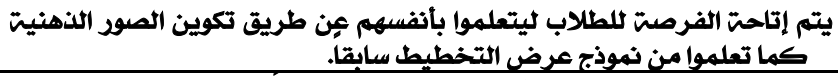 & مراجعت التخطيط & - \\
\hline يتم تشجيع الطلاب بتنفيذ الإجراءات السابقت بشكلا دائم ليتمكنوا من تكوين & الإستمراريت & 1 \\
\hline
\end{tabular}

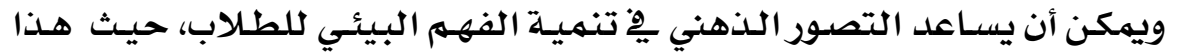

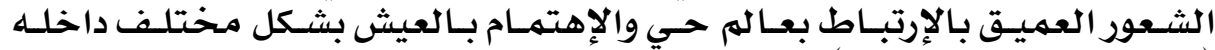

(Judson, Gillian, 2014)

\section{• وهن أهم إستراتيجيات التصور الذهني التي أعتمد عليها الباحث في بحثه:}

ا - إستراتيجية التصور البصري: Visual Imagery strategy

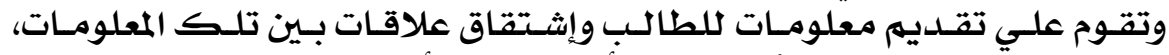

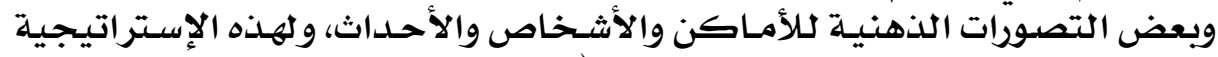

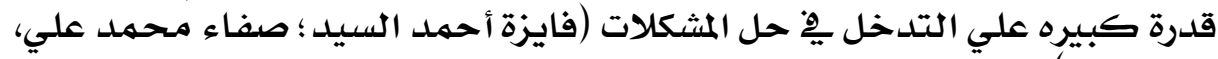
. (190، r...

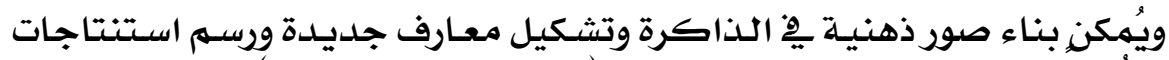

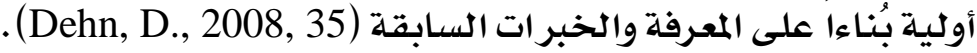

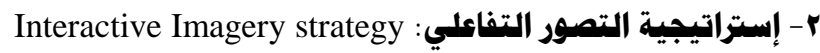

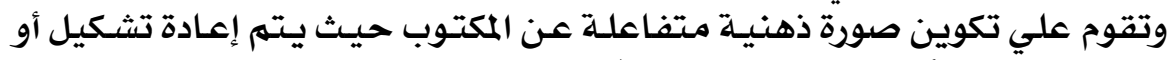

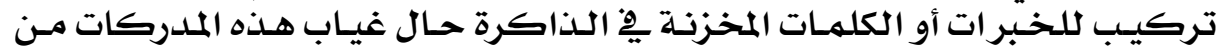

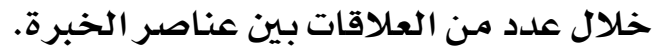

r ب إستراتيجية التصور المنفصل: Separate Imagery strategy

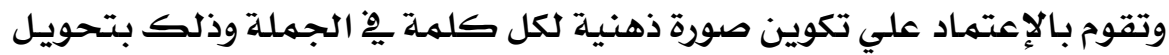

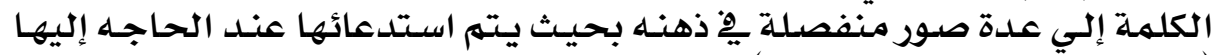

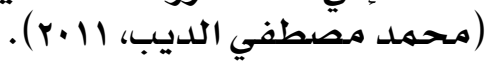

؟- إستراتيبية التوليف القصصي: Story strategy

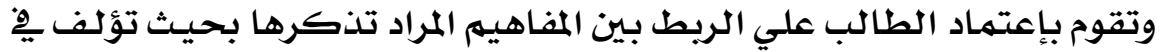

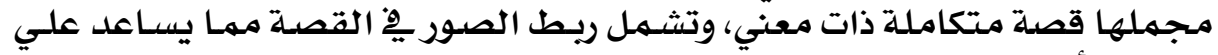

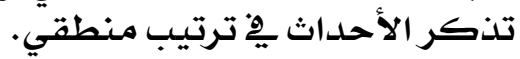




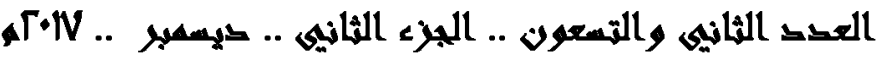

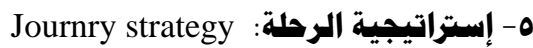

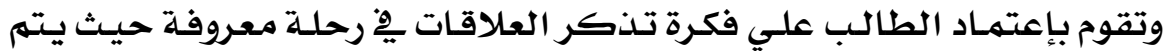

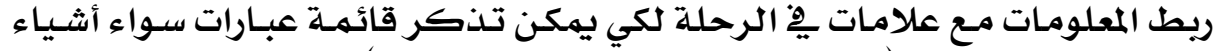

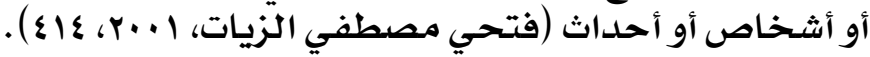

ب- ب التساهح/التعصب:

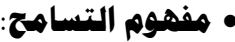

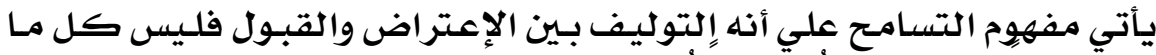

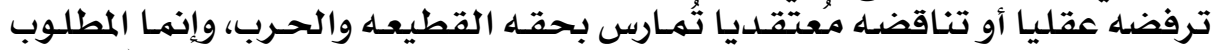

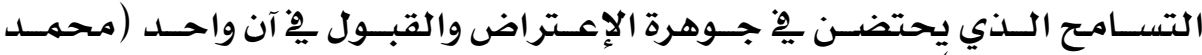

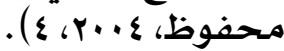

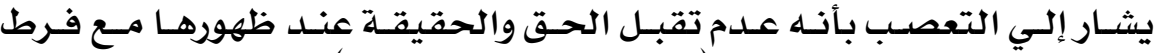

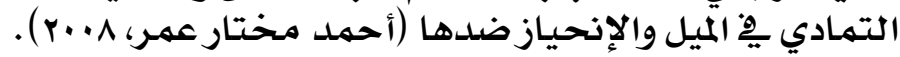

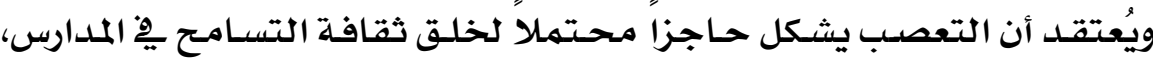

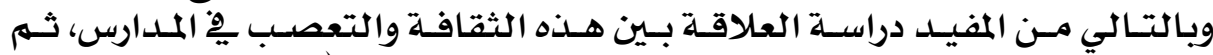

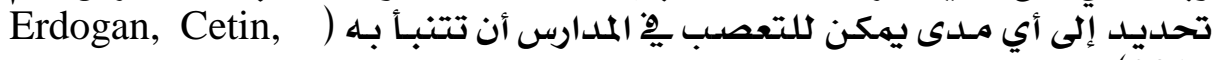
. (2016

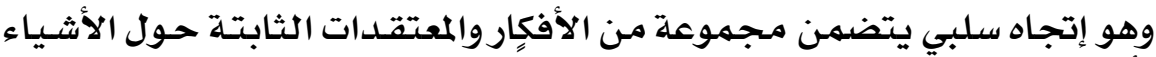

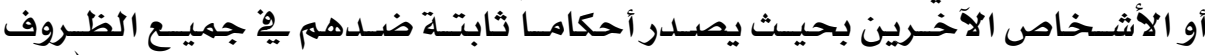

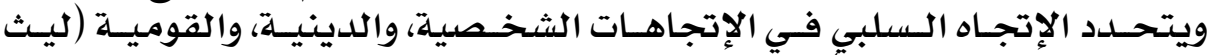

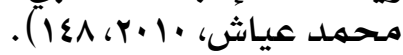

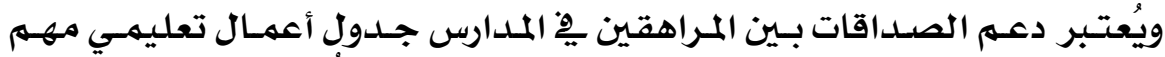

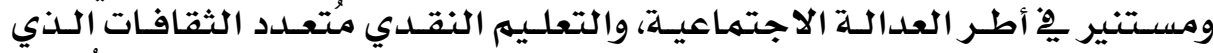

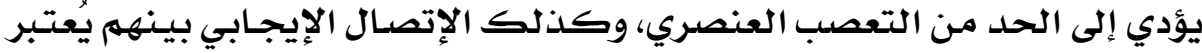

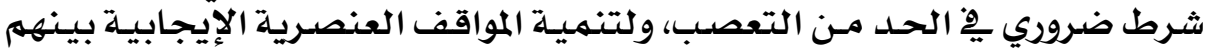

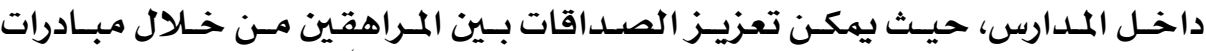
المشورة المدرسية (Pica-Smith, C; Poynton, T. A. 2015).

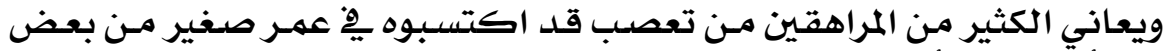

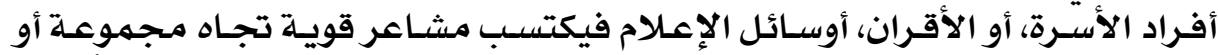

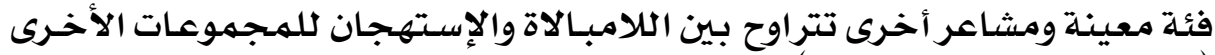

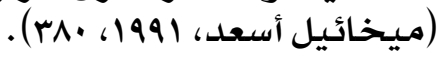

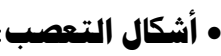

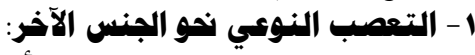

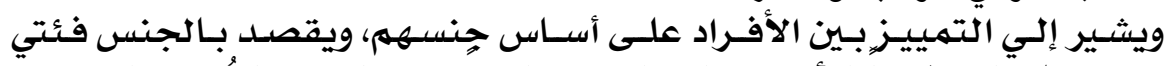

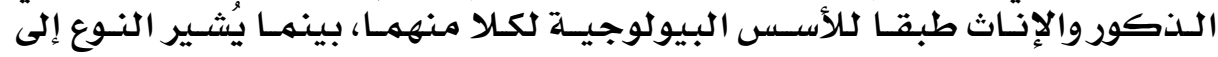




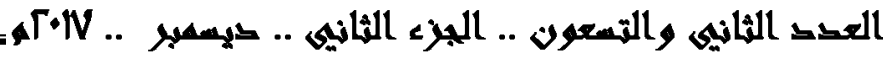

الملامـح السيكولوجية التي ترتبط بالخـصائص البيولوجيـة (معتز سـيد عبــ الله،

$.096199 \mathrm{~V}$

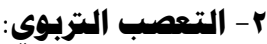

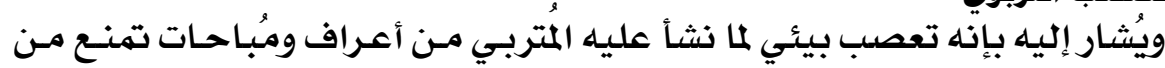

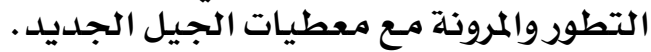

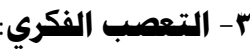

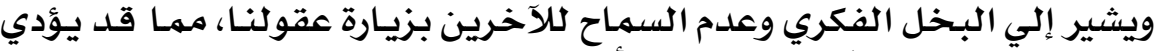

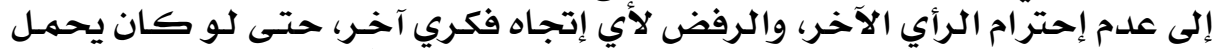

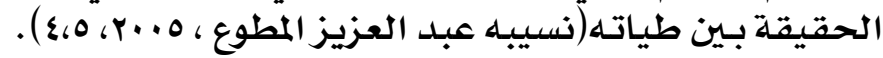

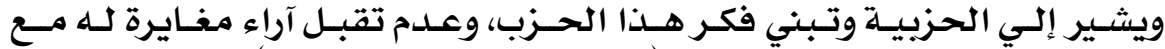

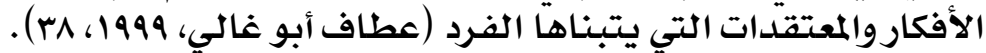

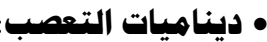

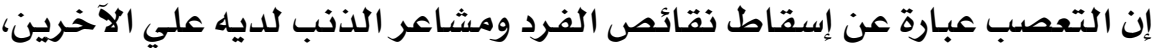

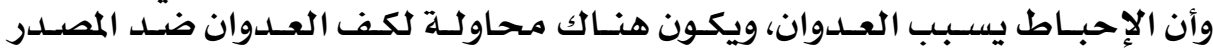

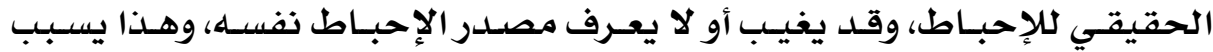

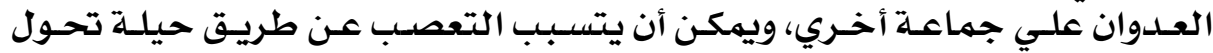

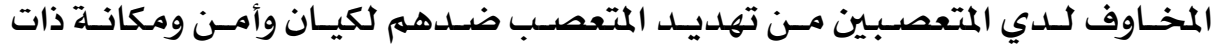

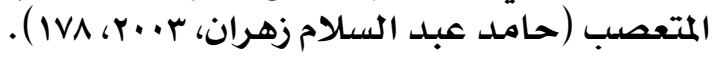

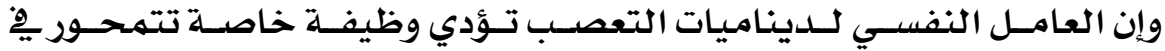

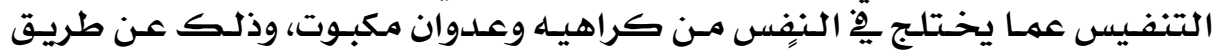

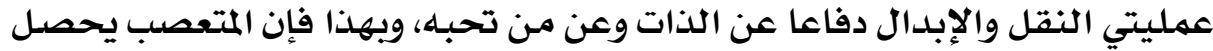

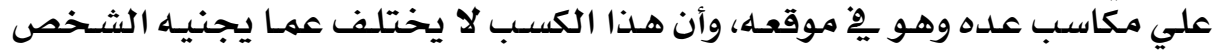

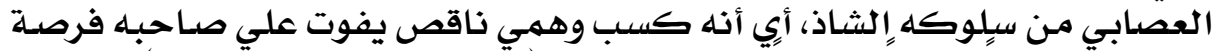

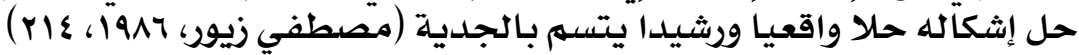

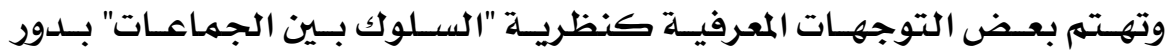

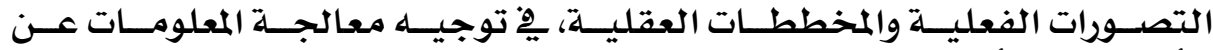

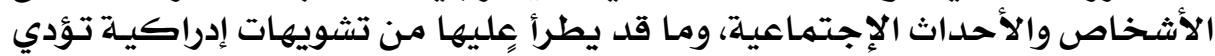

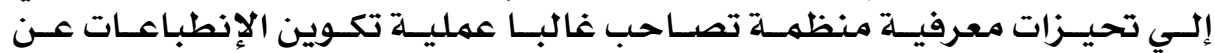

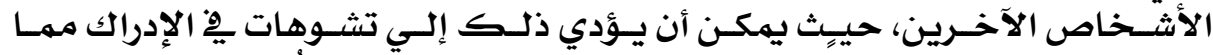

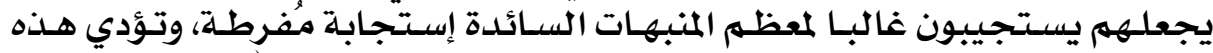

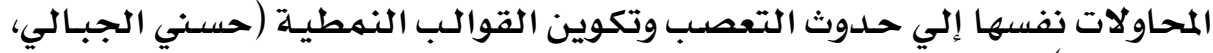

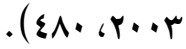

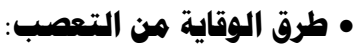
من أهم الحلول الوقائية لعدم الوقوع ِِِ دائرة التعصب هو: 


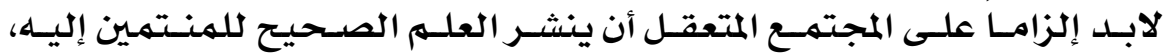

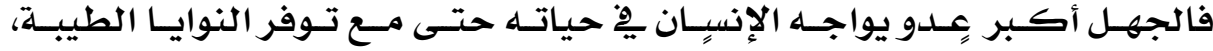

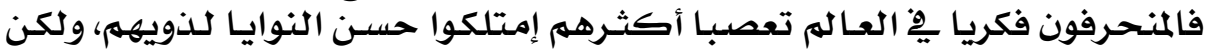
جهالهم سحب طاقاتهم وطاقات من إتبعوهم.

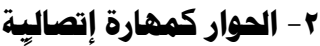

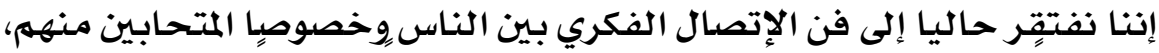

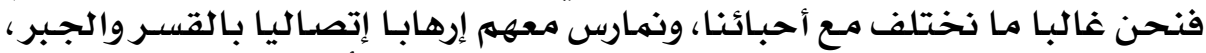

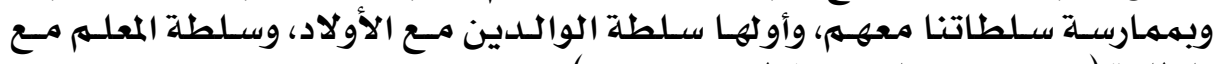

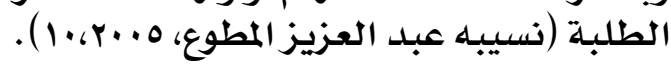

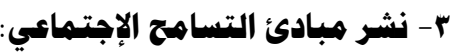

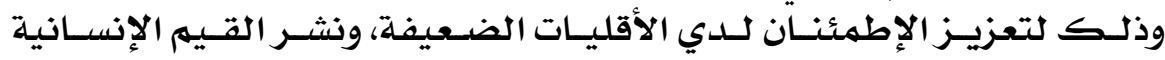
ومبادئ الديمقراطية الصحيحة بين الإنين الناس كافئة

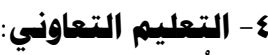

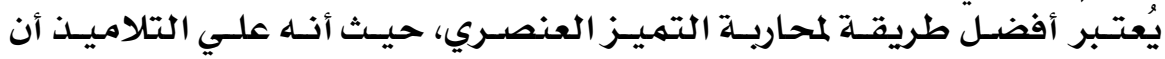
يتعلموا ويتعانوا مع بعضهم لفهم مشاكل معينة.

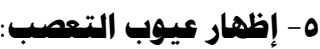

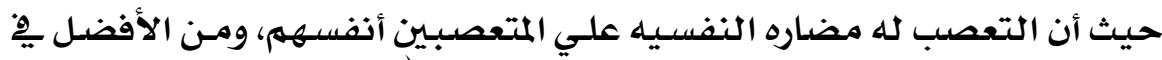

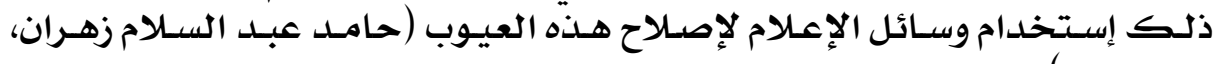

. (r r r r...r

ج- الإعاقة السمعية: Hearing Impairment

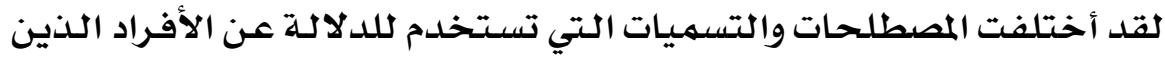

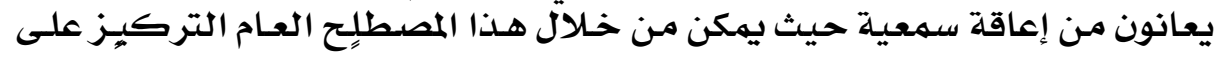

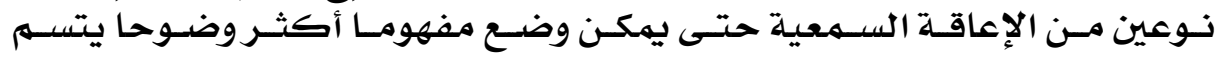
بالشمولية وهي:

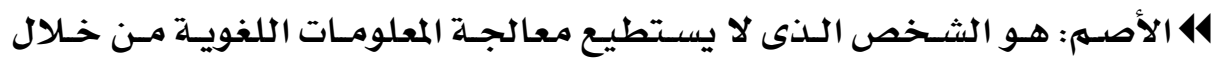

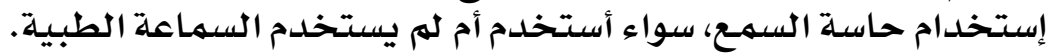

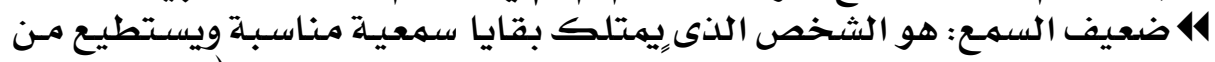

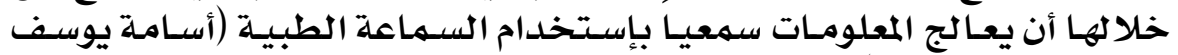

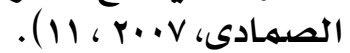

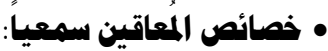

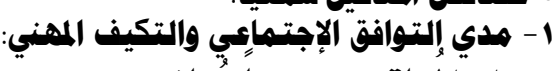

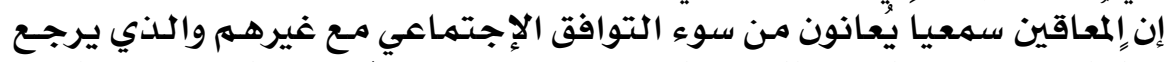

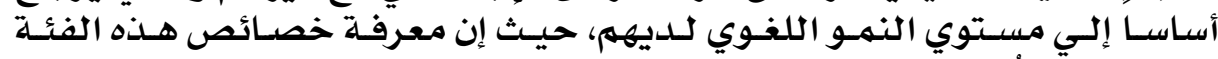

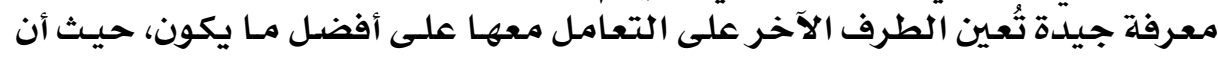

\section{rV.}




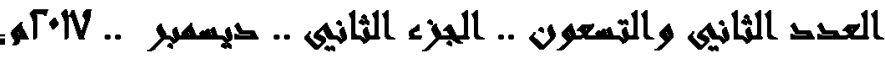

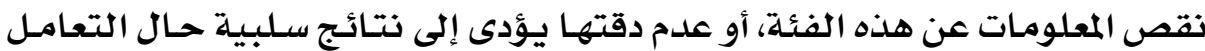

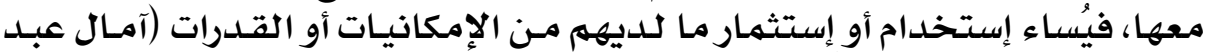

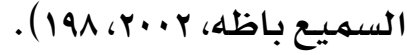

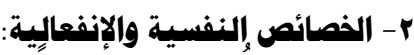

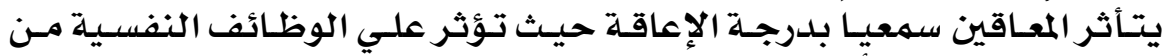

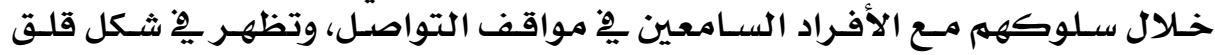

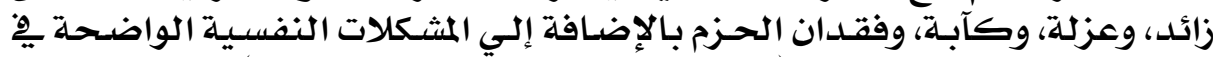

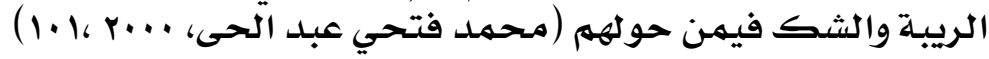

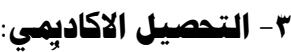

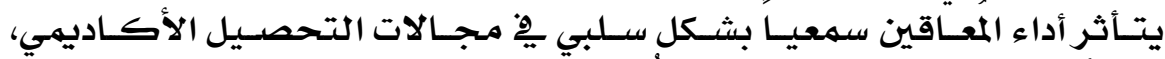

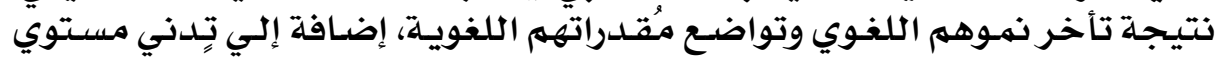

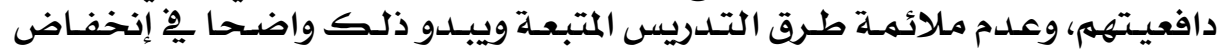

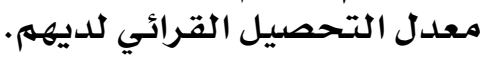

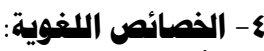

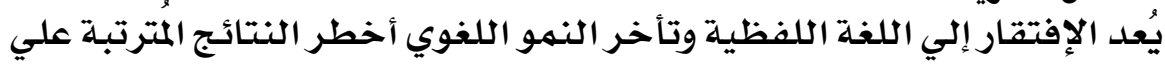

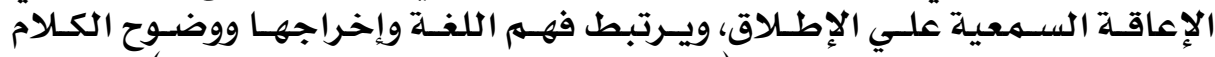

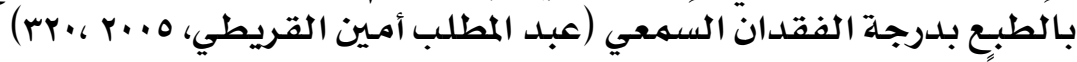

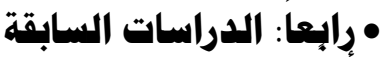

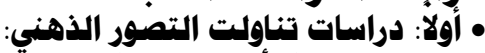

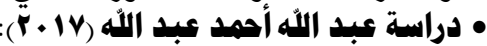

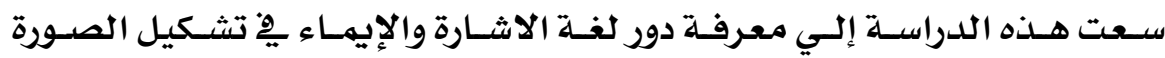

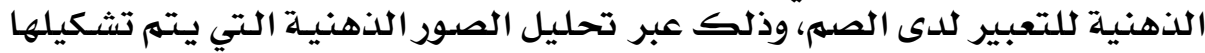

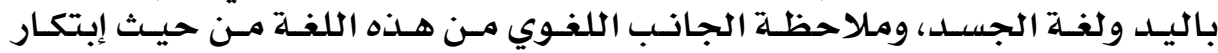

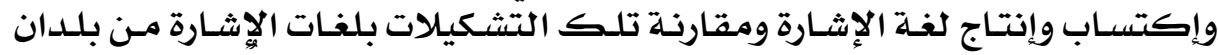

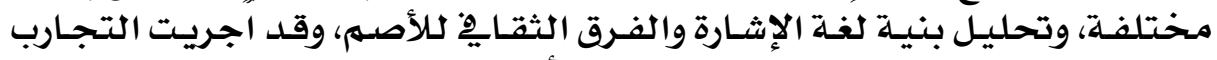

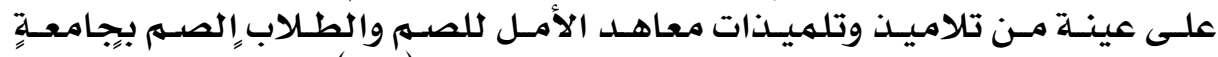

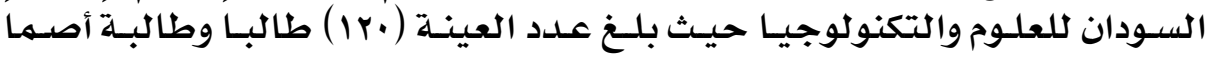

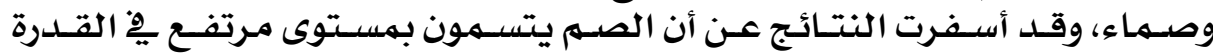

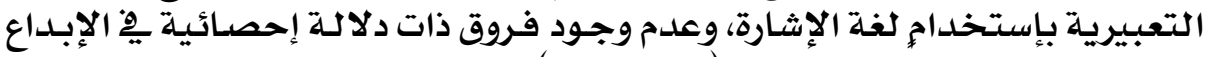

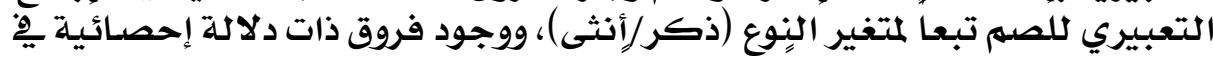

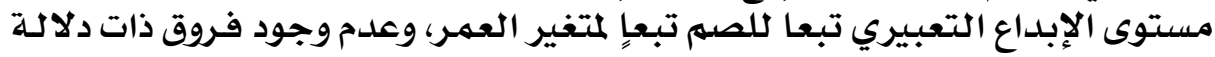

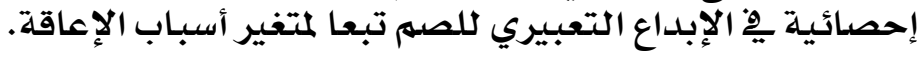

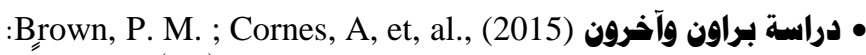

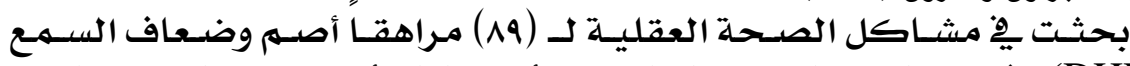
(DHH)

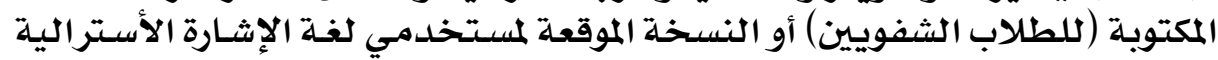




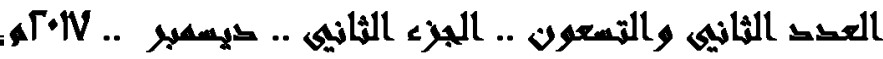

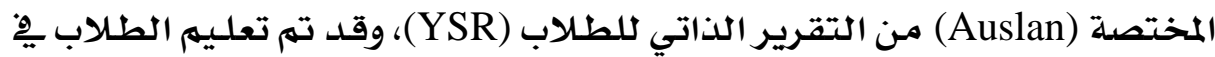

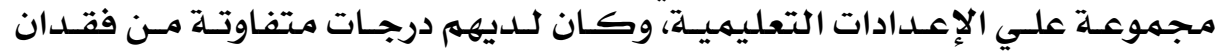

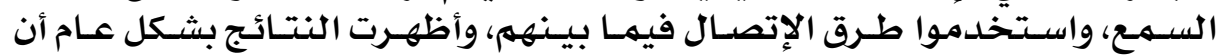

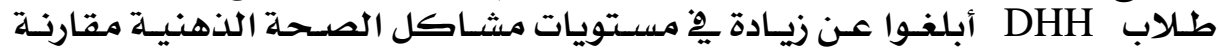

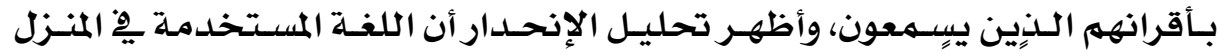

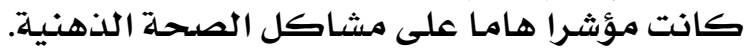

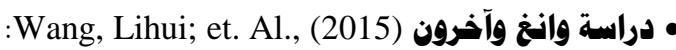

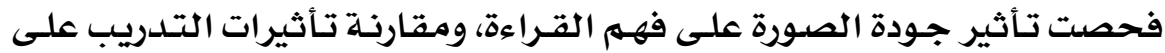

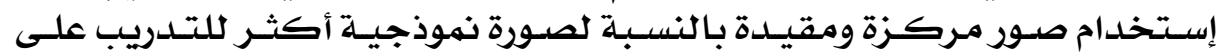

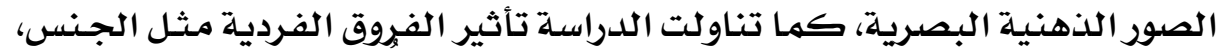

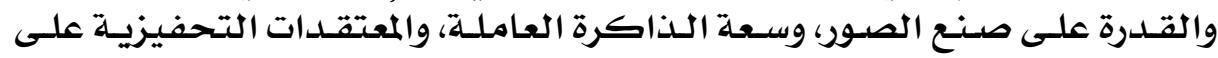

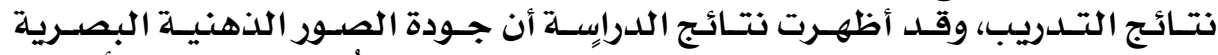

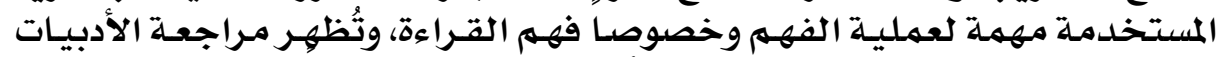

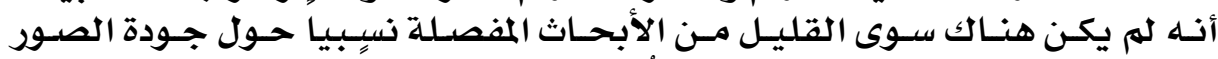

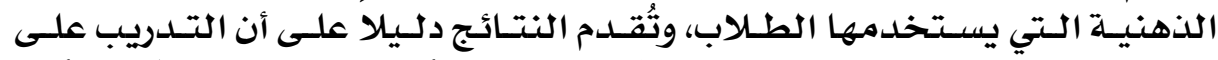

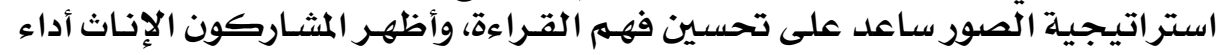

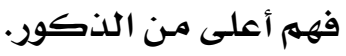

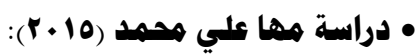

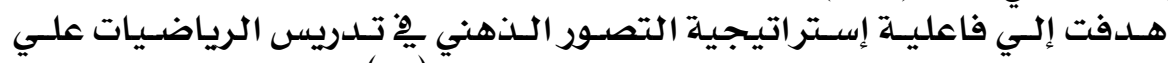

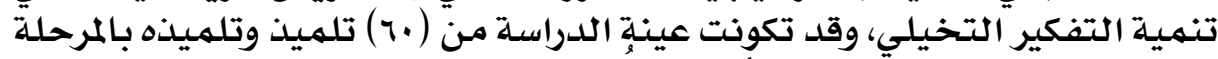

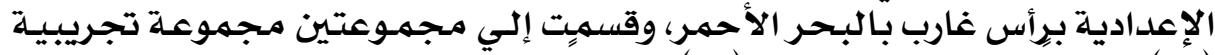

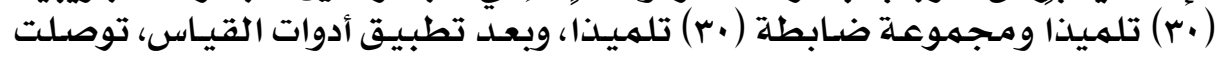

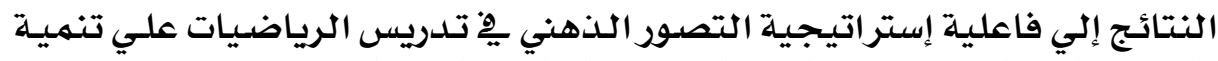

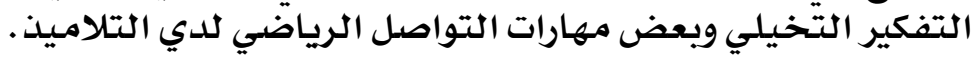

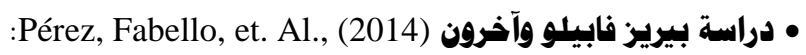

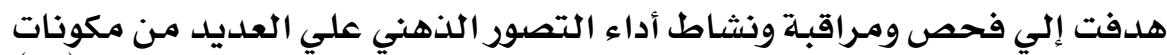

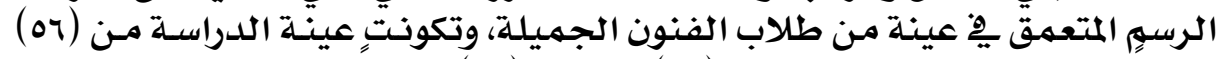

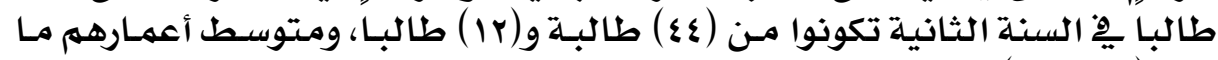

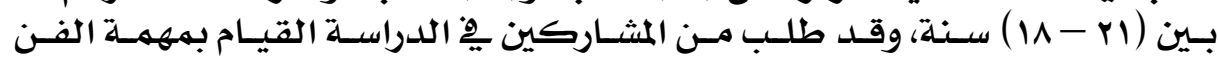

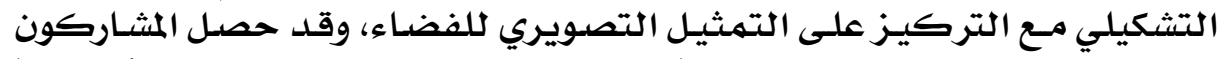

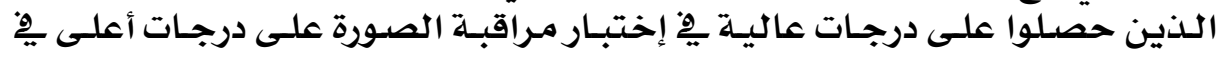

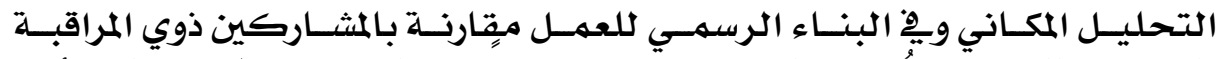

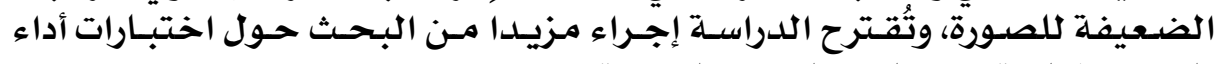

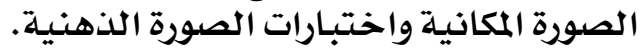

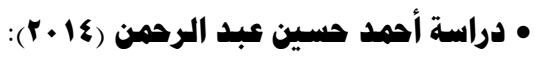

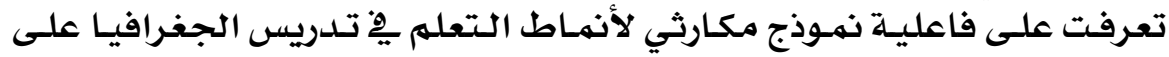

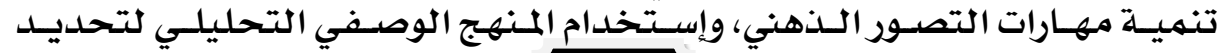




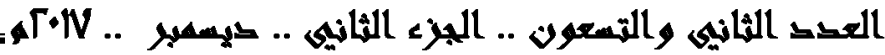

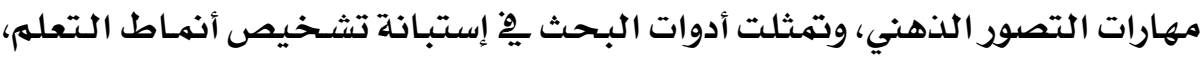

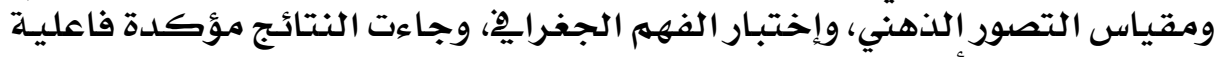

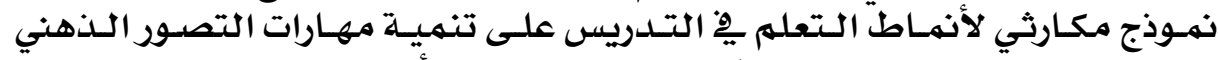

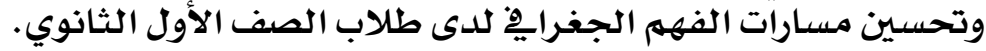

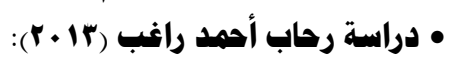

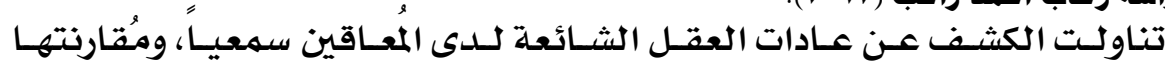

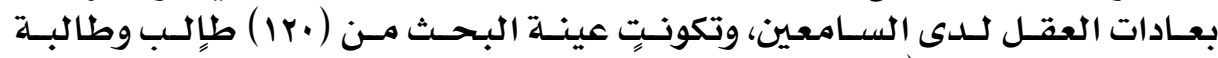

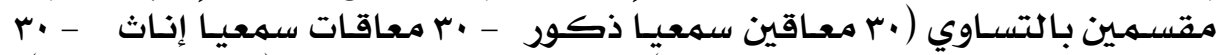

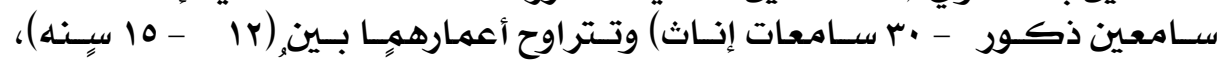

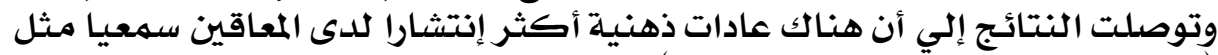

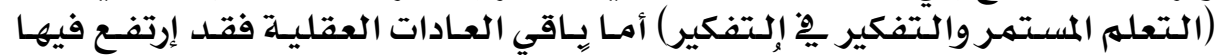

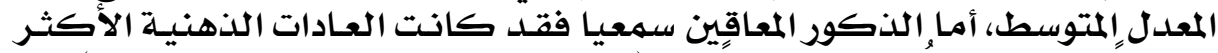

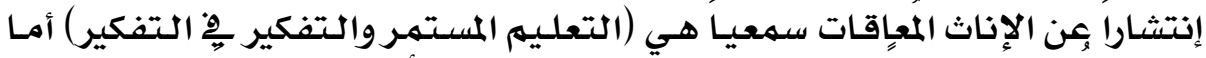

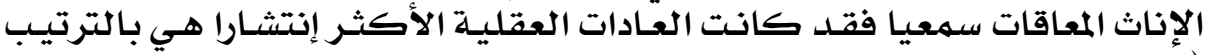

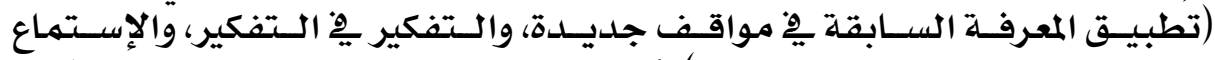

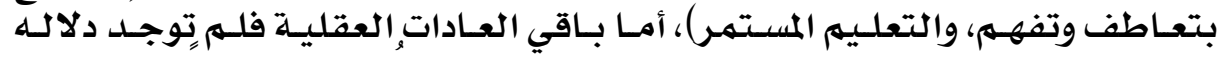

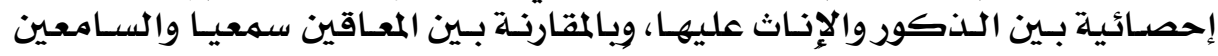

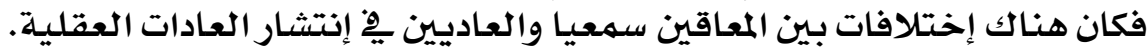

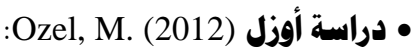

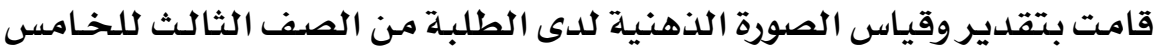

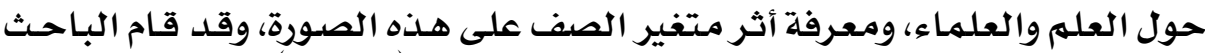

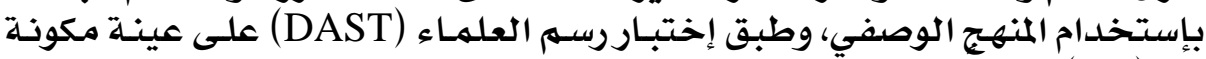

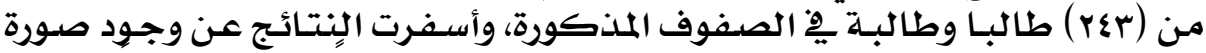

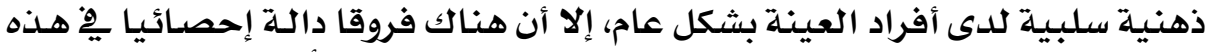

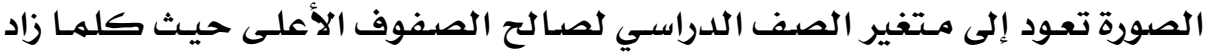

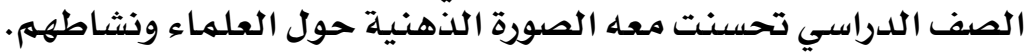

• دراسة بارسا وآخرون Barca, Laura; et. Al, (2012)

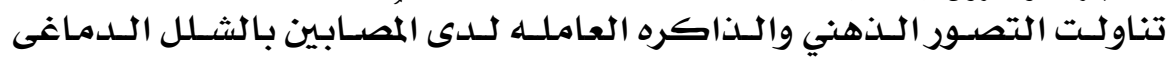

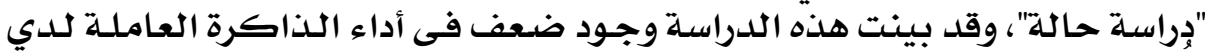

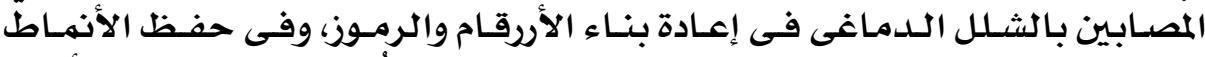

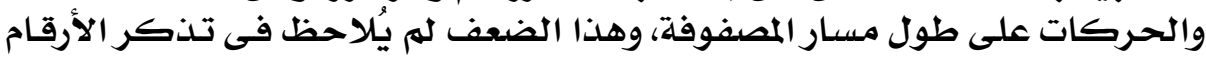

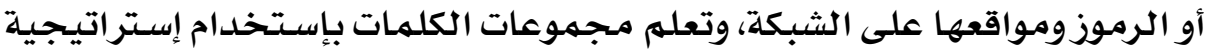

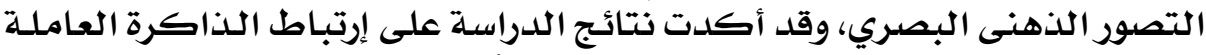

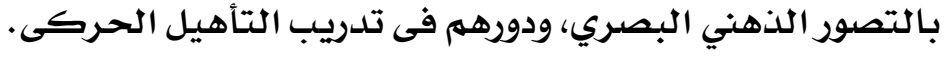

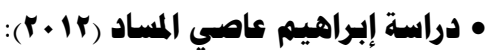

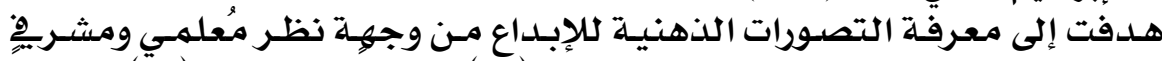

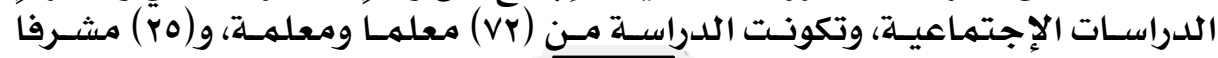




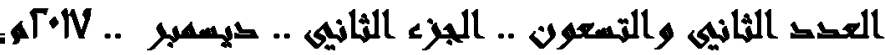

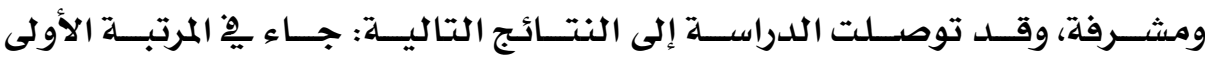

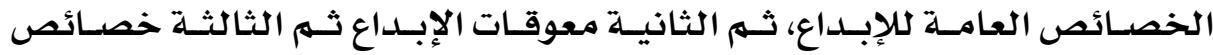

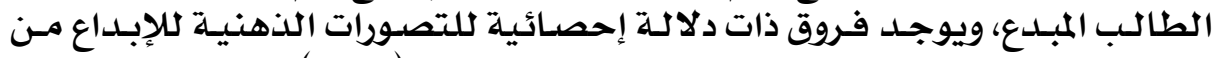

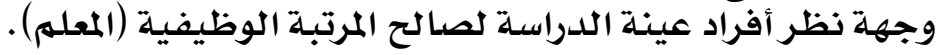

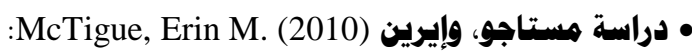

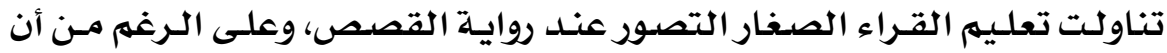

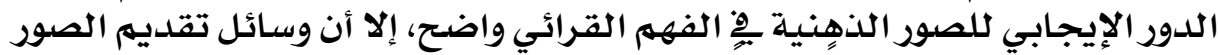

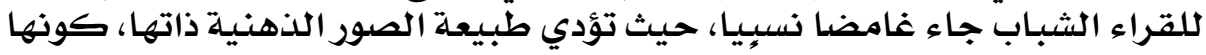

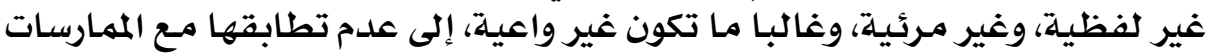

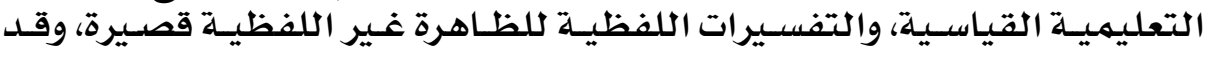

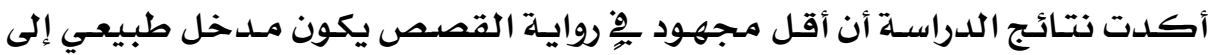

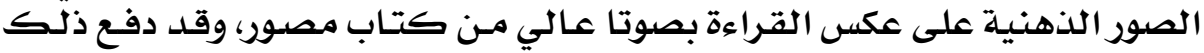

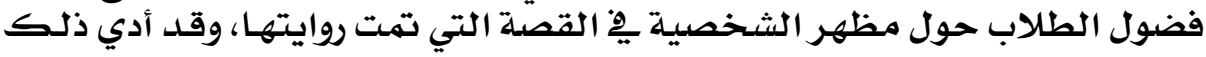

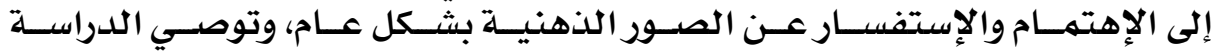

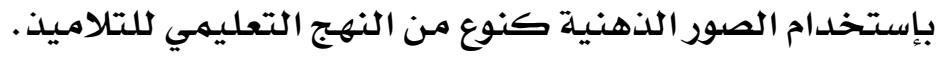

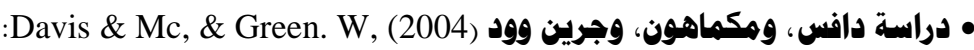

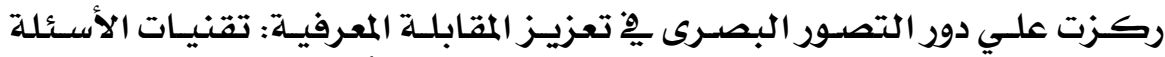

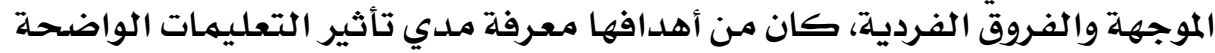

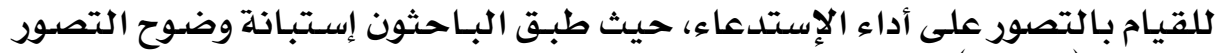

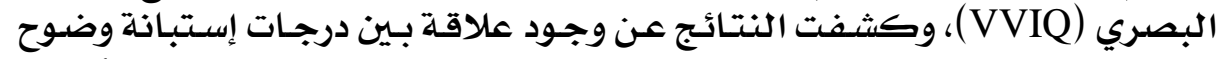

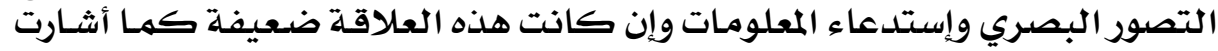

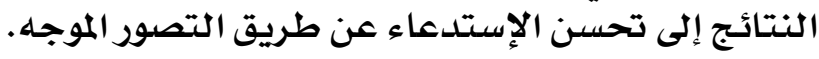

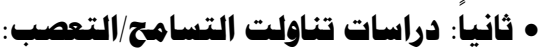

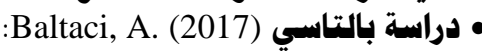

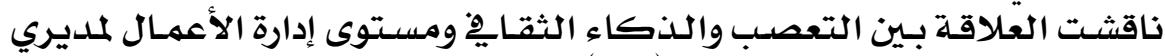

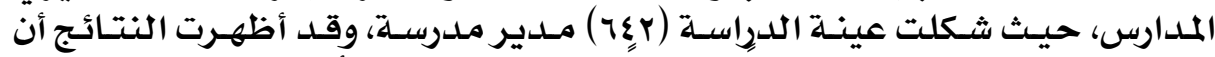

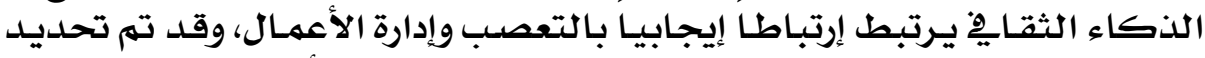

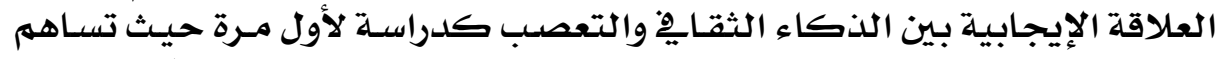

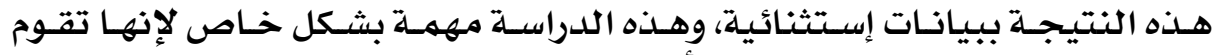

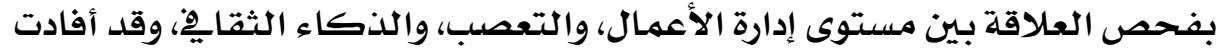

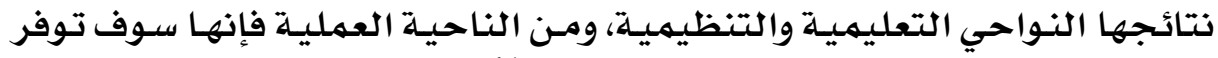

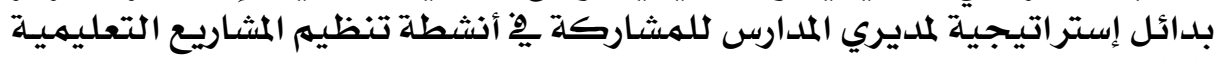

القادمة.

• دراسة خالد بن همهد الدهمش (r.17):

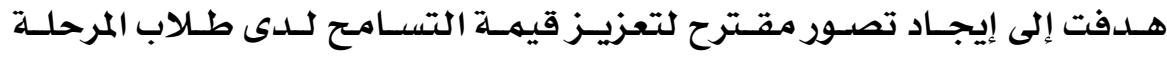

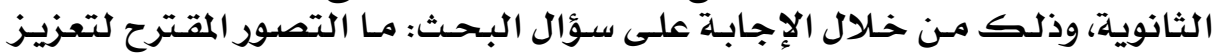




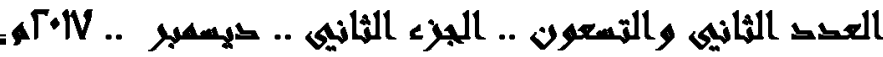

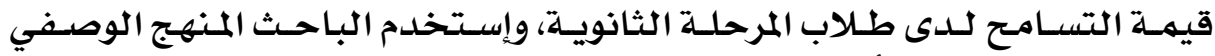

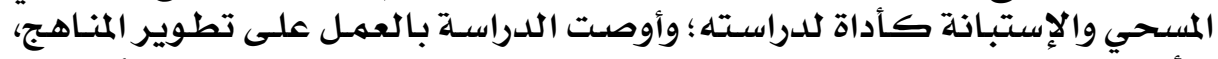

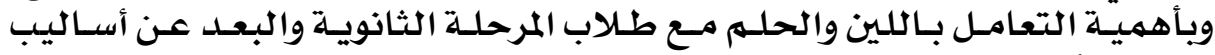

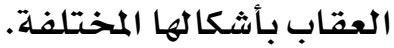

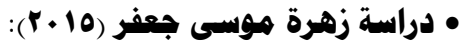

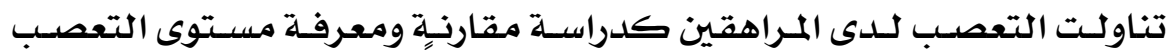

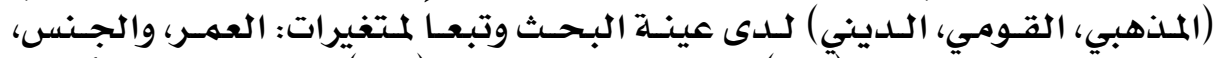

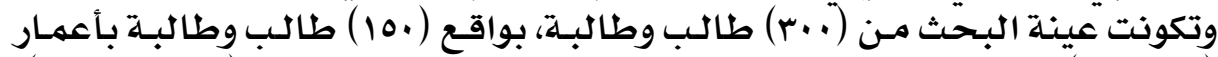

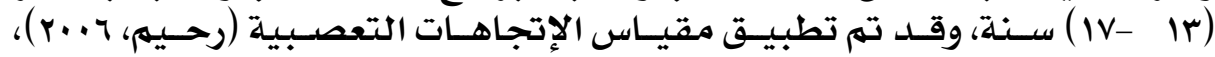

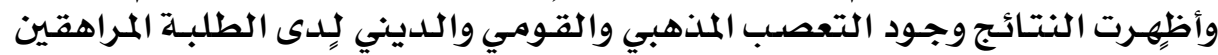

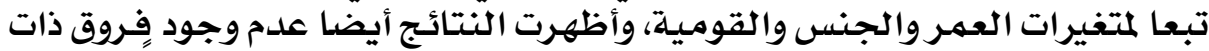

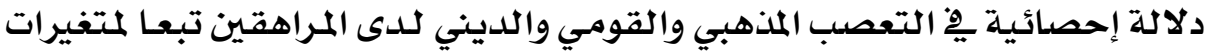

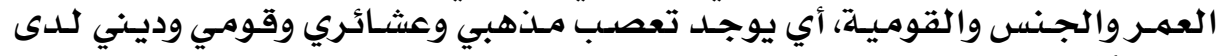

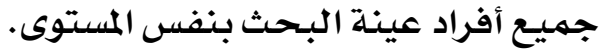

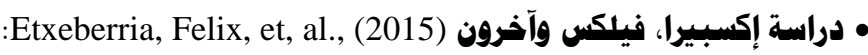

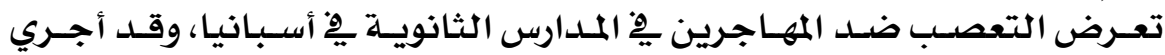

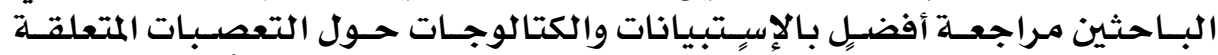

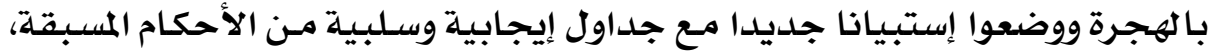

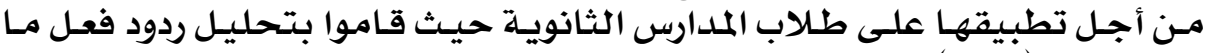

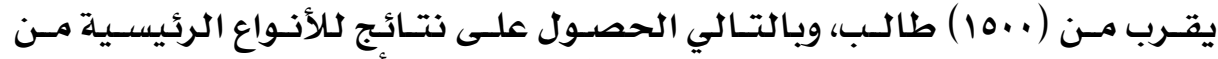

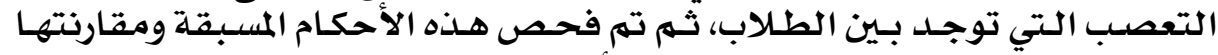

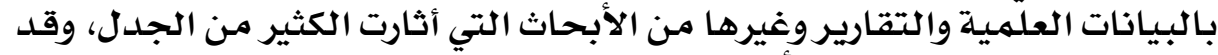

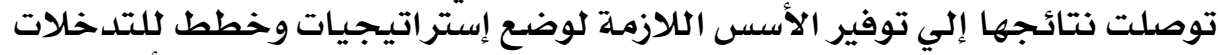

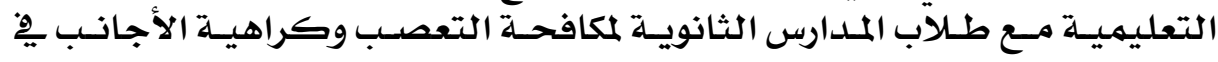
الملدارس.

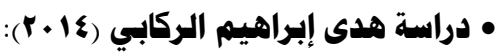

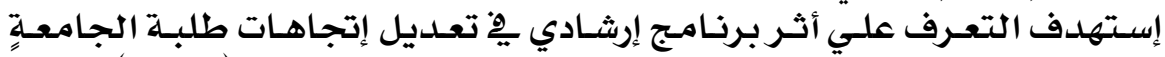

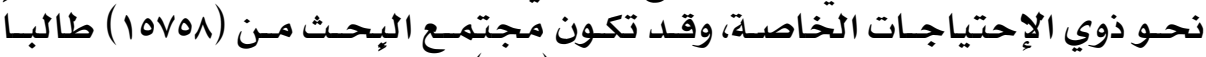

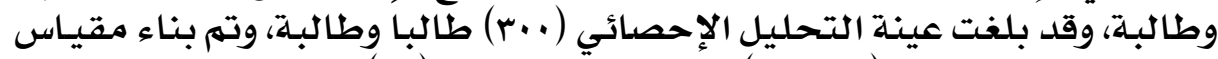

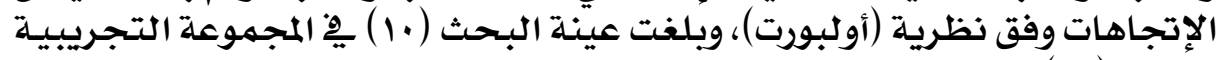

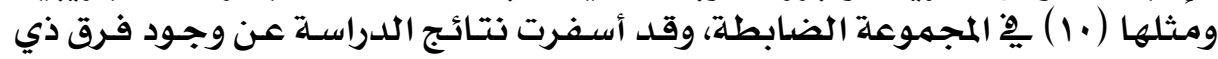

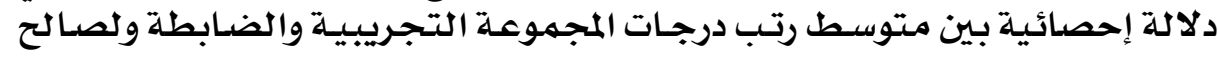

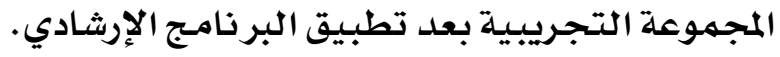

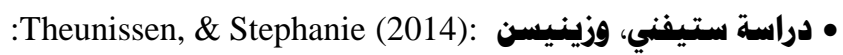

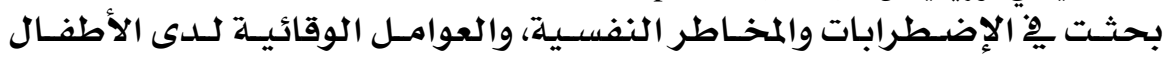

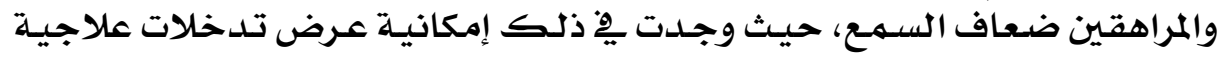




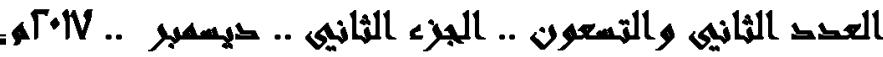

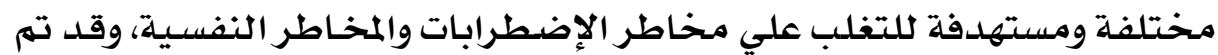

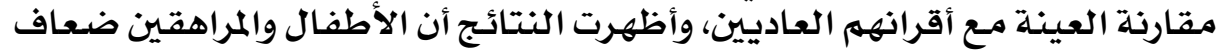

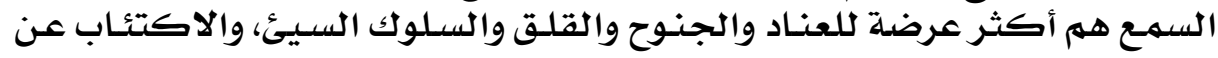
أقرانهم العاديين.

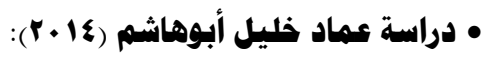

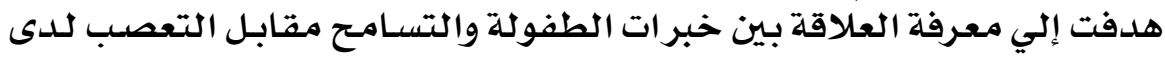

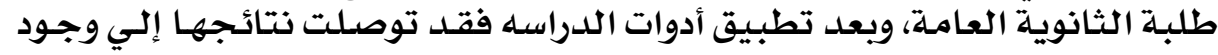

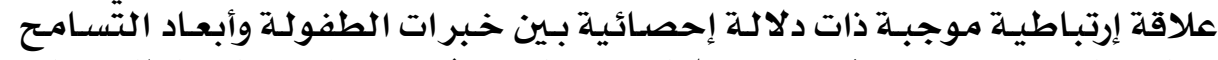

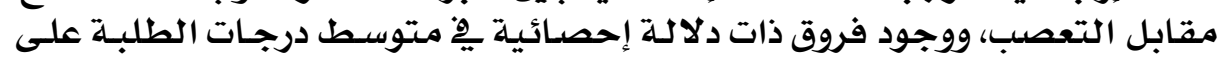

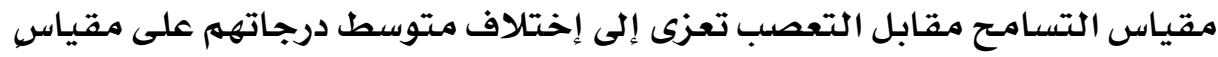

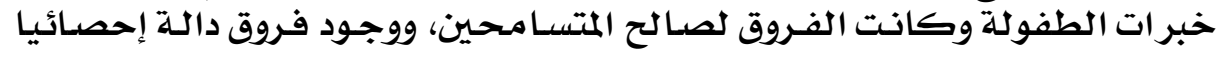

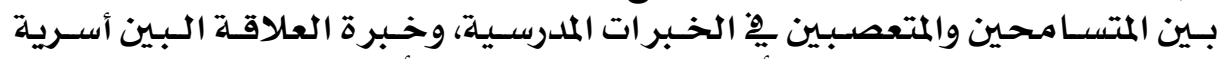

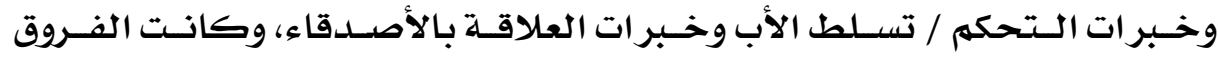
لصائح المتسـامحين.

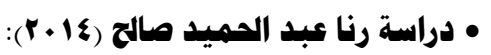

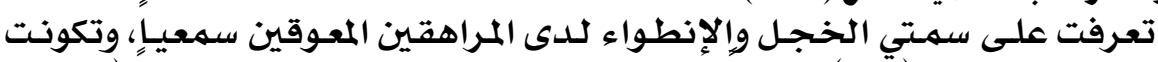

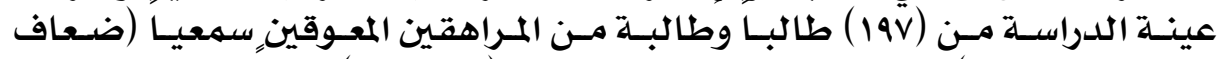

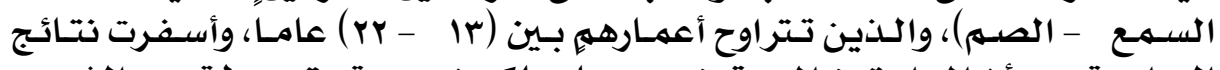

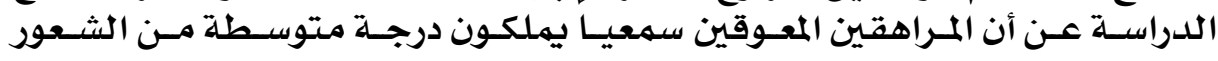

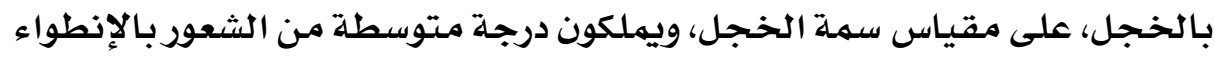

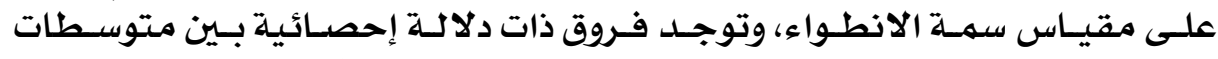

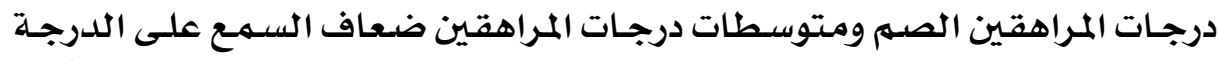

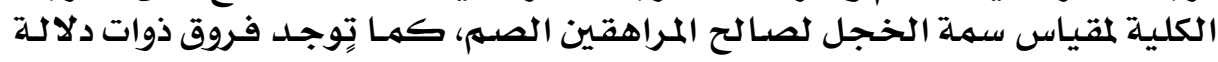

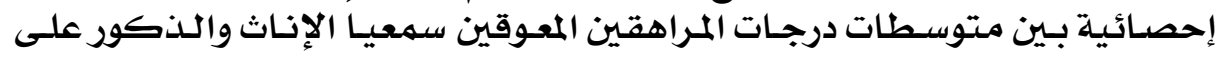

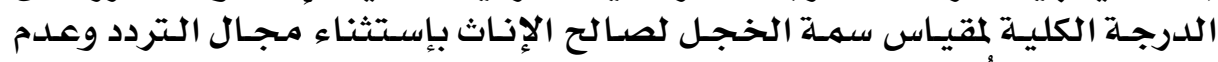

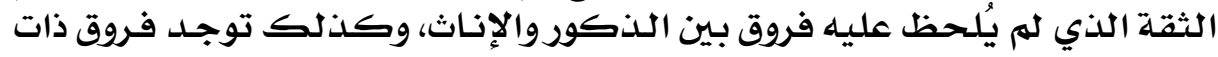

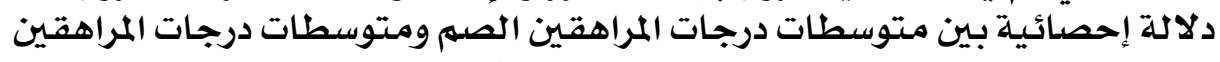

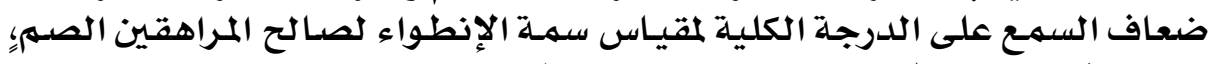

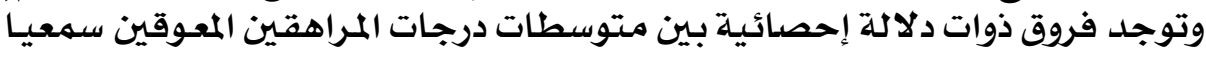

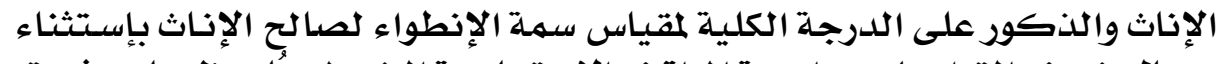

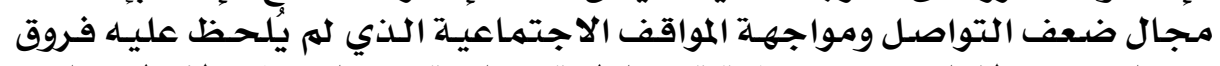

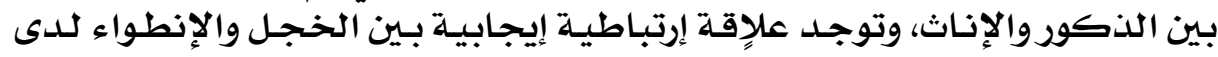

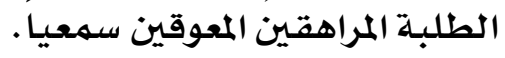

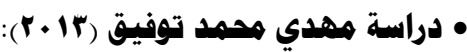

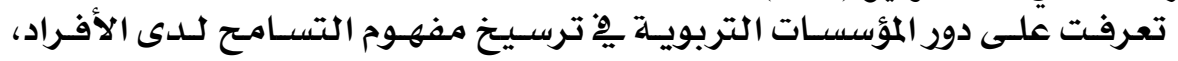

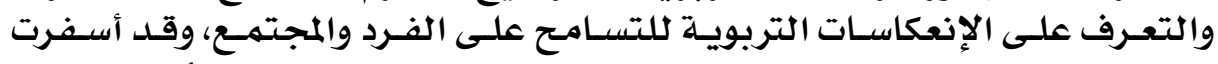

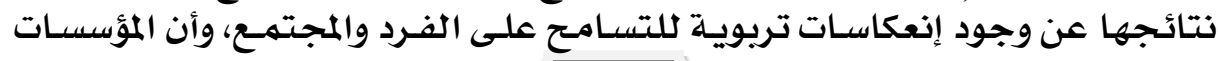




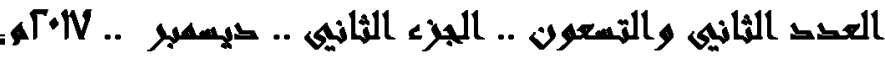

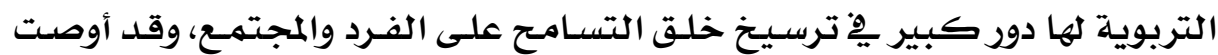

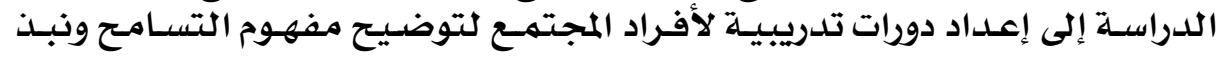

التعصد.

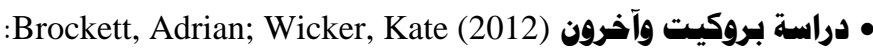

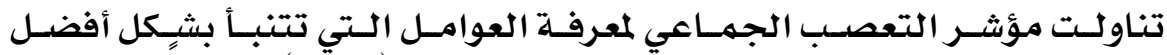

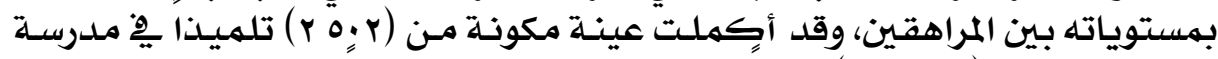

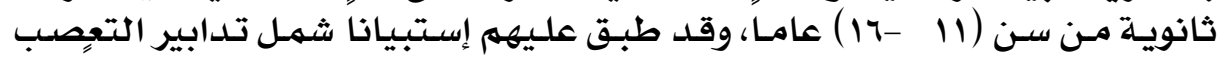

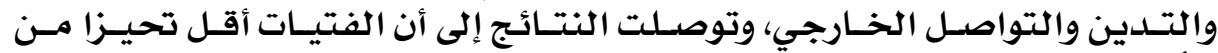

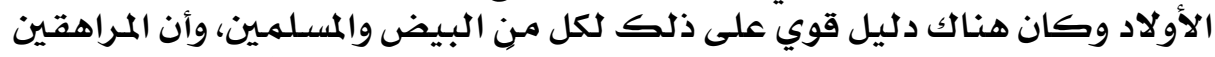
الذين هم يٌْ منتصف العمهر كانوا أكثر تعصبـا من المراهقين الآخرين.

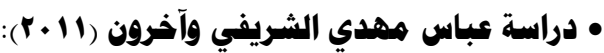

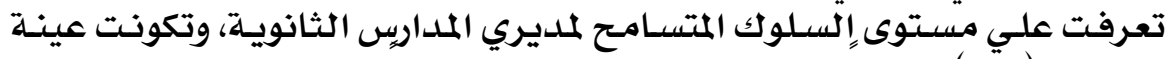

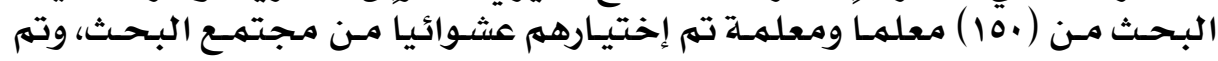

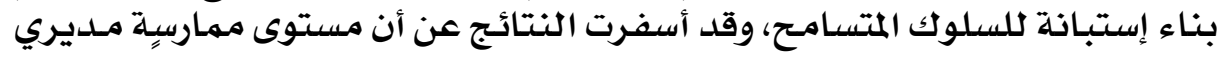

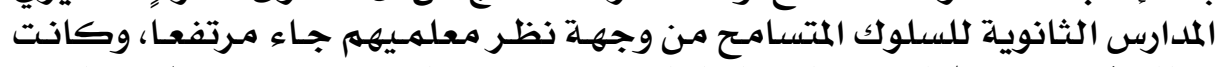

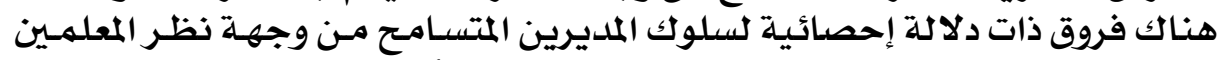

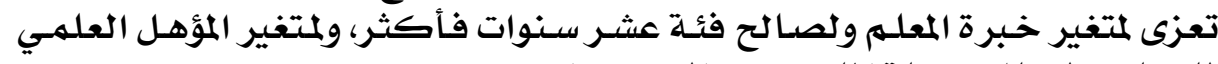

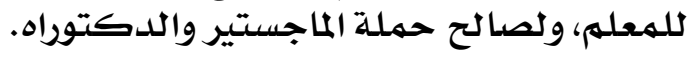

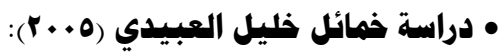

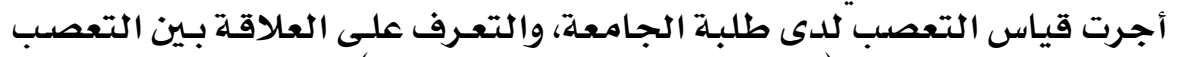

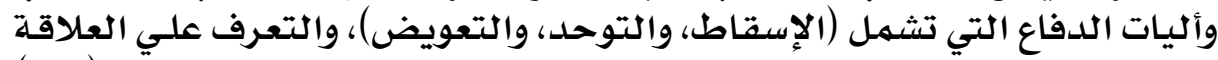

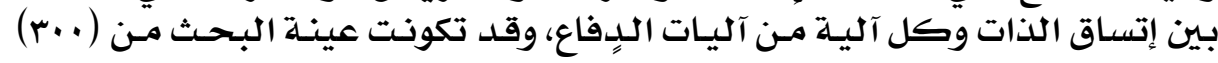

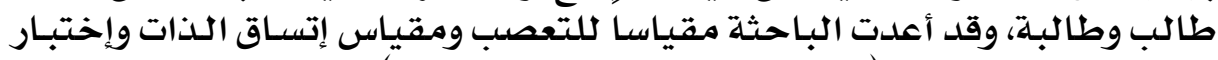

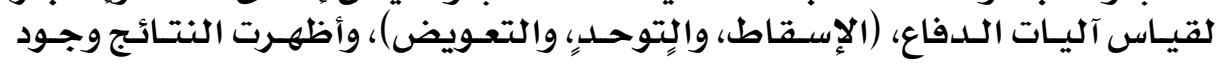

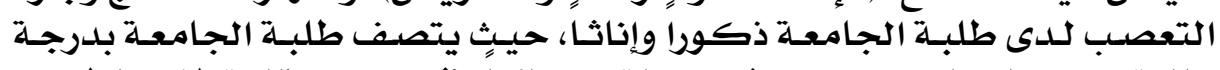

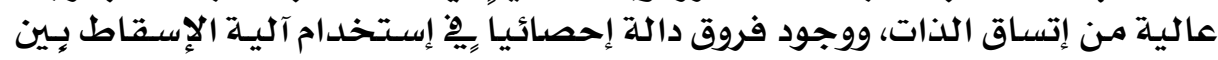

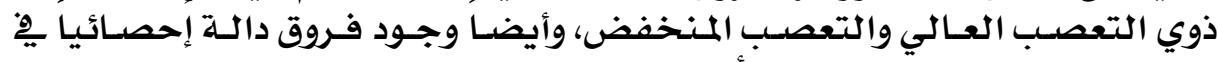

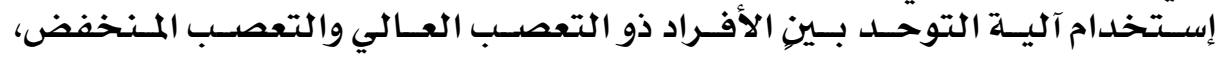

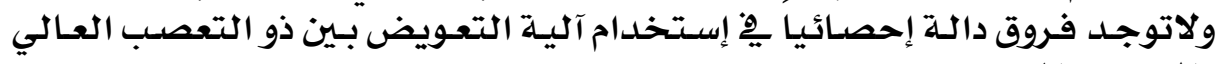

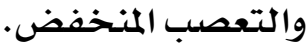

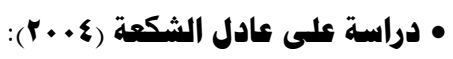

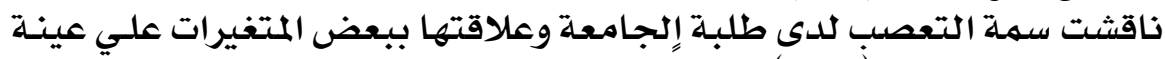

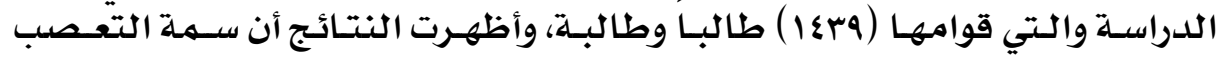

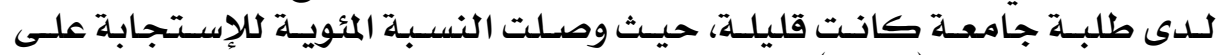

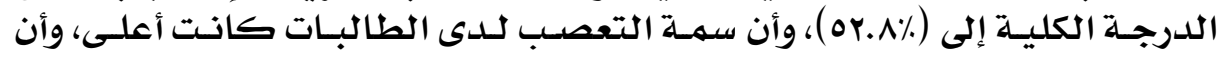

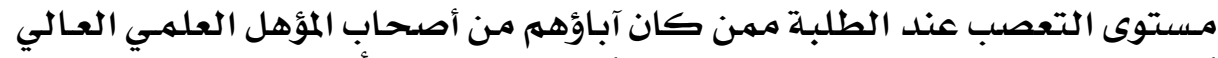

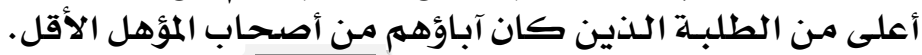




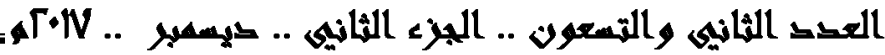

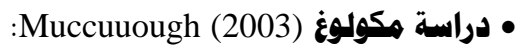

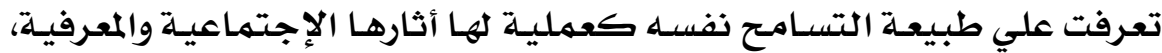

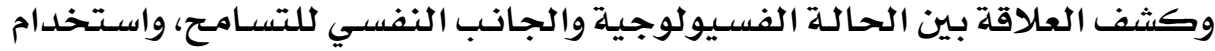

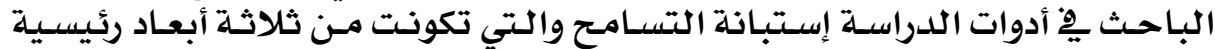

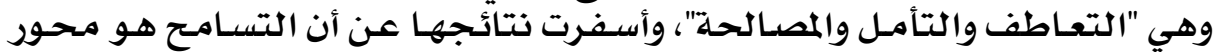

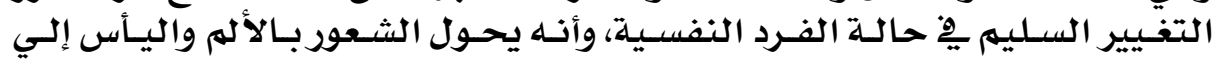

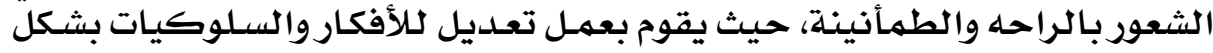

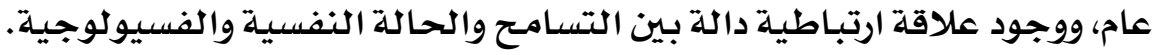

• تعليق علم علي الدراسات السابقة:

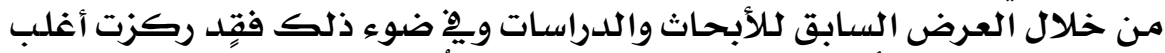

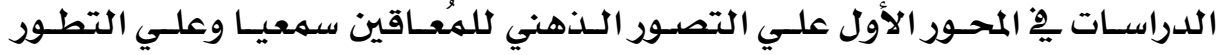

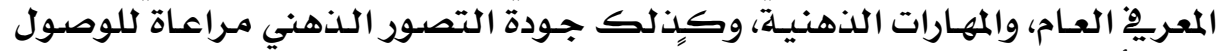

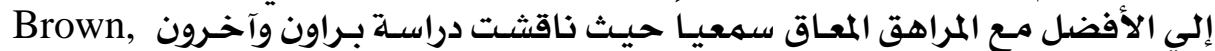

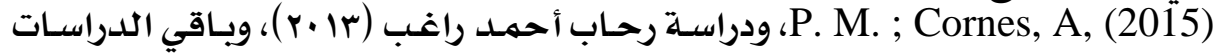

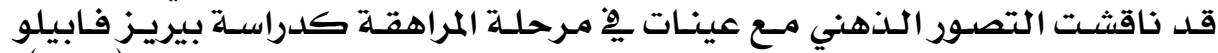

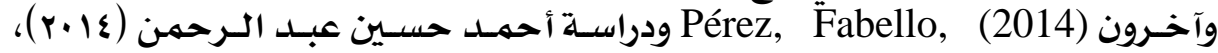

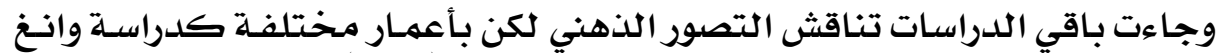

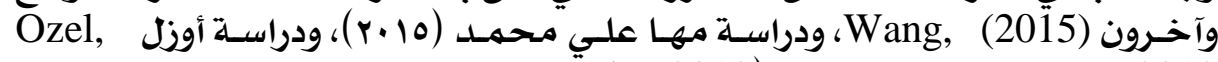

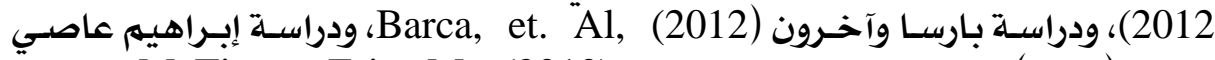

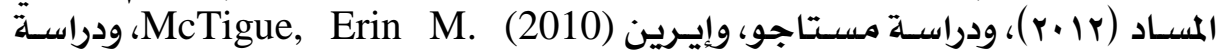

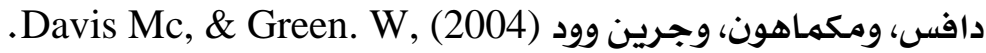

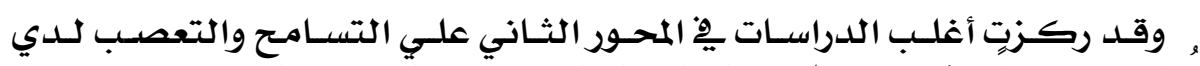

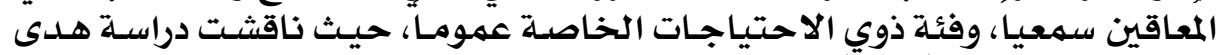

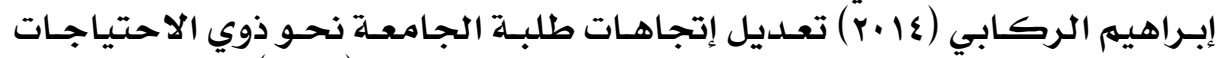

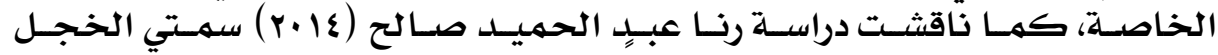

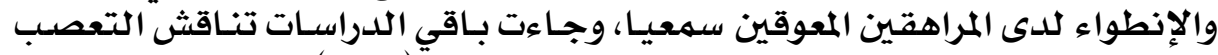

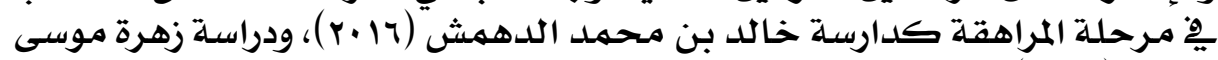

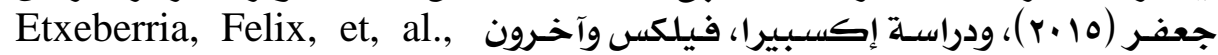

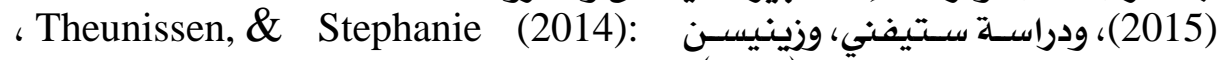

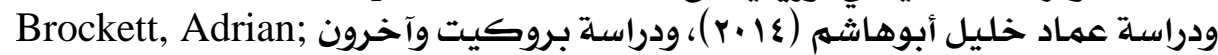

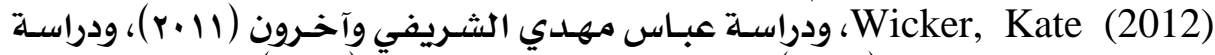

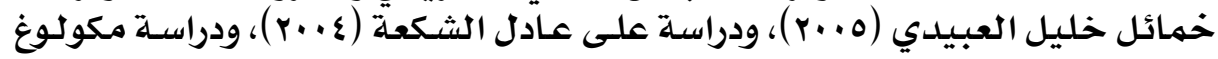
.Muccuuough (2003)

• سابعا: فروض البحث:

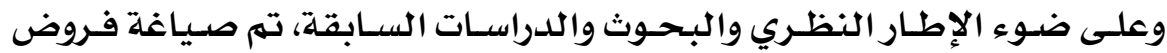
البحث الحادية فئ الآتي: 


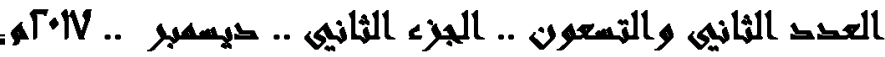

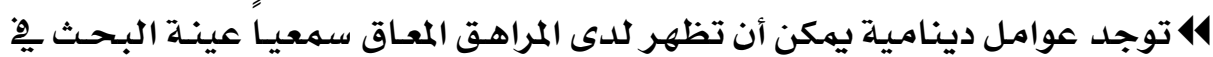

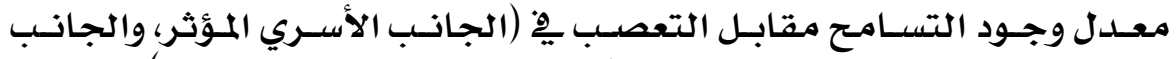

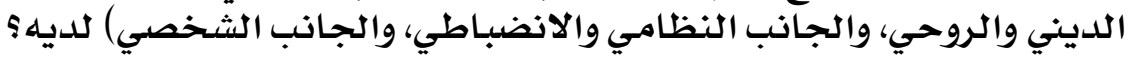

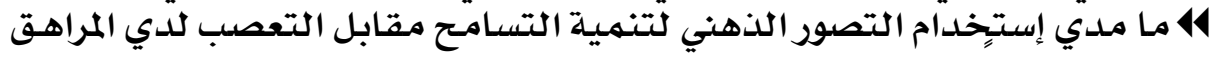

$$
\begin{aligned}
& \text { المعاق سمعيا عينة البحث. البحث. }
\end{aligned}
$$

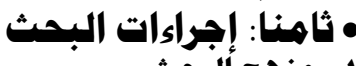

$$
\begin{aligned}
& \text { ا }
\end{aligned}
$$

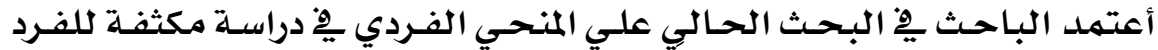

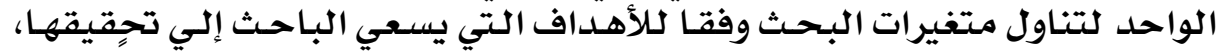

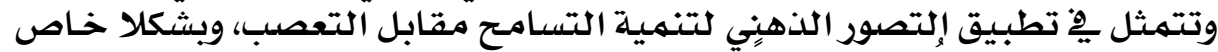

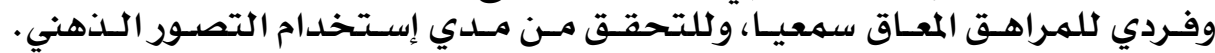

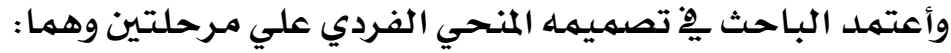

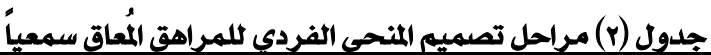

\begin{tabular}{|c|c|c|}
\hline الإجراء & المراحل & \\
\hline يتم قياس التسامح والتعصب قبل بدي التصور الذهنى. & مرحلت الخط القاهدي & 1 \\
\hline ليتم تنميت التسامح والتعصب للمعاق سمعياً. & مرحلت التتميتة & r \\
\hline
\end{tabular}

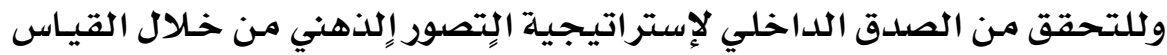

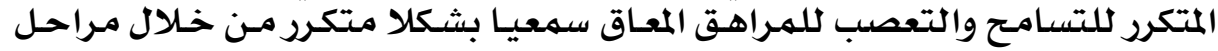

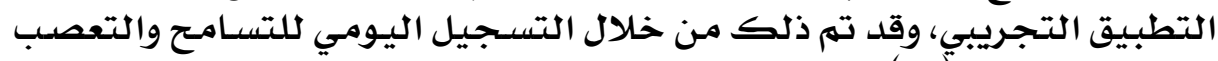

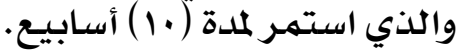
r r عينة البحث:

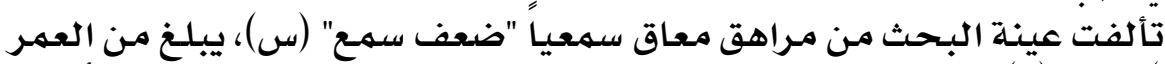

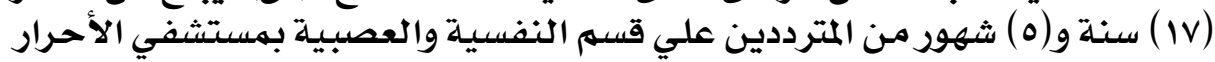

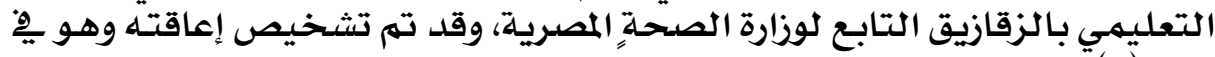

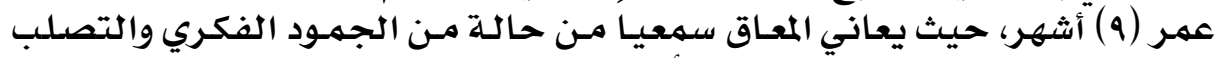

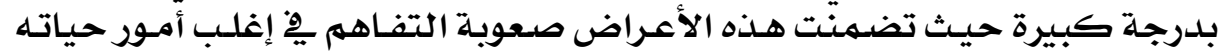

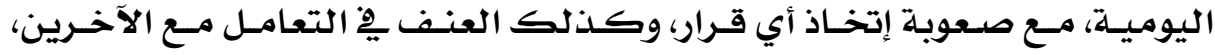

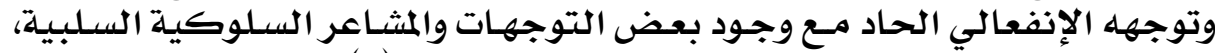

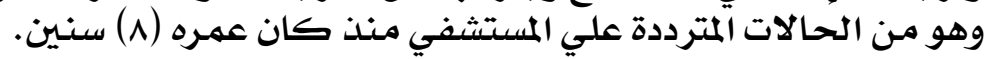

r- حدود البحث:

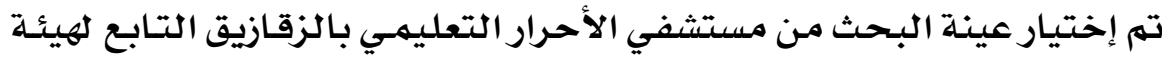

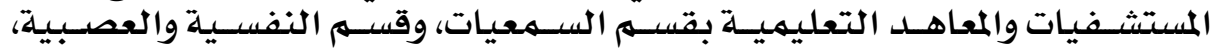

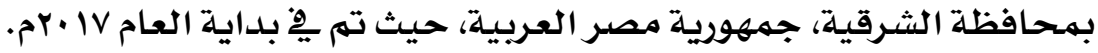

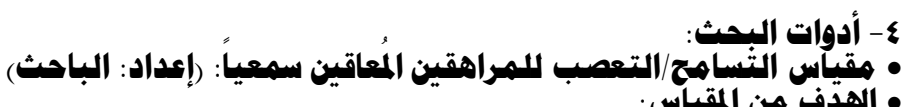

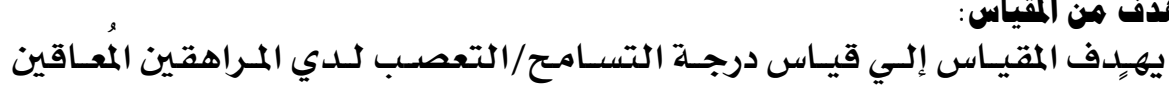




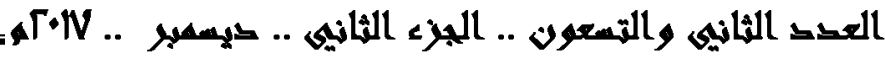

• وصف هقياس التسامح/التعصب:

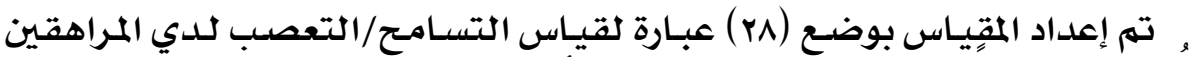

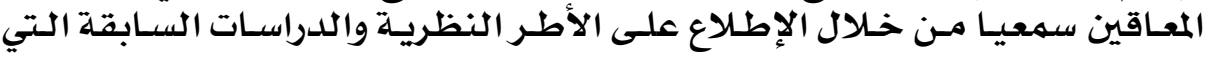

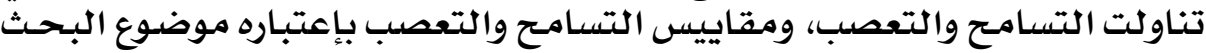

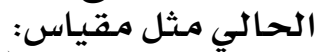

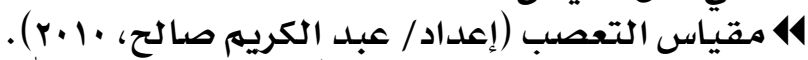

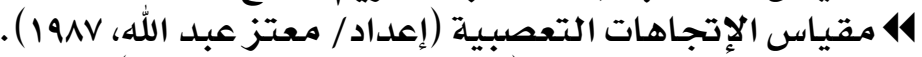

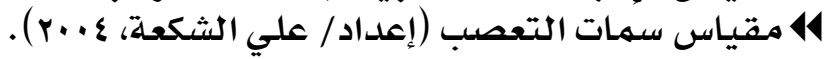

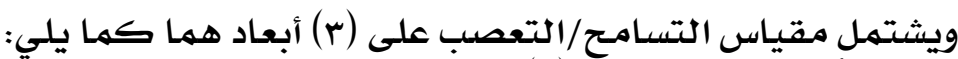

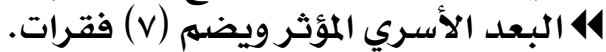

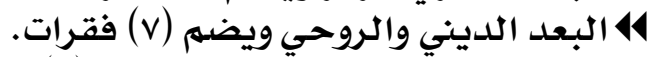

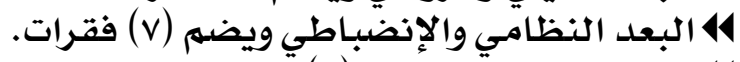

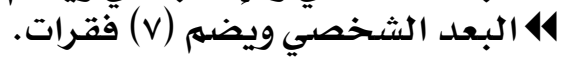

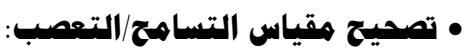

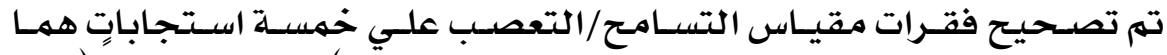

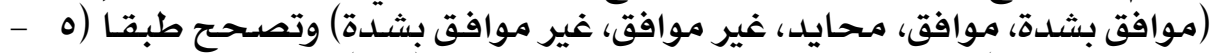

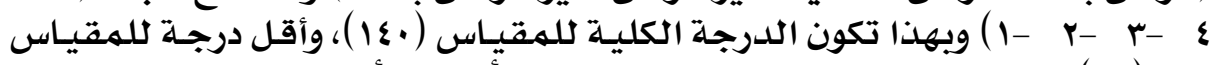

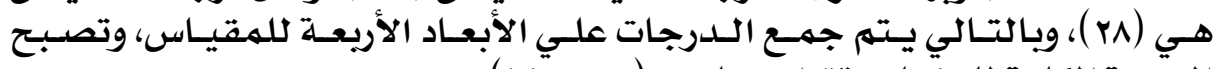

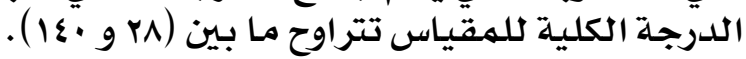

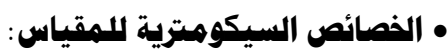

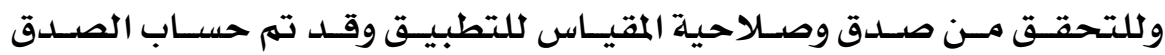

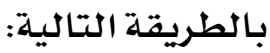

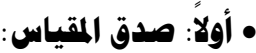

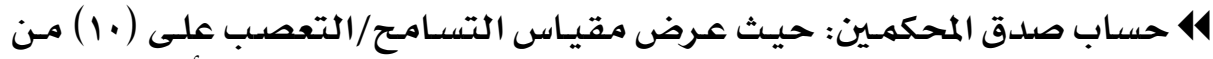

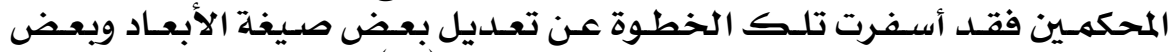

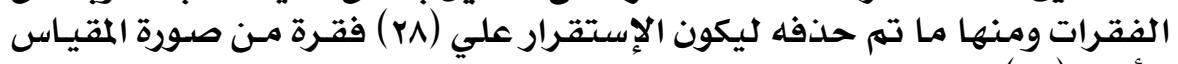

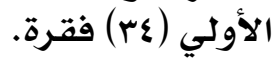

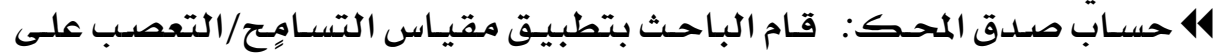

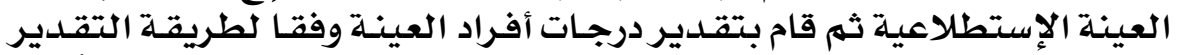

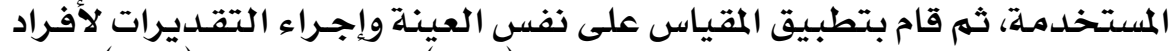

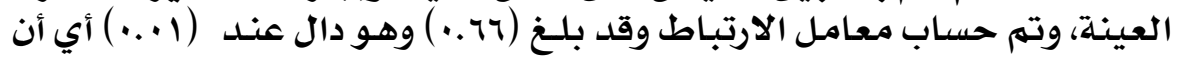
المقياس يتمتع بدرجة صداب من مناسبة.

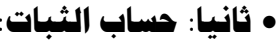

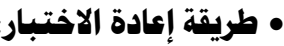

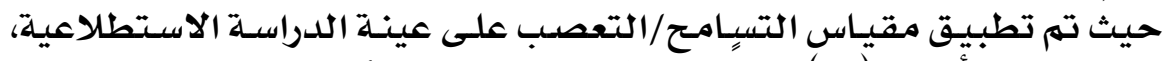
وبعد التطبيق الأول ب (10) يوما، تم تطبيق المقياس مرة أخرى على نفس العينس العينة،

\section{rᄉ.}




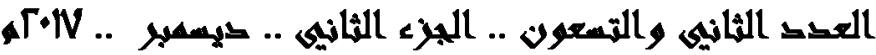

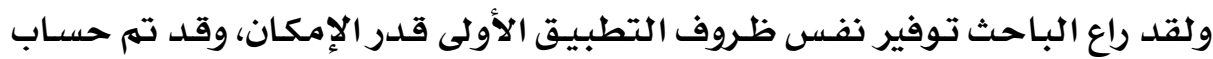

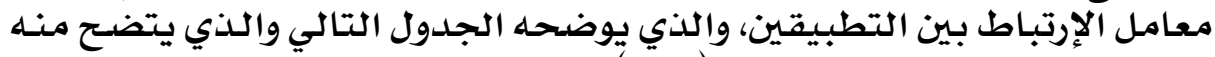

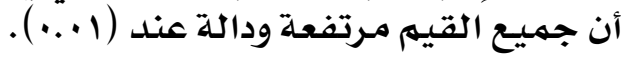

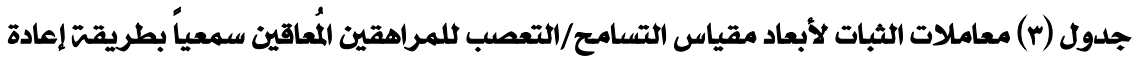
التطبيق

\begin{tabular}{|c|c|}
\hline 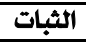 & أبعاد المقياس \\
\hline$\rightarrow \Delta \cdot A^{\prime}$ & البعد الأسري المؤثر. \\
\hline$\leftrightarrow 4 . \wedge 1$ & البعد الديني والروحي. \\
\hline$\Delta 4 . \wedge \cdot$ & البعد النظامي والإنضباطي. \\
\hline$\Delta+A \Lambda^{\mu}$ & البعد الشخصي. \\
\hline$\leftrightarrow 4$ & الدرجة الكليتً \\
\hline
\end{tabular}

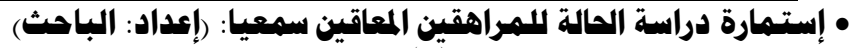

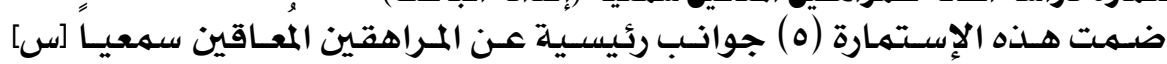

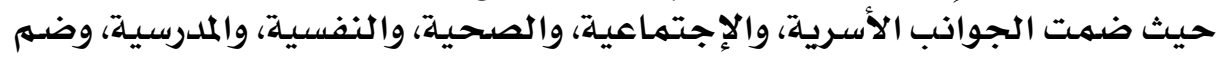

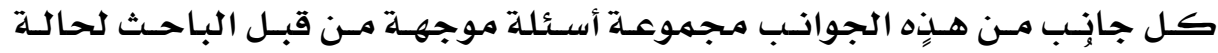

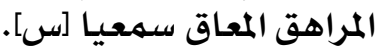

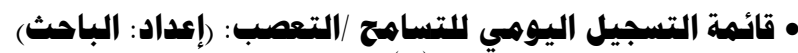

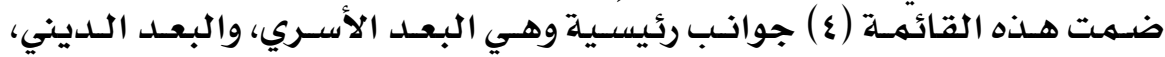

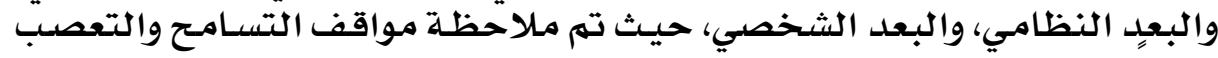

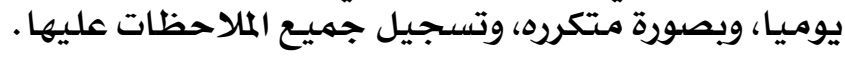

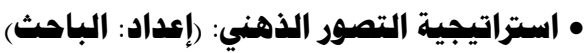

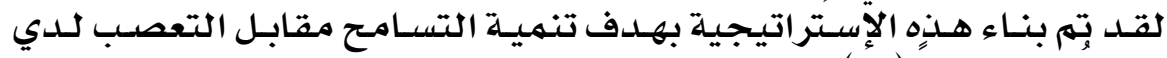

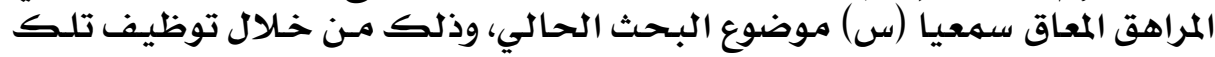

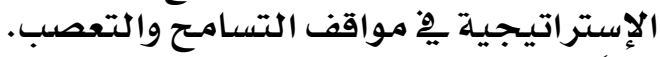

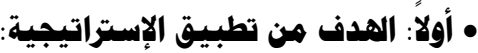

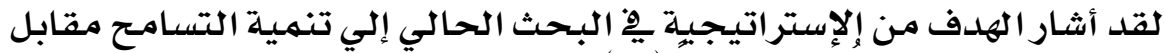

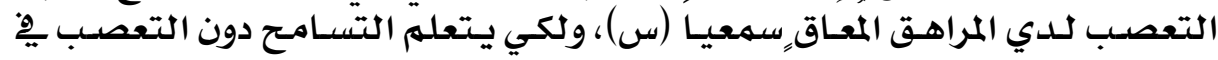

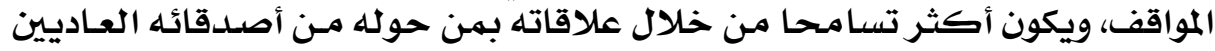

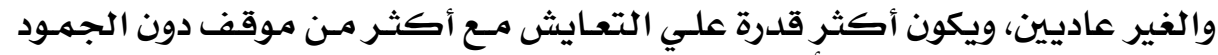

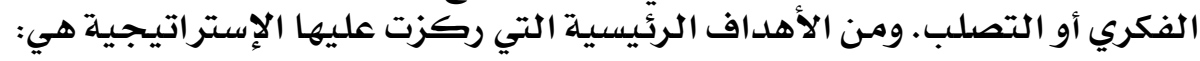

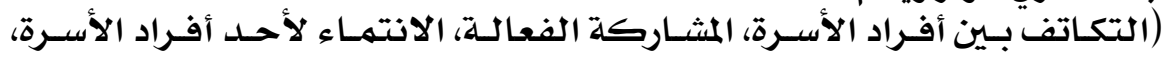

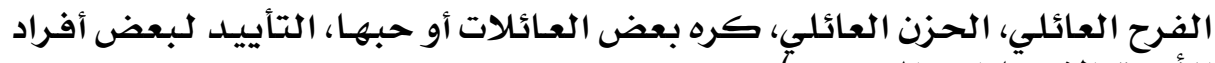

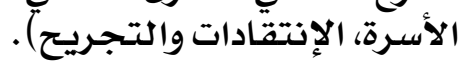

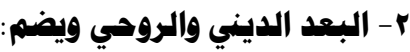

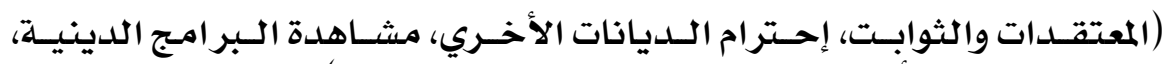

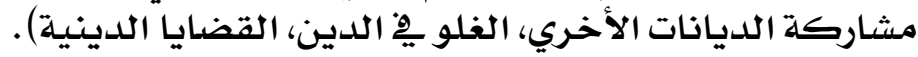




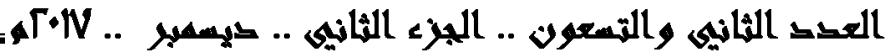

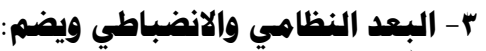

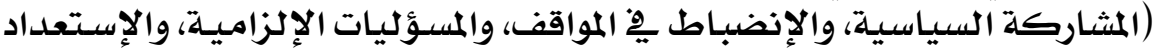

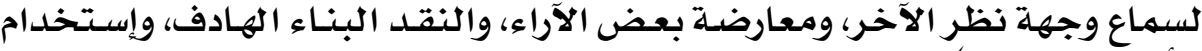

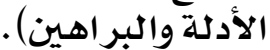

ع- البعد الشخصي ويضم:

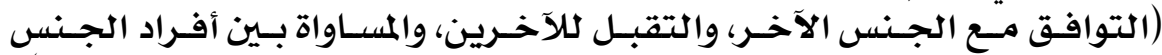

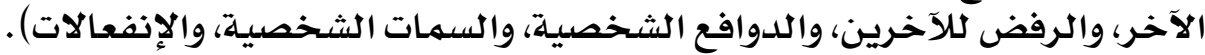

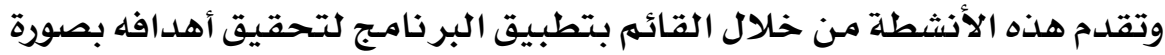

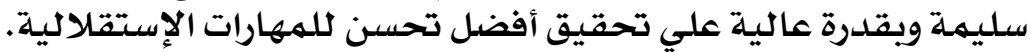

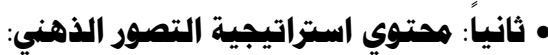

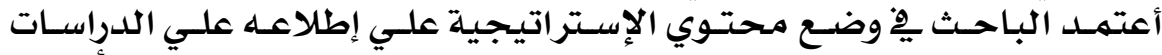

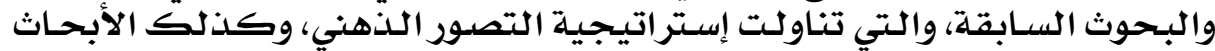

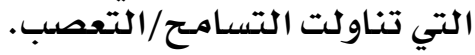

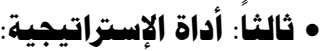

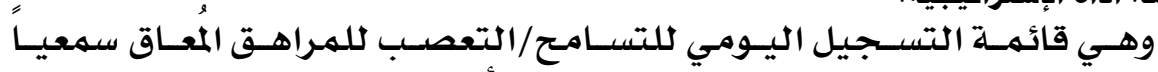

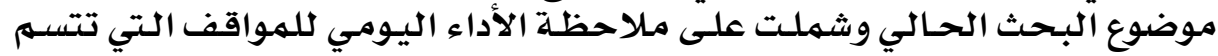

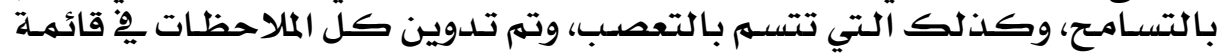
التسجيل.

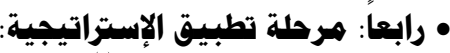

\begin{tabular}{|c|c|c|}
\hline التقييم الّذاتي/مستوى الأداء & مواقف التتسامح/التعضب & أبعاد التسامح/التعصب \\
\hline جيد/تشامح & التكاتف بين أفراد الأسرة & \multirow{4}{*}{ البعد الأسري المؤثر } \\
\hline جيد/تسامح & المشاركت الفعالة & \\
\hline متوسط/تعصب & الإنتماء لأحد أفراد الأسرة & \\
\hline جيد/تسامح & الإنتقادات والتجريح & \\
\hline جيد جدا/تسامح & المعتقدات والثوابت & \multirow{4}{*}{ البعد الديني والروحي } \\
\hline ممتاز/تسامح & إحترام الديانات الأخري & \\
\hline جيل جدا/تعصب & مشاهدة البرامج الدينية & \\
\hline جيد/تسامح & مشاركتَ الديانات الأخري & \\
\hline متوسط/تعصب & الأدلتّ والبراهين & \multirow{4}{*}{ البعد النظامي والإنضباطي } \\
\hline جيد جدا/تسامح & الإنضباط ي2 المواقف & \\
\hline ممتاز/تسامح & والمسؤليات الإلزاميتي & \\
\hline جيل جدا/تعصب & معارضتَ بعض الآراء & \\
\hline جيد/تعصب & الدوافع الشخصيت & \multirow{4}{*}{ البعد الشخصي } \\
\hline متوسط/تعصب & الرفض للآخرين & \\
\hline جيد/تسامح & السمات الشخصية & \\
\hline / / (تعصب & الإنفعالات & \\
\hline
\end{tabular}

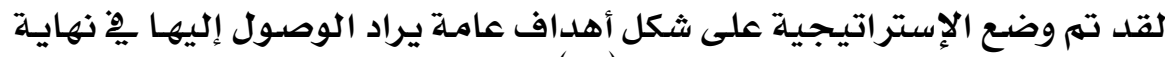

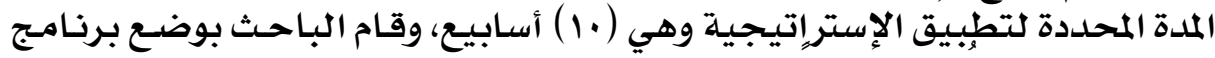

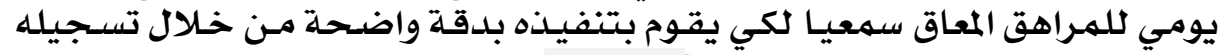




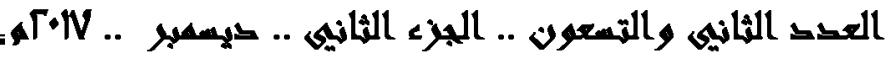

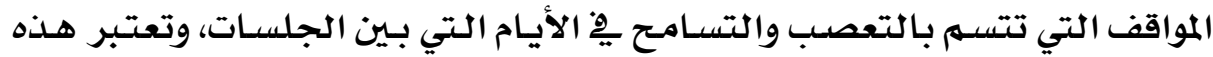

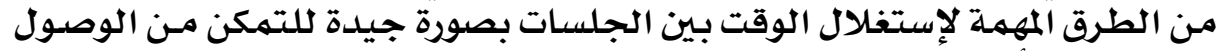

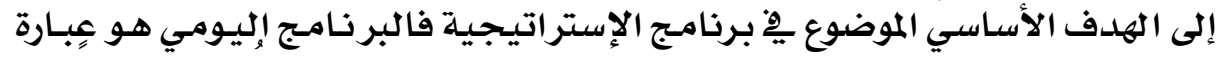

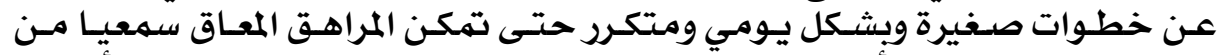

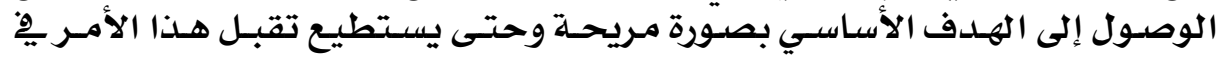

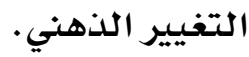

• خاهساً: الجوانب الأساسية لإستراتيجية التصور الذهني للهراهق المُعاق سمعياً:

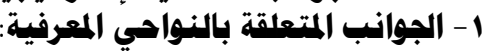

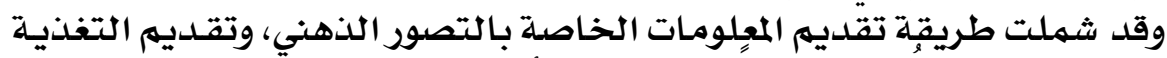

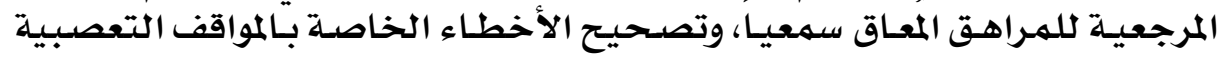

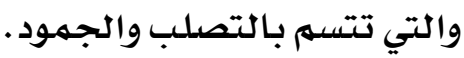

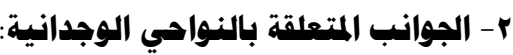

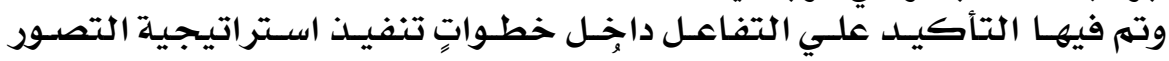

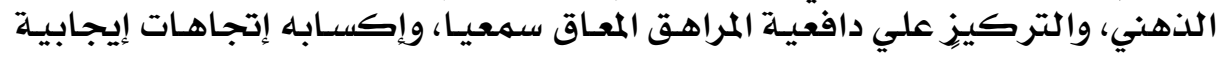

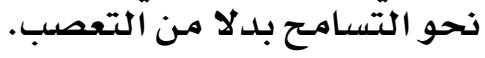

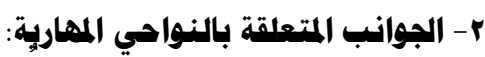

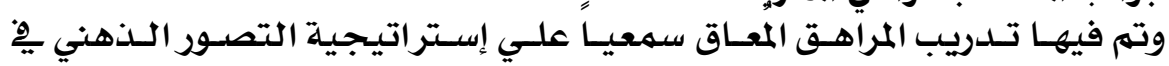

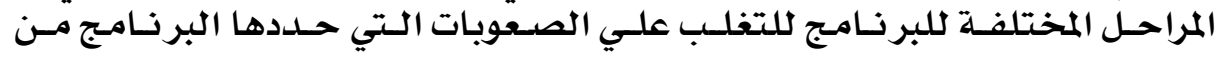

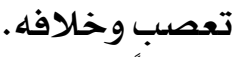

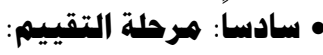

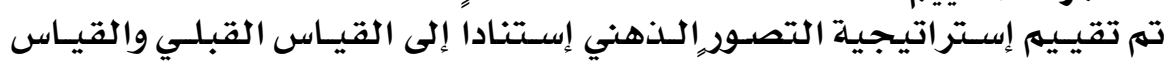

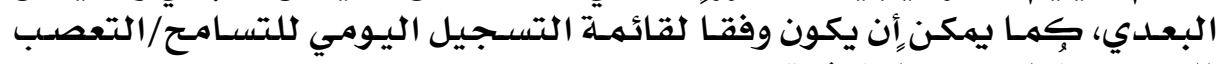
للمـراهق المعاق سمعيا المرفقة.

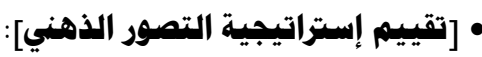

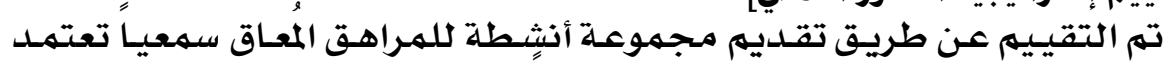

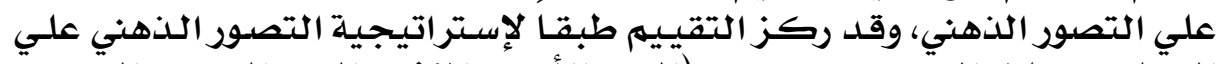

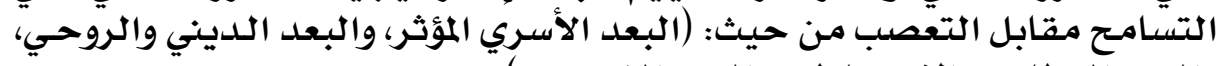

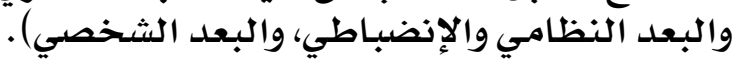

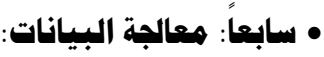

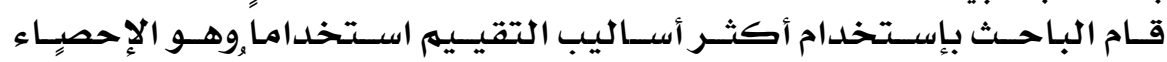

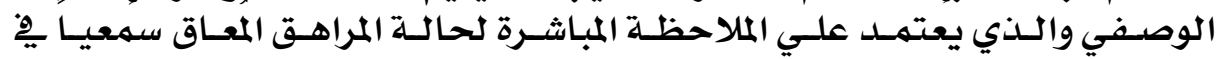

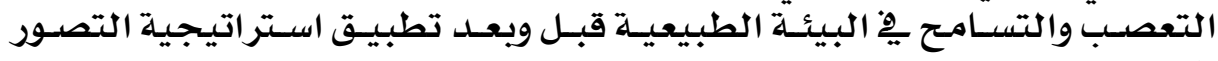
الذهني • ت تاسعا: الخطوات الإجرائية للبمث:

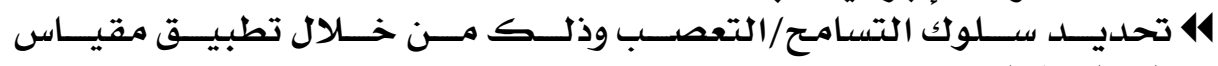

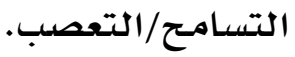




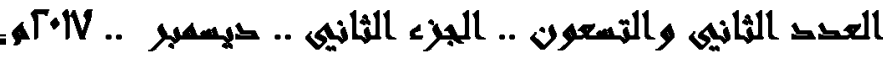

14 مـراقبـة وتسـجيل سـلوك التسـامـح/التعصـب مـن خـلال عـرض الفقـرات وعمـل

تحليل لذلكيلك وتجيل

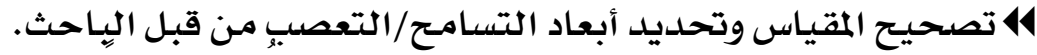

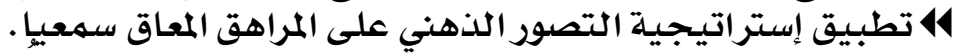

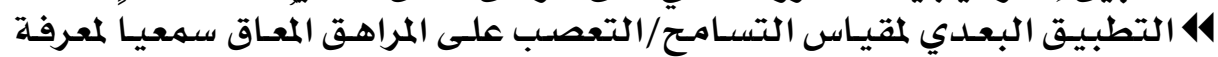

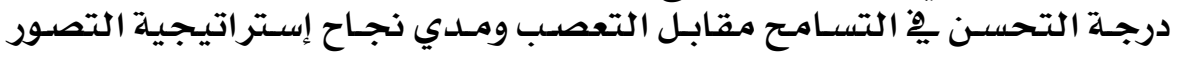

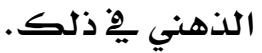

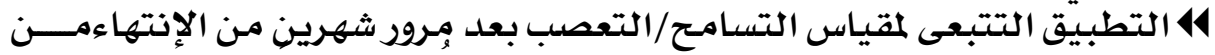

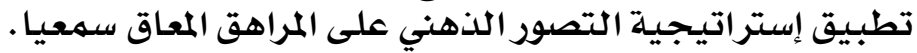

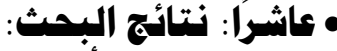

1- أنتائج التساؤل الأول:

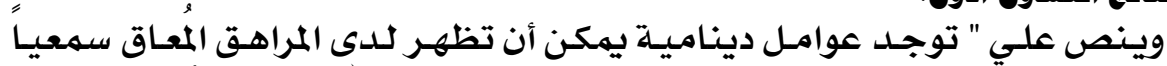

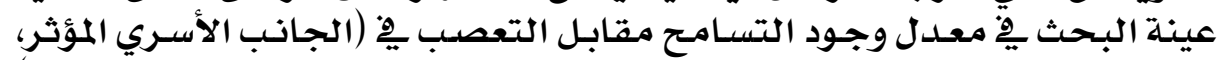

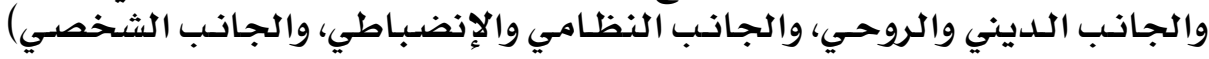
لديه؟

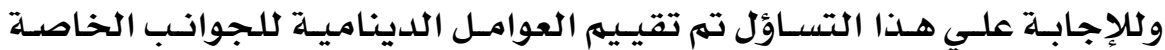

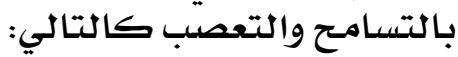
• أولاً: تم تطبيق مقياس التساهح/التعصب للهمراهـق المُعـاق سمعيساً والـذي تضسمن أربعـة أبعـاد أساسية وهمها كالأتي:

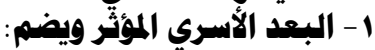

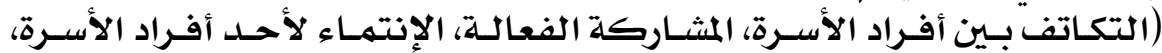

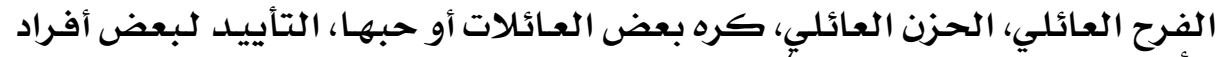
الأسرة، الإنتقادات والتجري، الحزيح).

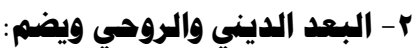

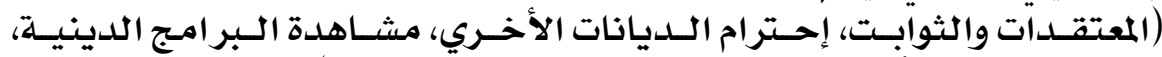

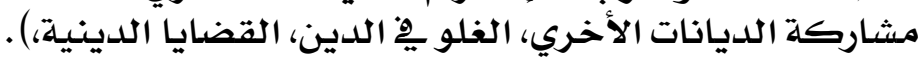

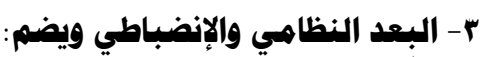

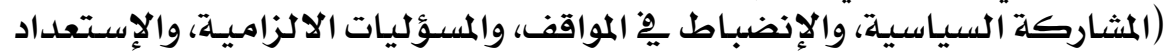

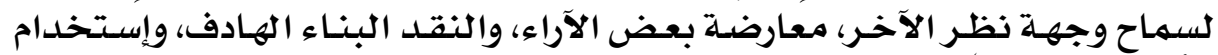

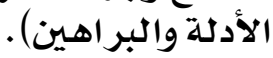

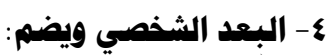

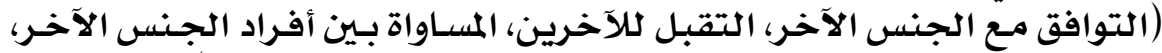

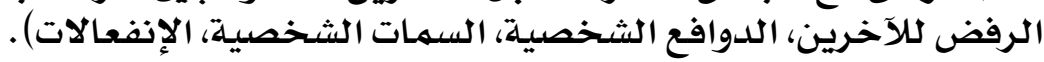

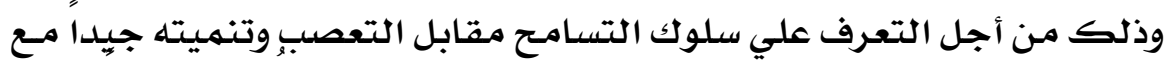

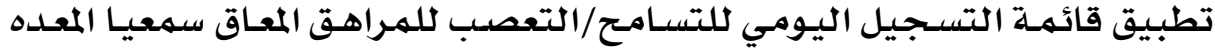




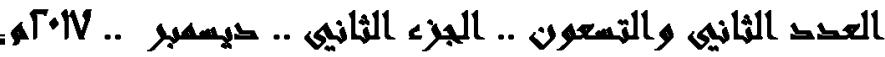

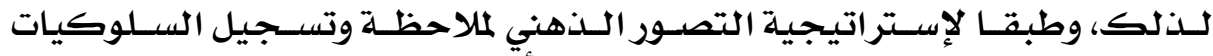

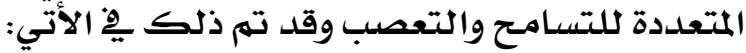

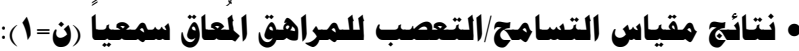

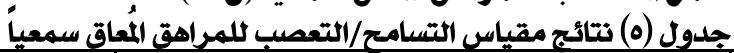

\begin{tabular}{|c|c|c|}
\hline الدرجت الخام & أبعاد مقياس التسامح//التعصب & م \\
\hline$r$ & البعد الأسرى المؤثر. & 1 \\
\hline 19 & البعد الدينى والروحي. & $r$ \\
\hline$r r$ & البعد النظامى والإنضباطى. & $r$ \\
\hline ra & البعد الشخصى. & $\varepsilon$ \\
\hline 1.r. & الدرجت الكليت & \\
\hline
\end{tabular}

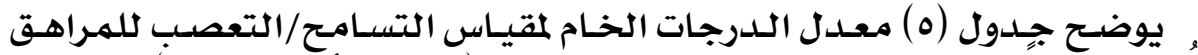

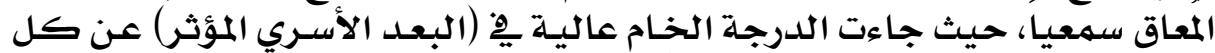

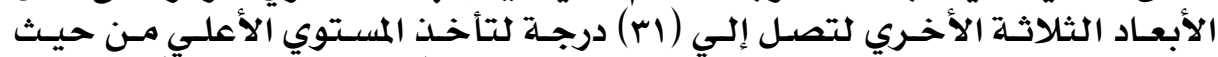

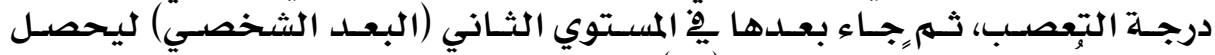

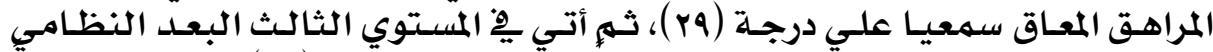

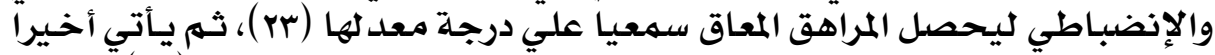

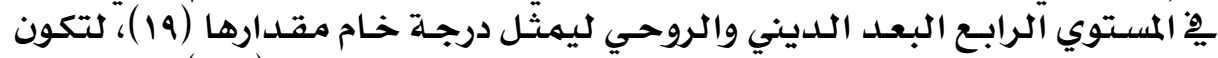

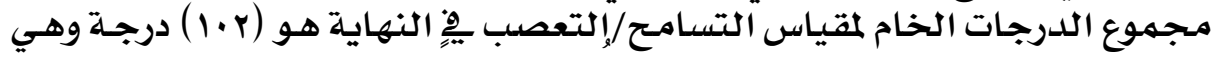

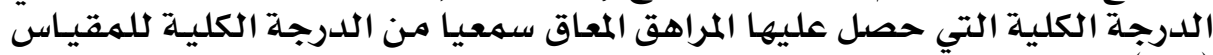

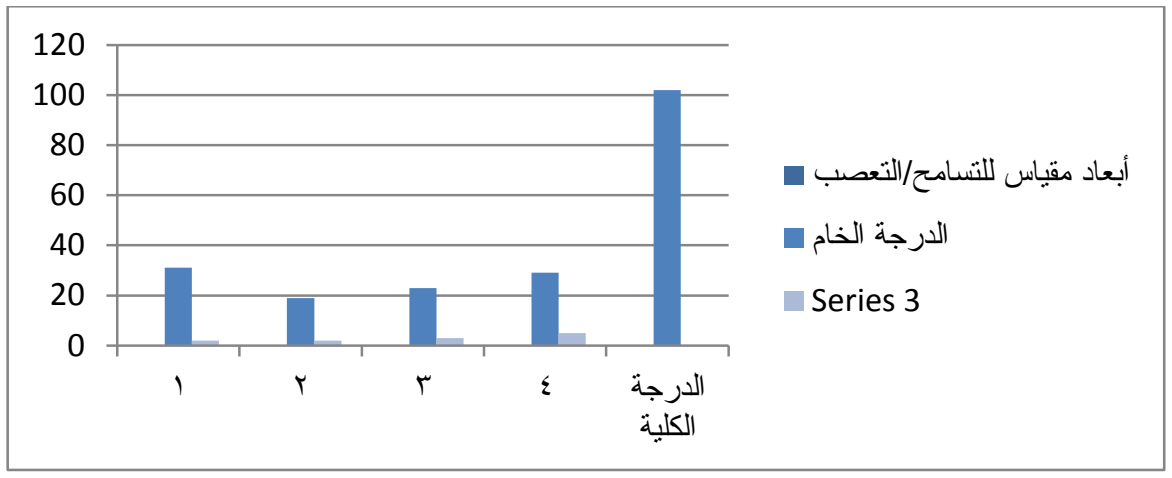

شكل (1) نتائج مقياس التسامح/التعصب للمراهق المعاق سمعياً

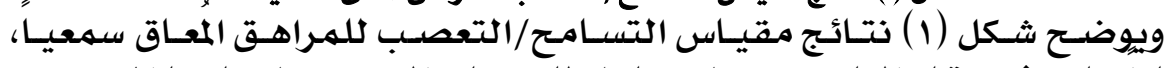

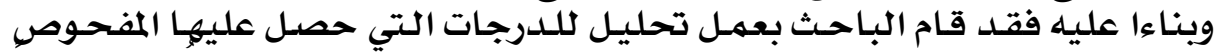

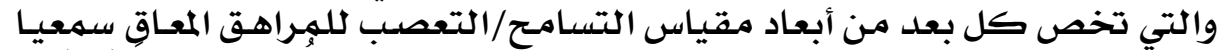

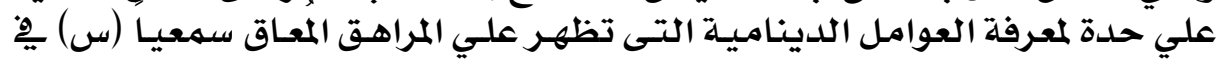

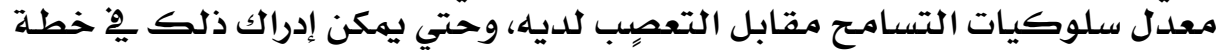

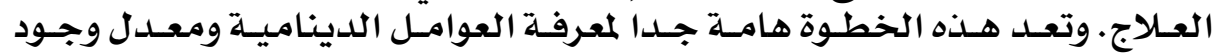

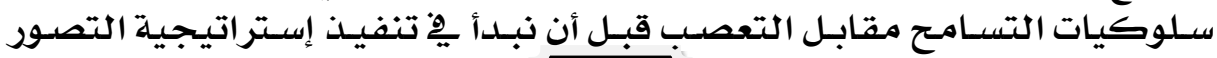




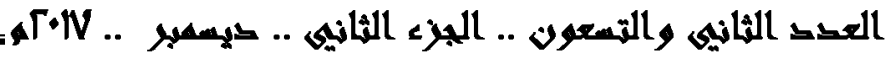

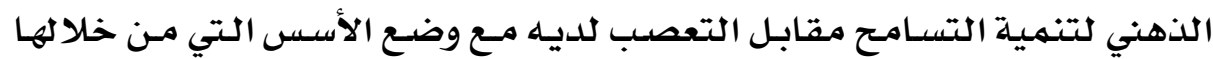

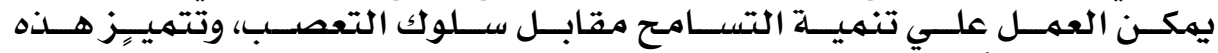

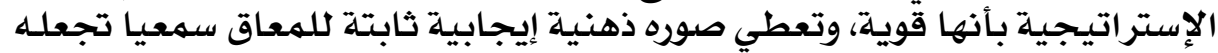

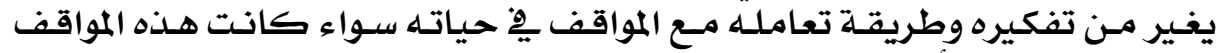

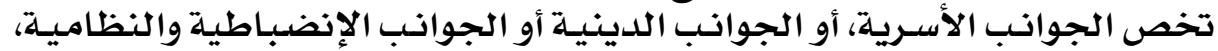
أو الجوانب الشخصية.

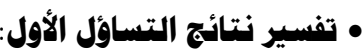

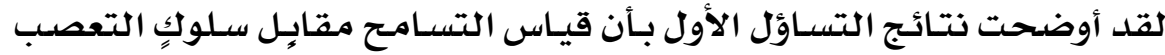

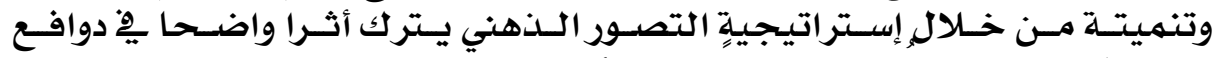

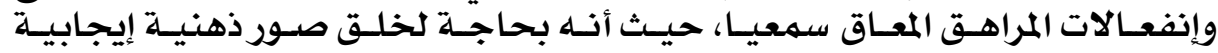

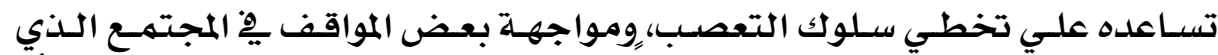

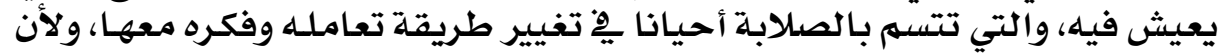

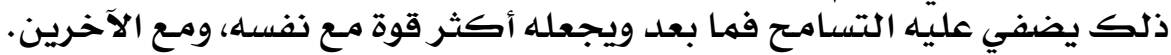

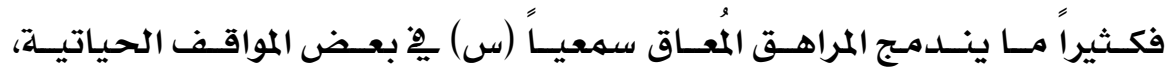

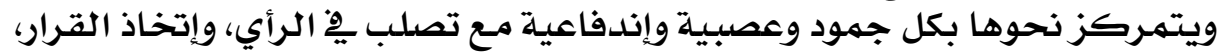

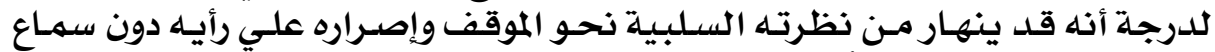

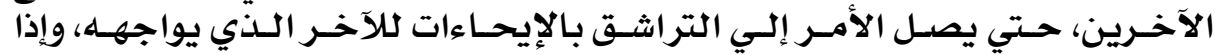

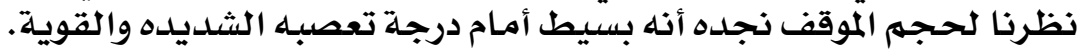

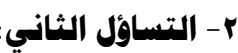

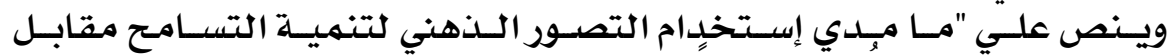

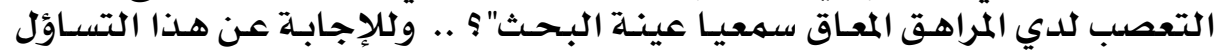

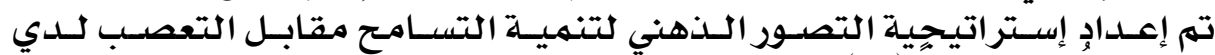

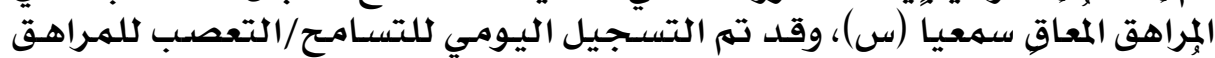

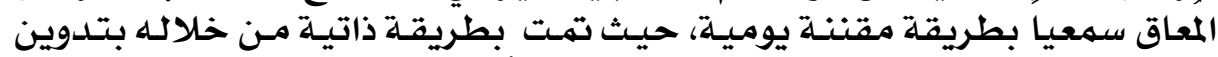

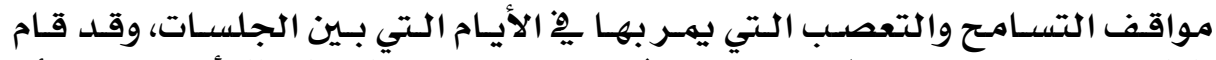

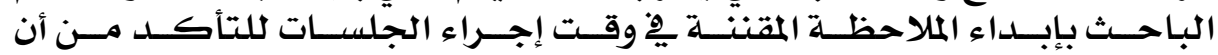

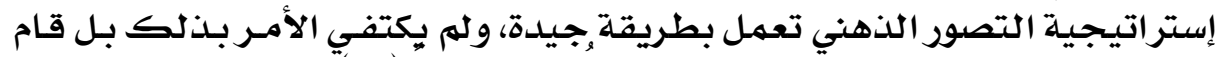

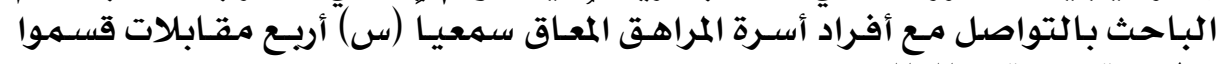
بطريقة مرتبة بالتواصل مالتالي: أفراد جدول (ج) المقابلات الأسريتيت خلال خطت تنفيذ استراتيجيت التصور الذهني للمراهق المُعاق سمعياً

\begin{tabular}{|c|c|c|}
\hline الأسبوع & الإجراء & المقابلات \\
\hline الأول & 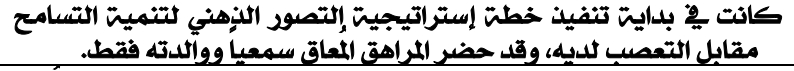 & المقابله الأولي \\
\hline السادس & سمعياً ووالدته ووالده واخخته الصغرئ التصور الذهني، وقد حضر المراهق المعاق & المقابله الثانيت \\
\hline العاشر & كانت ووائه نهايت خطتة التصور الذهني، وقد حضر المراهق المعاق سمعياً & المقابله الثالثتة \\
\hline & كانت عضد إجراء القياس التتبِيعي بعد الإنتهاء من خطتَ التصور الذهني، & | رابعتة \\
\hline
\end{tabular}




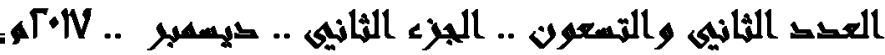

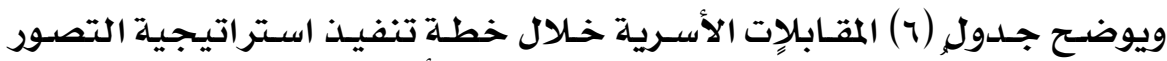

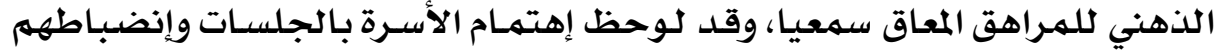

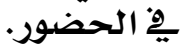

جدول (v) معدلات التسجيل اليومي الذاتي للتسامح والتعصب من قبل المراهق المُعاق سمعياً

\begin{tabular}{|c|c|c|c|c|c|c|c|c|}
\hline \multirow{2}{*}{\multicolumn{2}{|c|}{ تعصبيم التذاتي }} & \multicolumn{6}{|c|}{ معدلات التسحيل آليومى الذذاتى للتسامح والتعصب } & \multirow{2}{*}{ الأسبوع الأيام } \\
\hline & & الخميس & الأربعاء & الثلادجاء & الأهنين & الأحد & السبت & \\
\hline (عاثى) & تعصب & $\Leftrightarrow$ & $\leftrightarrow$ & $\wedge \wedge$ & 4 & $\leftrightarrow$ & $\wedge \wedge$ & الأول \\
\hline (عالى) (ع) (ع) & تعصب & - & $\leftrightarrow$ & 4 & $\wedge \wedge$ & $\wedge \wedge$ & 4 & الثثانى \\
\hline (عالى) (ع) & تسامح & $\leftrightarrow$ & $\wedge \wedge$ & $\wedge \wedge$ & 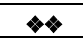 & $\Lambda \wedge$ & $\wedge \wedge$ & الثثالث \\
\hline (عالى) (ع) (2) & تسامـح & - & $\lambda \wedge$ & $\lambda \wedge$ & $\leftrightarrow$ & $\wedge \wedge$ & $\lambda \wedge$ & الرابع \\
\hline تتوسط) & تسامح () & $\wedge \wedge$ & $\diamond$ & 4 & $\wedge \wedge$ & 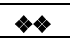 & 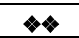 & الخامس \\
\hline غعيف) & تعصب ) & $\wedge \wedge$ & $\Lambda \wedge$ & - & - & 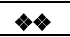 & $\Lambda \wedge$ & السادس \\
\hline توسط) & تسامح () & 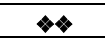 & $\wedge \wedge$ & $\wedge \wedge$ & 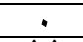 & $\leftrightarrow$ & $\wedge \wedge$ & السابع \\
\hline 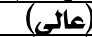 & تسامح & - & 4 & - & $\wedge \wedge$ & $\wedge \wedge$ & $\wedge \wedge$ & الثامن \\
\hline (عاثى) & تسامح & $\wedge \wedge$ & $\wedge \wedge$ & $\wedge \wedge$ & $\lambda \wedge$ & $\wedge \wedge$ & - & التاسع \\
\hline (عالى) (ع) & تسامح & $\lambda \wedge$ & $\lambda \wedge$ & $\lambda \wedge$ & $\lambda \wedge$ & - & - & الماثر \\
\hline
\end{tabular}

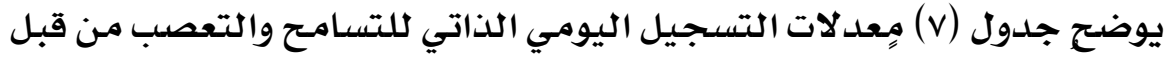

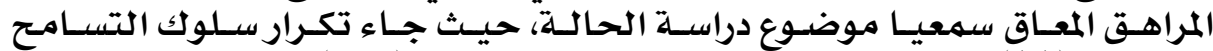

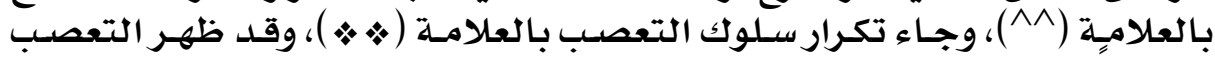

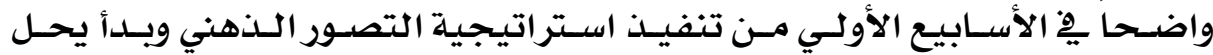

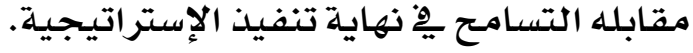

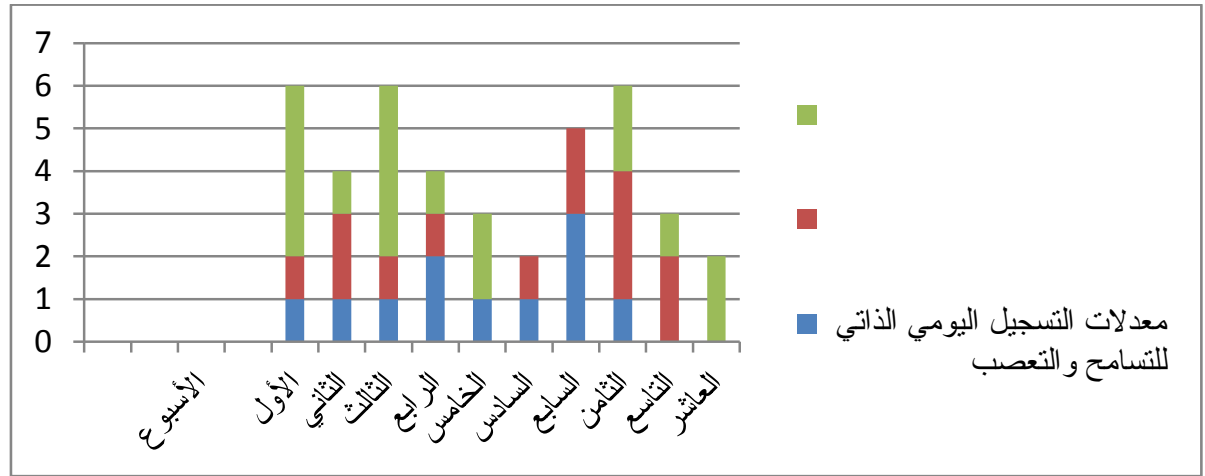

هكل (Y) معدلات التسجيل اليومي الذاتي للتسامح والتعصب من قبل المراهق المُعاق سمعياً

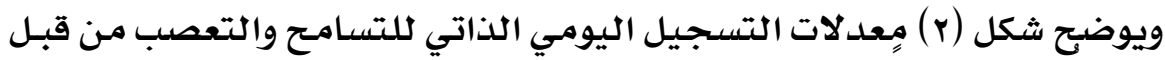

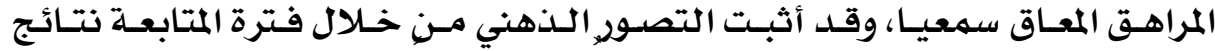

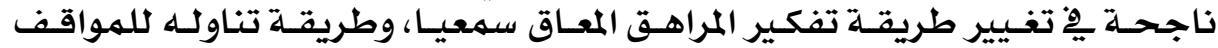

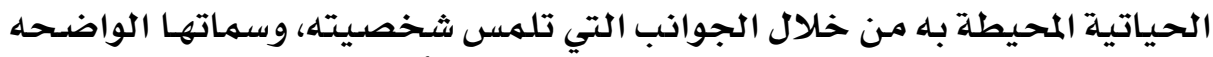

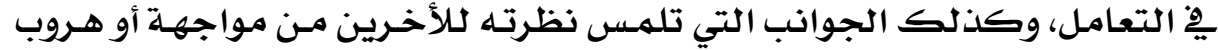

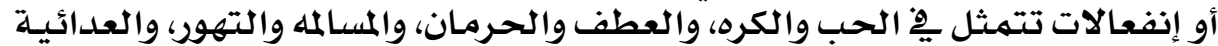

\section{$\mathrm{Y} \wedge \mathrm{V}$}

$$
\text { والتصالح مـع الذات. }
$$




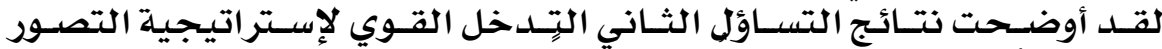

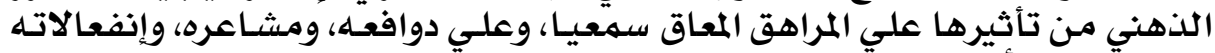

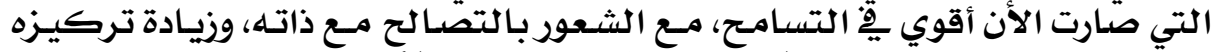

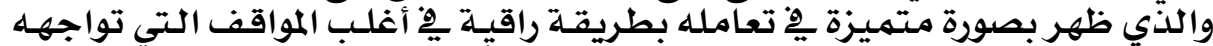

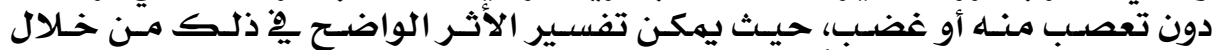

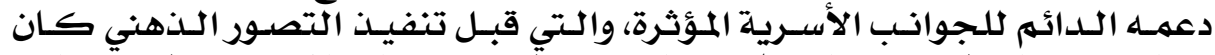

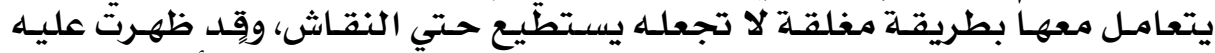

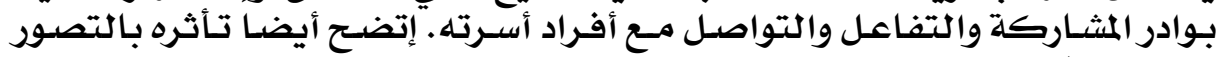

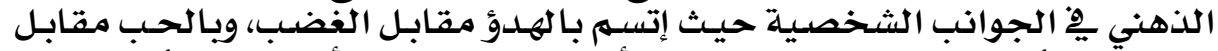

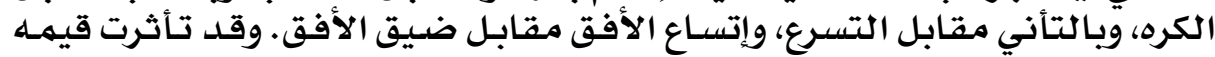

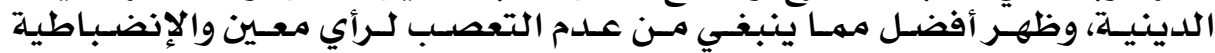

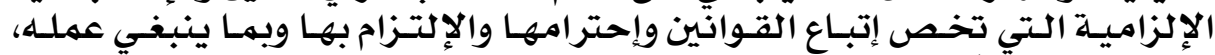
ومراعاة شعور ألآخرين.

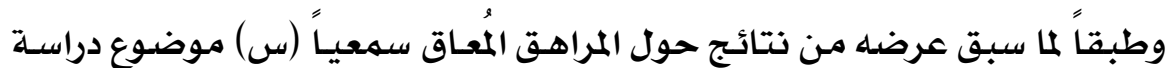

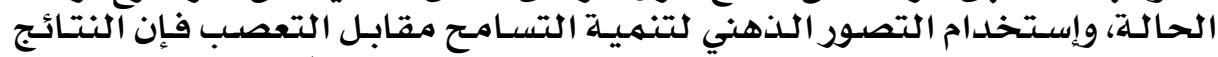

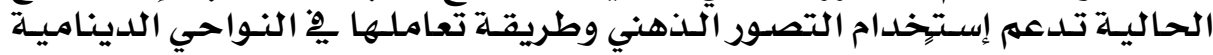

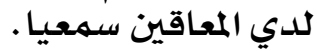

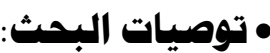

لقد أكد الباحث علي بعض التوص التوليات من خلالال العرض الِّابق فيما يلي:

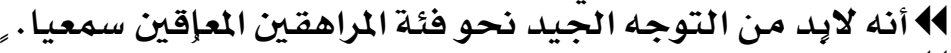

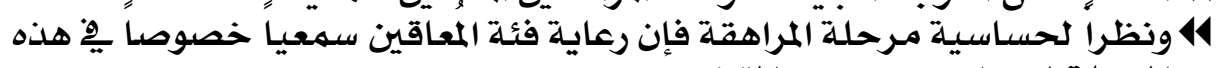

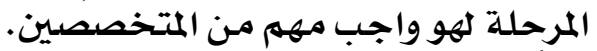

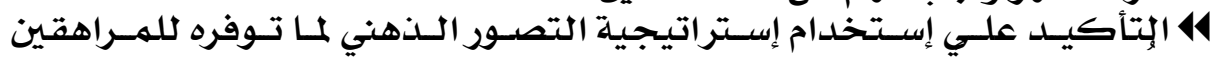

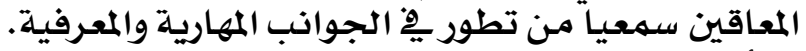

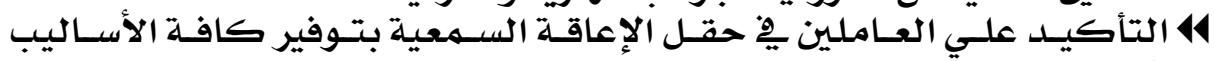

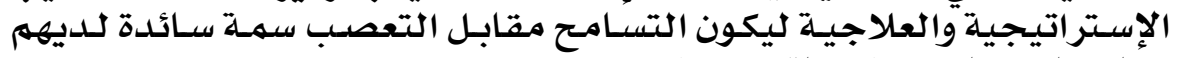

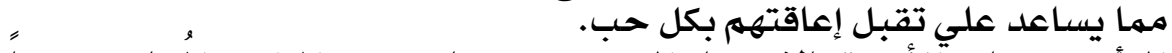

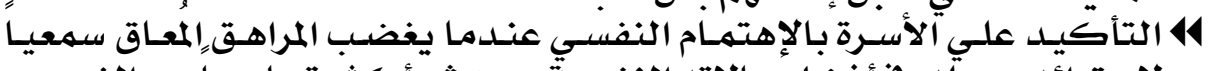

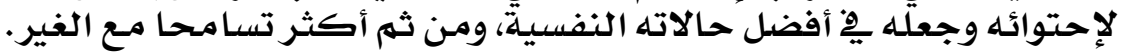

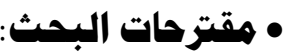

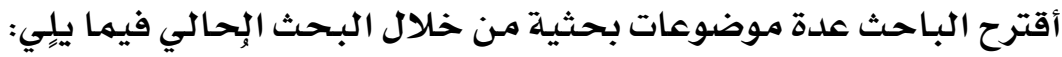

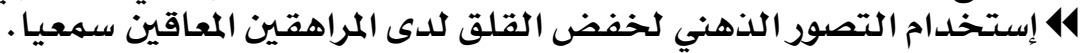

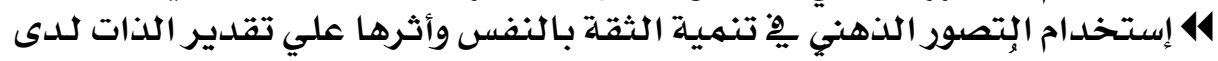
المراهقين المعاقين سمعياً.

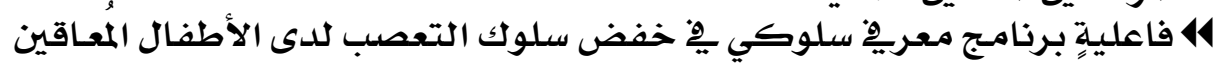
سمعيا. 44 الحسأسية النفسية وعلاقتها بالتعصب لدى المراهقين المُحاقين سمعياً. 


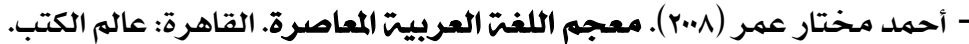

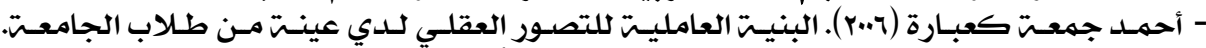

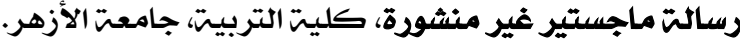

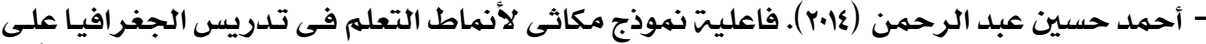

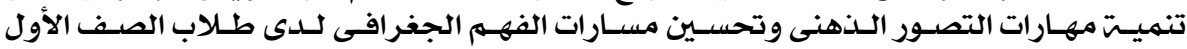

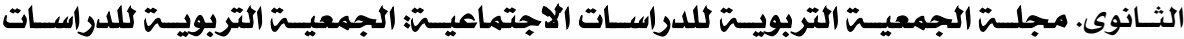

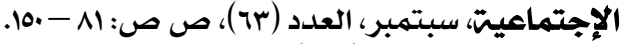

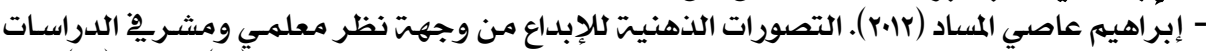

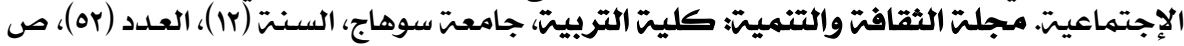
ص:-1:-0.0.

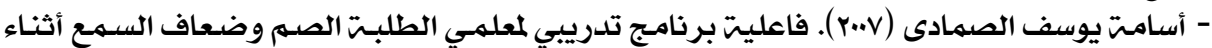

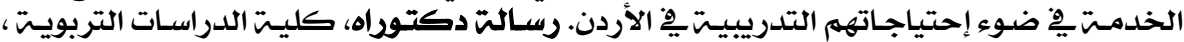

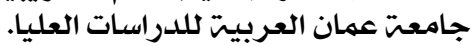

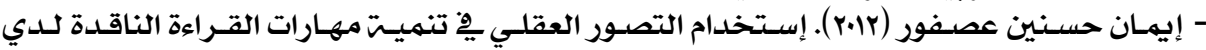

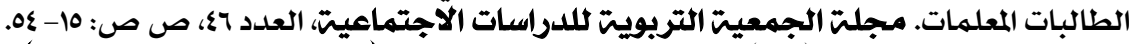

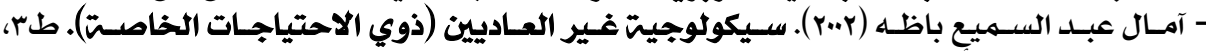

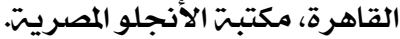

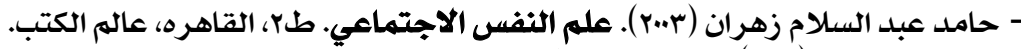

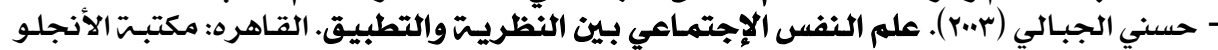
المصريت.

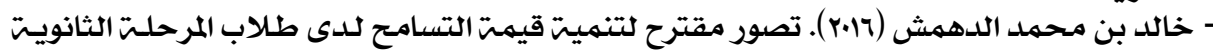

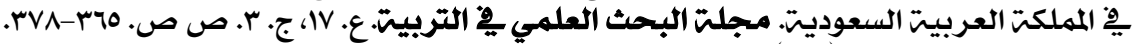

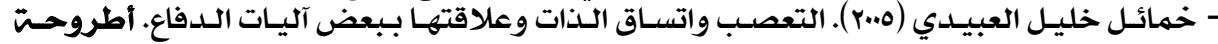

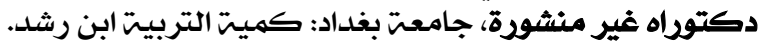

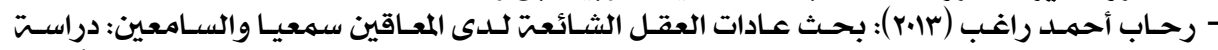

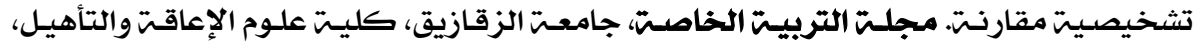

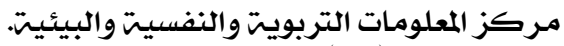

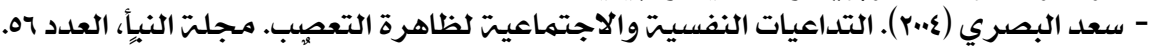

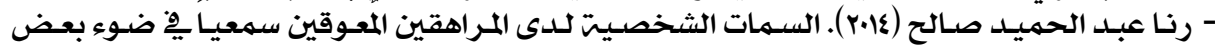

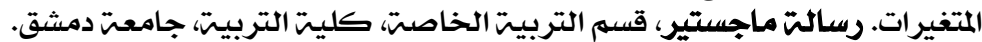

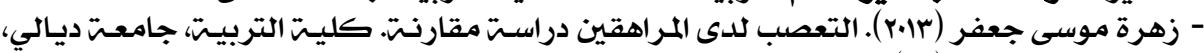

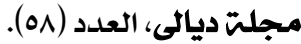

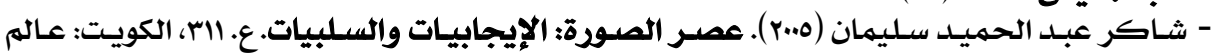
المعرفتة.

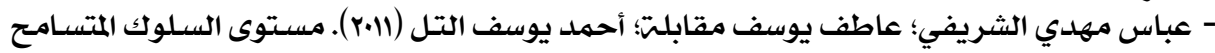

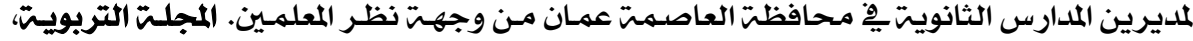

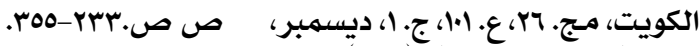

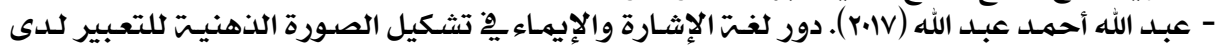

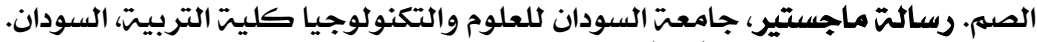

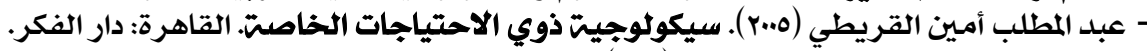

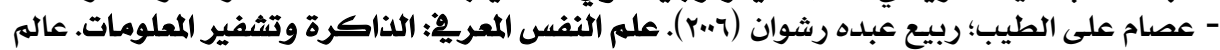
الكتب: القاهرة. 


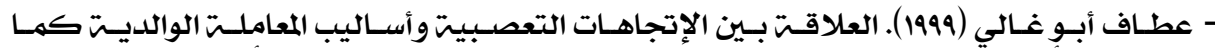

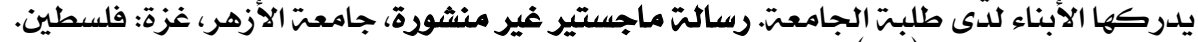

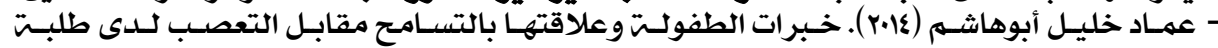

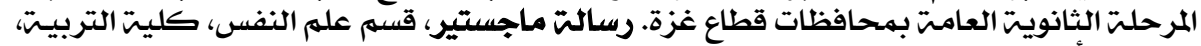

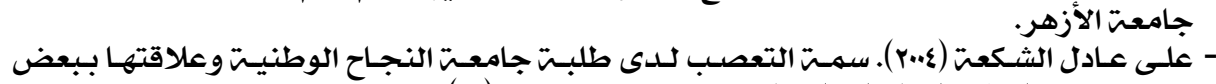

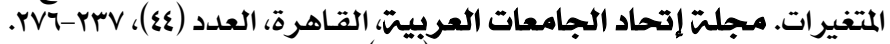

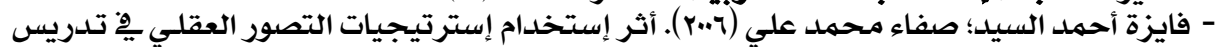

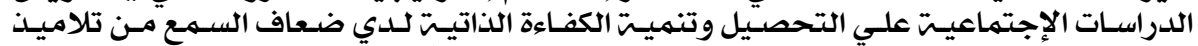

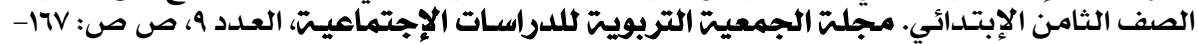
.rYs - فتحي مصطفي الزيات (ا.יץ). علم النفس المعربِ "مدخل ونماذج ونظريـات". الجزءء (r)، القـاهرة:

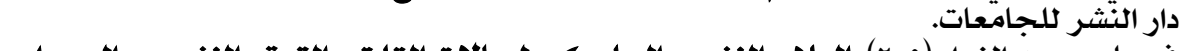

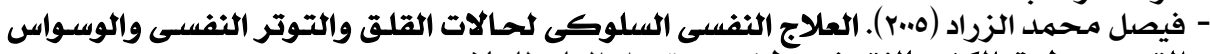

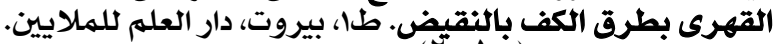

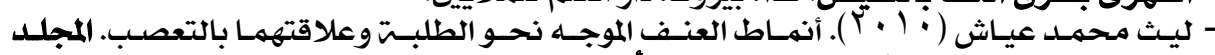

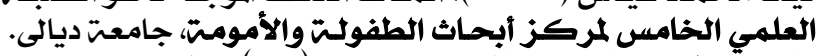

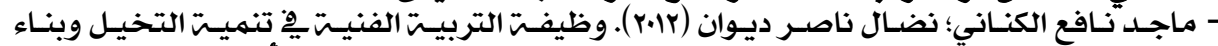

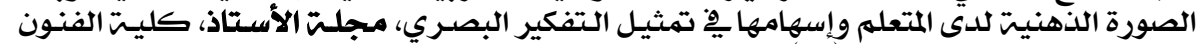

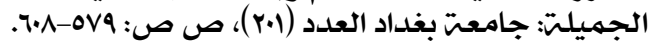

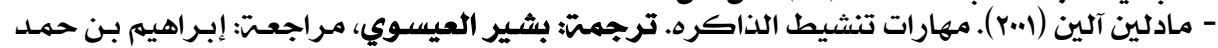

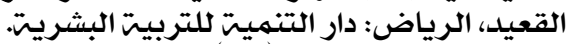

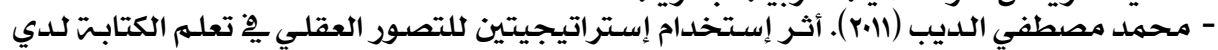

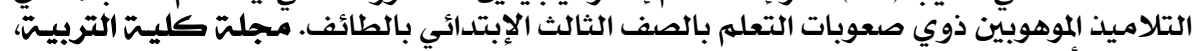

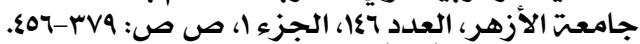

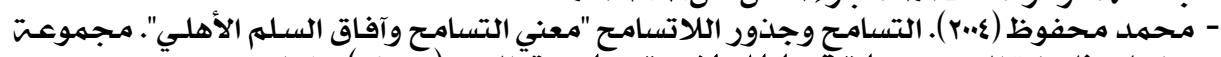

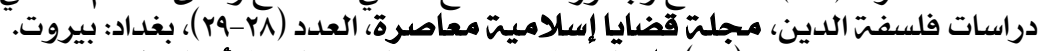

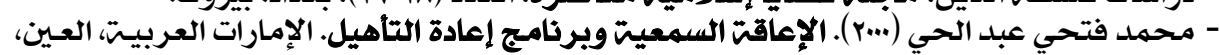

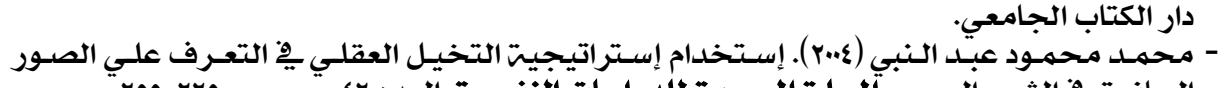

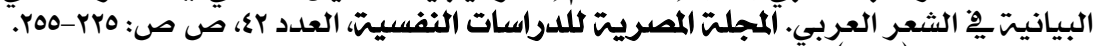

- مصطفي زيور (1919) .

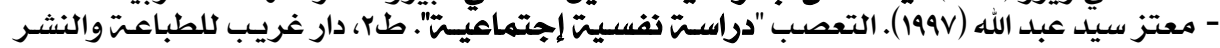

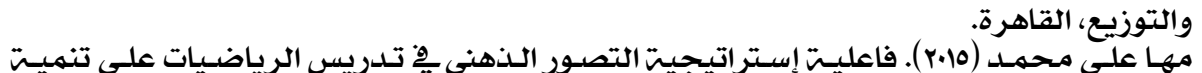

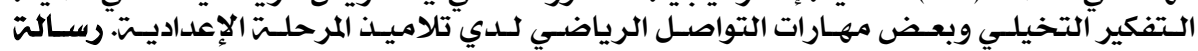

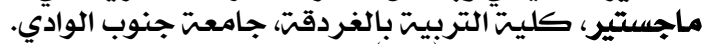

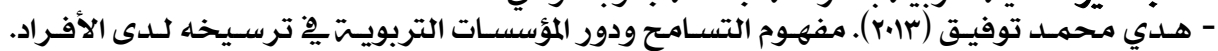

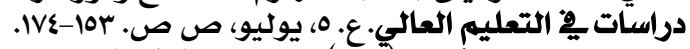

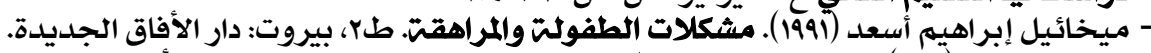

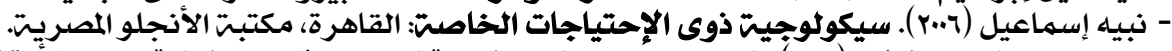

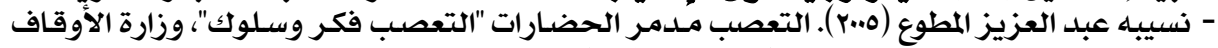

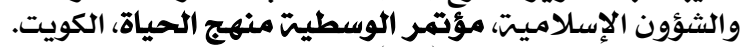

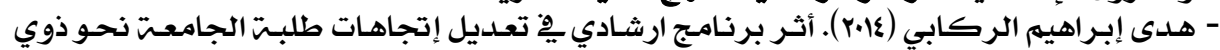

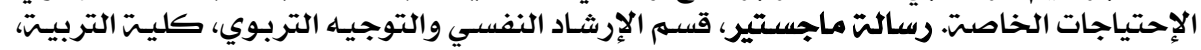
جامعت بغداد. - يوسف عبد الكريم سعد (0.. ). علم النفس الطفولتّ والمراهقت. طا، منشورات جامعت حلب: سوريا. 
- Anderson, J. (2015): Cognitive Psychology and it is implications (8th ed) NEW York: Worth puplishers.

- Baltaci, Ali (2017): Relations between Prejudice, Cultural Intelligence and Level of Entrepreneurship: A Study of School Principals. International Electronic. Journal of Elementary Education, v9 n3 p645-666 Mar.

- Barca, Laura; Frascarelli, Flaminia; Pezzulo, Giovanni (2012): Working memory and mental imagery in cerebral palsy: A single case investigation. Neurocase. Vol.18(4), Aug 2012, pp. 298-304.

- Brown, P. Margaret; Cornes, Andrew, (2015): Mental Health of Deaf and Hard-of-Hearing Adolescents: What the Students Say. Journal of Deaf Studies and Deaf Education, v20 n1 p75-81 Jan.

- Brockett, Adrian; Wicker, Kate (2012): Outgroup Prejudice among Secondary Pupils in Northern England: Are the Predictors at the Individual, School or Neighbourhood Level? Research in Education, v88 p11-28 Nov.

- Crawley, S.J., \& Merrit, K. (1996): Remediating reading difficulties. 2nd ed) Madison: Brown \& Benchmark Puplisher.

- Day, Richard, R (1993): new ways in teaching reading, Alexandry Virginia:Teacher of English to Speakers of other Languages.Ins (TESOL).

- Davis, M. McMahon, M. and Greenwood, K. M.(2004): The role of visual imagery in the enhanced cognitive interview:guided questioning techniques and individual differences. Journal of investigative Psychology of Offender Profiling; Vol.1, Issue1,PP.33 51.

- Dehn, G. (2008): Working Memory and Academic Learning Assessment And Intervention. New Jersey: John Wiley \& sons.

- Dominic, Conroy, \& Martin S. Hagger, (2017): Learning via Mental Imagery. Anesthesia and analgesia, June, 123(2).

- Erdogan, Cetin (2016): Analysis on the Relationship between Trust Culture and Prejudices in Primary Schools. Eurasian. Journal of Educational Research, n63 p153-168.

- Etxeberria, Felix; Murua, Hilario; Arrieta, Elisabet; Garmendia, Joxe; Etxeberria, Juan (2015): Prejudices against Immigrants in Secondary School. Intercultural Education, v26 n5 p339-360.

- Gergan K. J. \& Gergan M. M. (1981): Social Psychology HarcoutBrace Jovanovich, In. U.S.A.

- Ghoshal, Raj Andrew; Lippard, Cameron; Ribas, Vanesa; Muir, Ken (2013): Beyond Bigotry: Teaching about Unconscious Prejudice.Teaching Sociology, v41 n2 p130-143 Apr.

- Hadyn, D, \& Sara, L, (2002): Deaf and hearing children's comprehension of Picture stories and judgment of social V(5), N 3 ,Pp248-265.

- Hibbing, A., \& Rankin-Erickson, J. (2003): A Picture is worth a thousand words: Using Visal images to improve conprehention for middle school struggling readera. The Reading Teacher, 56 (8). Pp (758-770). 
- Jordan, Evelyn (1995): Improving college prep student reading skills through the use of Selected comprehension strategies .Masters Theses, Nova Southeastern University.

- Judson, Gillian, (2014): The Role of Mental Imagery in Imaginative and Ecological Teaching. Canadian Journal of Education, v37 n4.

- Matlin, M., (2005): Cognition, Sixth Edition, Tohan Wiley \& Sons, Inc.

- McCabe, J.A. (2014): Learning and Momory Strategy Demonstrations for the Psychology Classroom. Washingoton, DC: Office of Teaching Resources in Psychology, Society for the Teaching of Psychology.

- Moran, A., Campbell, M., Holmes, P., \& Maclntyre, T., (2012): Mental Imagery action observation and skill learining (2nd ed) New York Taylor and Francis.

- McTigue, Erin M. (2010): Teaching Young Readers Imagery in Storytelling: What Color Is the Monkey?. Reading Teacher, Sep, v64 n1 p53-56.

- Mecullough Michal (2003): Forgiveness in Change, Department of Psychology and Religions studies, University of Miami.

- Olivier, E. (2002): Mental imagery ability in high-and lowperformance collegiate basketball players, An Unpublished phd. Dissertation, Bostor University.

- Olivier Houdé, (1998): Vocabulaire de sciences cognitives. 1ér édition, PUF, Paris.

- Ozel, M.(2012): Children's Images of scientists: dose grade level made a difference? Theory and practice, 12(4) 3178-3198.

- Pérez-Fabello, María José; Campos, Alfredo; Meana, Juan Carlos, (2014): Vividness and Control of Mental Imagery and the Components of In-Depth Drawing. Creativity Research Journal, v26 n2 p244-247.

- Pica-Smith, Cinzia; Poynton, Timothy A. (2015): Supporting Interethnic and Interracial Friendships among Youth to Reduce Prejudice and Racism in Schools: The Role of the School Counselor. Professional School Counseling, v18 n1 p82-89.

- Schauer, Sheryl A. (2005): Using guided mental imagery to improve reading comprehension. Unpublished Dissertation 1 Arizona State University. (UMI NO 317324)

- Stednitz, \& Epkins, (2006): Girls and Mothers Social Anxiety, Social skills, and Loneliness: Associations after Accounting for Depressive Symptoms, Journal of Clinical Child and Adolescent Psychology, 35 (1) $145-155$.

- Theunissen, Stephanie C. P. M., (2014): Psychopathology and Its Risk and Protective Factors in Hearing-Impaired Children and Adolescents: A Systematic Review. Md, phd. JAMA Pediatr. 2014; 168(2):170-177.

- Wang, Lihui; Lawson, Michael J.; Curtis, David D, (2015): The Effect of Image Quality Training on Reading Comprehension of EFL Students Using the Keyword Method. Language Teaching Research, Jul, v19 n4 p435-454. 